

\section{Public sournulor Transportation}

Gary L. Brosch, Editor

Patricia Henderson, Managing Editor

\section{Editorial Board}

Robert B. Cervero, Ph.D.

University of Califomia, Berkeley

ChesterE.Colby

MKCentennial

GordonFielding, PhD.

University of Califormia, Irvine

DavidJ.Forkenbrock,PhD.

Universityoflowa

JoséA.Gớmez-lbáñez, $\mathrm{PhD}$.

HanvardUniversity
Naomi W. Ledé, Ph.D.

Texas Southern University

William W. Millar

American Public TransitAssociation

Sandra Rosenbloom, Ph.D.

University of Arizona

Lawrence Schulman

Orbital Sciences Corp.

George Smerk, D.B.A.

Indiana University

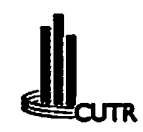

The Journal of Public Transportation (ISSN 1077-291X) is published quarterly by the Center for Urban Transportation Research (CUTR) in the College of Engineering at the University of South Florida. The contents of this document reflect the views of the authors, who are responsible for the facts and the accuracy of the information presented herein. This document is disseminated under the sponsorship of the U.S. Department of Transportation, University Research Institute Program, in the interest of information exchange. The U.S. Government assumes no liability for the contents or use thereof. Subscriptions are complimentary and may be obtained by contacting the Center for Urban Transportation Research, University of South Florida, 4202 E. Fowler Avenue, CUT 100, Tampa, FL 33620-5375, (813) 974-3120, email:phenders@cutreng.usf.edu. 


\section{Public solven or Transportation}

Volume 2, No. 2, 1999

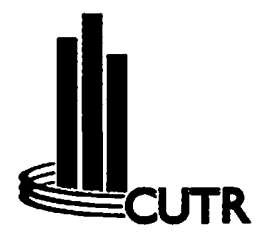

C 1999 Center for Urban Transportation Research

National Center for Transit Research Center for Urban Transportation Research

College of Engineering - University of South Florida 4202 E. Fowler Avenue, CUT 100, Tampa, FL 33620-5375

(813)974-3120 - Fax (813)974-5168

E-mail:phenders@cutreng.usf.edu

Web Site: $h t t p: / / w w w . c u t r e n g . u s f . e d u$ 


\section{Public sourexilor \\ Transportation}

Volume 2, No. 2, 1999

\section{Contents}

Time-Distance Diagrams: A Powerful Tool

for Service Planning and Control

Eric C. Bruun, Vukan R. Vuchic \& Yong-Eun Shin

Stakeholder Preferences in

Advanced Public Transportation System Planning

Jonathan Levine, Soonae Park, Steven E. Underwood \& Richard R. Wallace

The "Ins and Outs" of APCs: An Overview

of Automatic Passenger Counters

MichaelR. Baltes \&Joel R. Rey

Development and Evaluation of Transit Signal Priority Strategies

Michael Garrow \& Randy Machemehl

The Advanced Technology Bus and the

Evolution of Workplace Expertise

DavidW.Partain

"Our troubled planet can no longer afford the luawy of pursuits confuned to an ivory tower. Scholarship has to prove its worth, not on its own terms, but by service to the nation and the world."

- Oscar Handlin 


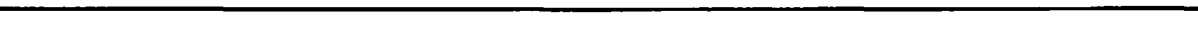




\title{
Time-Distance Diagrams: A Powerful Tool for Service Planning and Control
}

\author{
Eric C. Bruun \\ National Transit Institute, Rutgers University \\ Vukan R. Vuchic \\ Department of Systems Engineering, University of Pennsylvania \\ Yong-Eun Shin \\ Dong-Eui University, Pusan, Korea
}

\begin{abstract}
Graphical scheduling is an old technique that has been neglected, or never acquired, in many North American transit agencies. It retains its advantages in basic schedule design and analysis as it eases the solution to problems that are difficult to solve analytically. Even information about simple routes is enhanced by the detailed operating characteristics inherent in detailed vehicle trajectories and by the relative ease with which accelerated service and service recovery strategies can be investigated. It also can be used to confirm and refine solutions that are generated by analytic methods. The methodology is reviewed in the context of such planning applications. Graphical scheduling has additional advantages in operational control with the advent of modern ITS technologies. Bymovement of the cursor on a terminal screen, detailed information about all activity along a route becomes available. It is possible to link the altering of trajectories through clicking and dragging to the automatic issuance of control commands and updates of passenger information. These and other possible uses of the technique in an operational context are presented.
\end{abstract}




\section{Introduction}

Development and use of graphical schedules for planning and supervision of transit systems operations is by no means a new subject. It is a time-proven method used for both development and analysis of schedules. Yet, its use is far from universal. While many transit and railway systems use graphical schedules in their daily operations for multiple purposes, the entire concept and technique is virtually unknown in most North American transit systems, including the largest ones. The latest dispatching/control software packages in the United States that monitor buses in real-time through Automatic Vehicle Location (AVL) do not use it either. However, this software does display GIS maps showing vehicle location along streets, as well as checkpoint data in spreadsheet format.

While the spreadsheet format is useful, the data display format that for many purposes reveals the most information - the time-distance diagram - should also be available. Actually, the graphical method is superior to the numerical ones for many applications. The purpose of this paper is to broaden the knowledge about this technique in those parts of the transportation community where it is not used and, often, where it is not even known.

This paper is organized as follows. The following section describes the concept of the time-distance diagram and explains how it is designed and interpreted. The third describes several applications in scheduling and the advantages this technique provides. The fourth section describes its advantages in real-time operational control, an area of vital interest with the advent of highly capable Intelligent Transportation Systems (ITS) that provide precise vehicle locations and numerous communications options. The final section is a concluding summary.

\section{Definition of Time-Distance Diagram}

A time-distance diagram, as the name implies, is used to plot motion of a vehicle or train - henceforth referred to as Transit Unit or TU-with time on the horizontal and distance on the vertical axis. The distance axis usually has a length equal to the route length, with the terminals defining the end points. Each TU has an individual trajectory describing its position and movement over time. The family of trajectories 
form a time-distance diagram representing a complete schedule for one, sometimes for several, lines.

The detail at which the trajectory of a TU is presented should reflect the purpose of the analysis. In some cases, particularly when the distances between planned stops are very long, the trajectory need be no more than a straight line connecting the departing terminal at the dispatch time to the other terminal at the arrival time, usually in minutes. In other cases it may be necessary to provide very detailed trajectory showing all accelerations, decelerations, and station dwell time periods. These detailed TU trajectories are commonly plotted in seconds.

Using a rapid transit line as an example of a detailed trajectory, the line is modeled as a series of interstation spacings where the train accelerates with constant rate $a_{i}$, cruises at speed v, and decelerates at rate $b$. Each station $i$ has a dwell time $t_{s i}$. Travel time on any interstation spacing is composed of the time intervals required for accelerating to cruising speed, running at cruising speed, decelerating into the station, and the station dwell time. This kind of trajectory, shown in Figure 1, may be constructed for individual interstation spacings, or for entire lines.

For certain analyses, it is necessary to compute the incremental time lost by stopping at station $\mathrm{i}$, or $\mathrm{T}$. This is the time that TU needs for travel with stopping at one station, as compared to the travel time on the same section while moving at cruising speed, without stopping at the station. This incremental time consists of additional time due to deceleration in entering station $i, t_{b}$, dwell time at station $i, t_{s}$, and incremental time for acceleration while departing station $i, t_{a}$. Figure 2 shows a straight-line approximation of time lost for each stop, referred to as $T_{p}$, instead of exact acceleration and deceleration paths. This straight line simplification is convenient for plotting, and yet sufficiently accurate for most scheduling purposes. Each incremental time lost is connected to the next by a straight-line with slope equal to the cruising speed between them. Therefore, if the cruising speeds on different spacings are equal, the sloped lines are parallel. On line sections where cruising speeds vary, the slopes also change among interstation spacings.

Figure 2 also shows trajectory of another TU, following the first one. The horizontal separation between trajectories represents the headway between TUs, $h$. The 


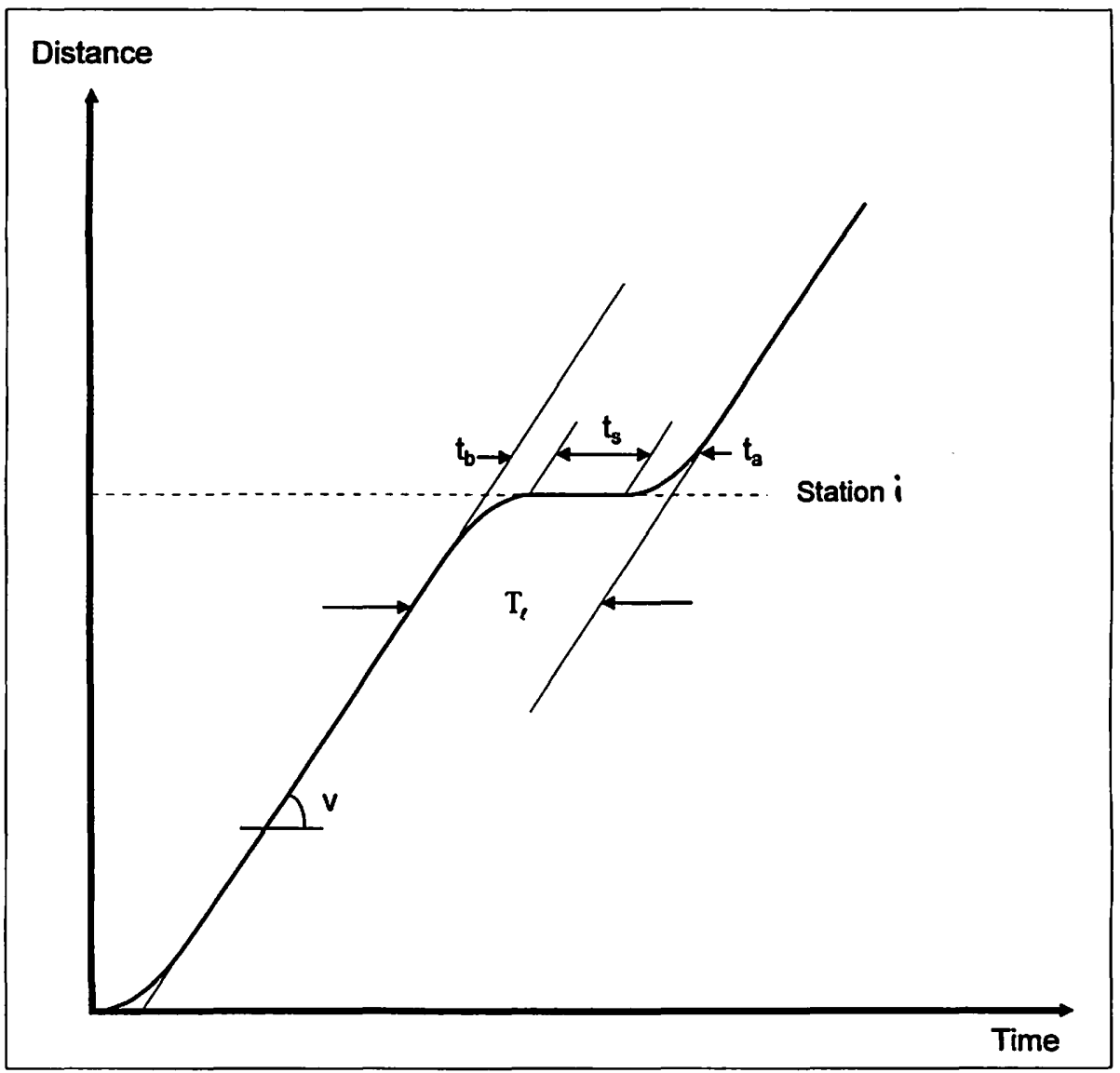

Figure 1. Time-distance diagram showing elements of TU motion.

minimum allowable headway depends on vehicle performance, route alignment, and control system characteristics (e.g., manually driven on street, discrete block, moving block, etc.). The vertical separation at any point in time represents the distance separation between corresponding points on successive TUs, or their spacing, $s$. The minimum spacing, which corresponds to the minimum headway, consists of three components: the TU length, the distance passed during the driver's reaction time, and actual braking distance. The minimum safe spacing is often also presented as a continuous line in front of the TU trajectory, and it is known as the TU shadow. There are 


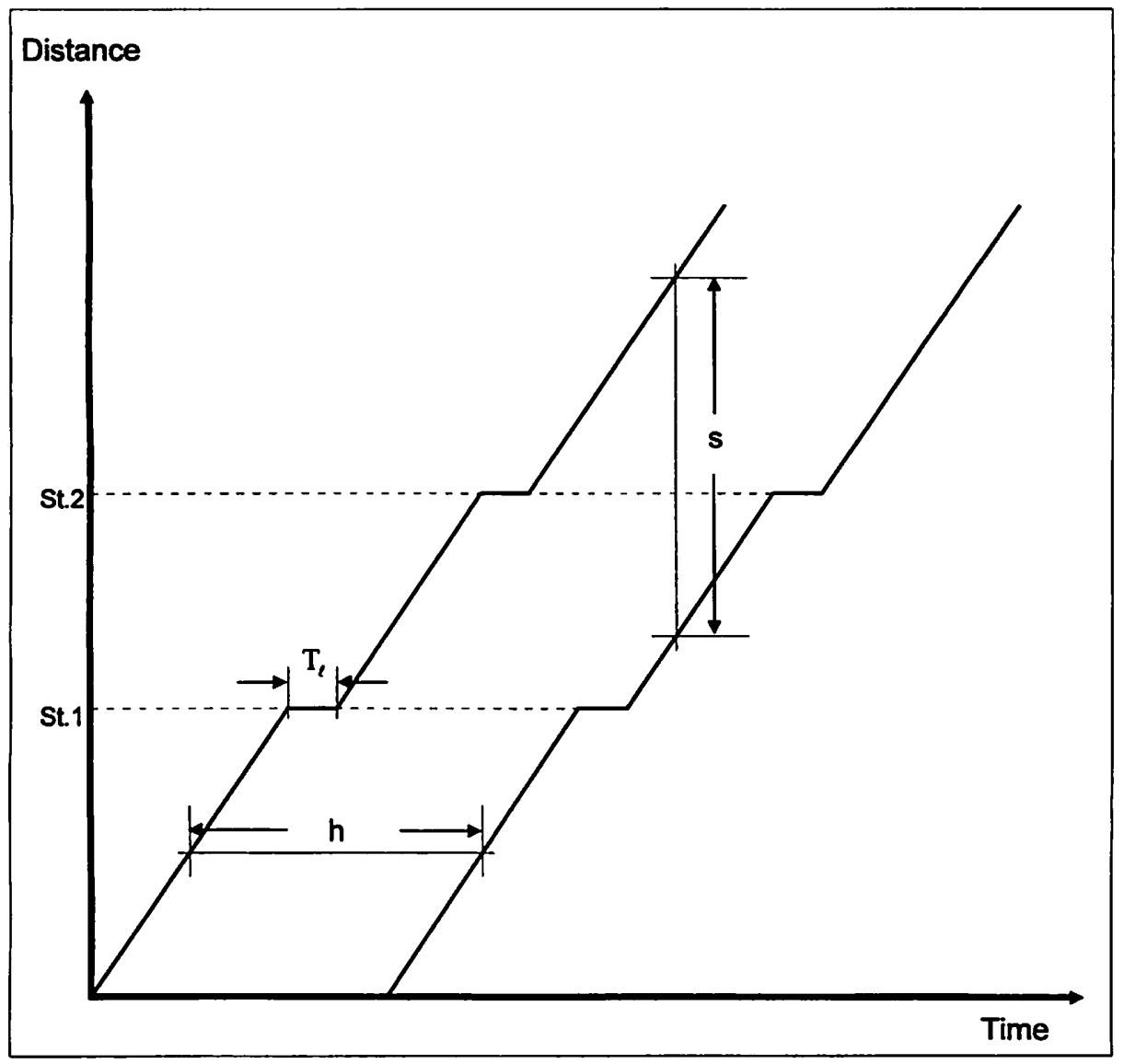

Figure 2. Graphical schedule of two successive trains.

actually different regimes or degrees of safety, and the reader interested in this detailed analysis is referred to Vuchic (1981). For TUs that travel on the same path, such as a rail track or bus lane, once any minimum is violated, the schedule is infeasible. In practice, there should be separation well beyond the minimum to ensure schedule reliability. When trajectories reflect actual operations instead of the intended schedule, as soon as any revised trajectory can be projected to violate the minimums, delays can be anticipated, unless corrective action is taken to re-separate them. 
Graphical schedules have a visual clarity that numerical schedules can never provide. Tables with numerical values of $\mathrm{TU}$ departures at different points along a line may contain errors that are not immediately noticeable. When plotted graphically, every incorrect time is immediately conspicuous. Uneven travel speeds, TUs traveling at less than the minimum headway, or any conflicts in TU travel paths are also easy to detect on graphical schedules.

Graphical schedules can also be useful to present actual running of trains where some skip different stations along the line. An example is shown in Figure 3 for the CalTrain commuter railroad serving communities south of San Francisco. The plot is based on scheduled departures of every train at every station, and shows different headways during the a.m. peak and midday periods, as well as the relationship of local and partial express peak period trains.

In addition to schedules for TUs traveling on the same track in the same direction, graphical analysis can also be used to find meetings of TUs moving in opposite directions on the same track or path. Figure 4 shows train scheduling for a single

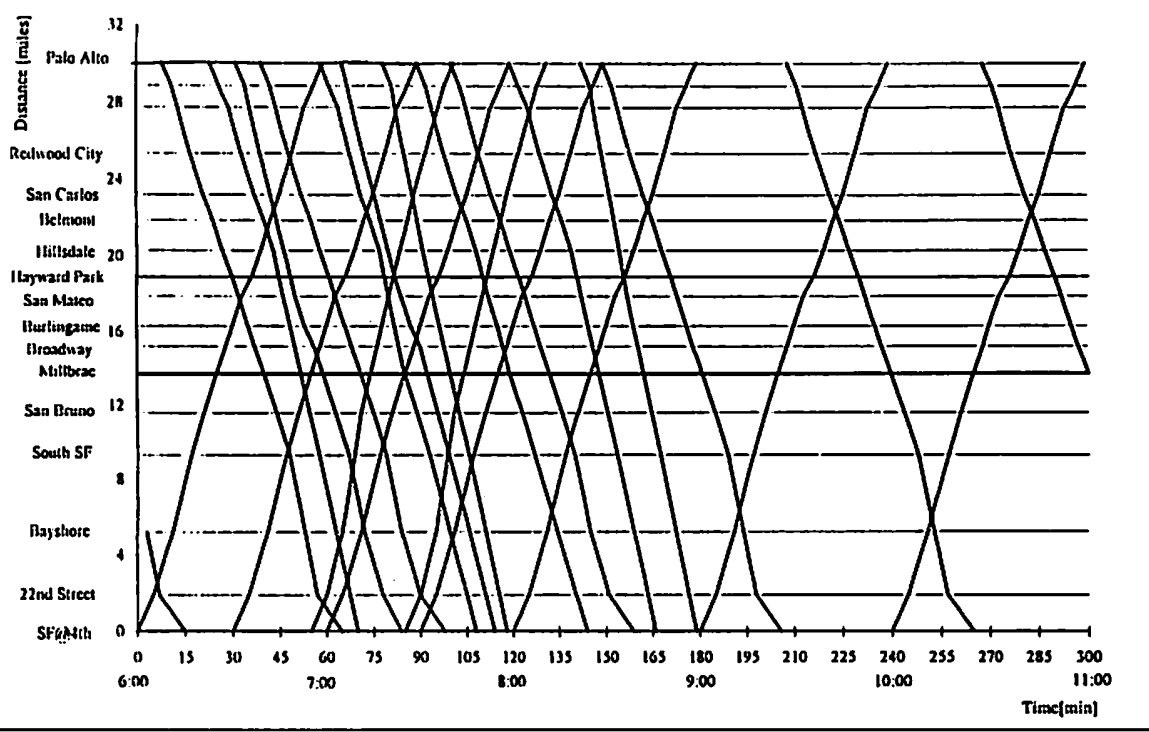

Figure 3. Graphical presentation of a.m. peak and midday schedule for Calmrain, San Francisco Bay Area. 
track section $A-B$ of a double track line. If the trajectories cross each other along the shared section, as shown by the dashed line in the figure, the operation is infeasible. A feasible schedule is shown by the solid lines, which intersect on a double track section.

As another example, this graphical method was used to verify a temporary schedule involving single-tracking during reconstruction of the Market-Frankford

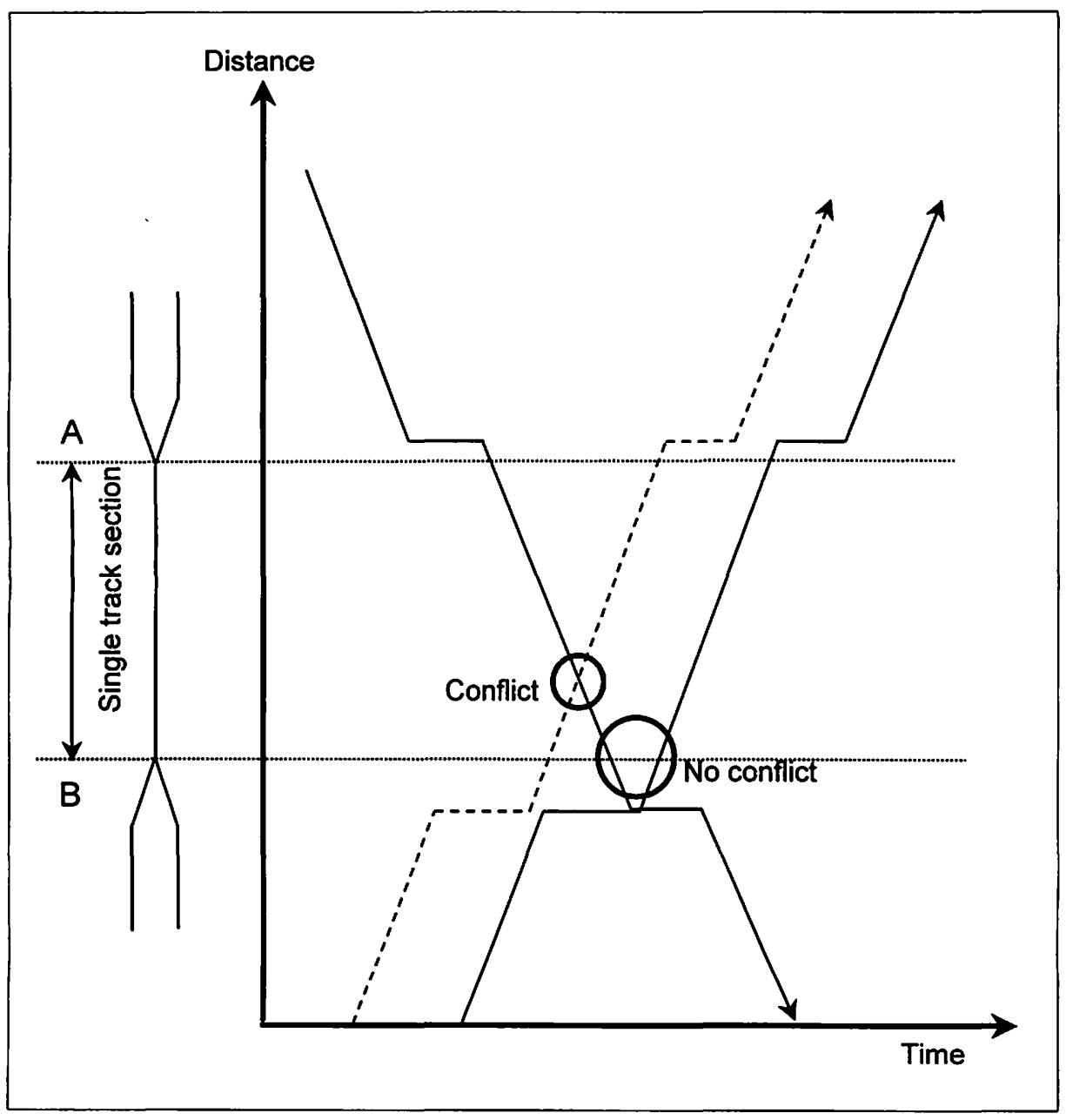

Figure 4. Use of time-distance diagram to schedule train meets outside of a single track section. 


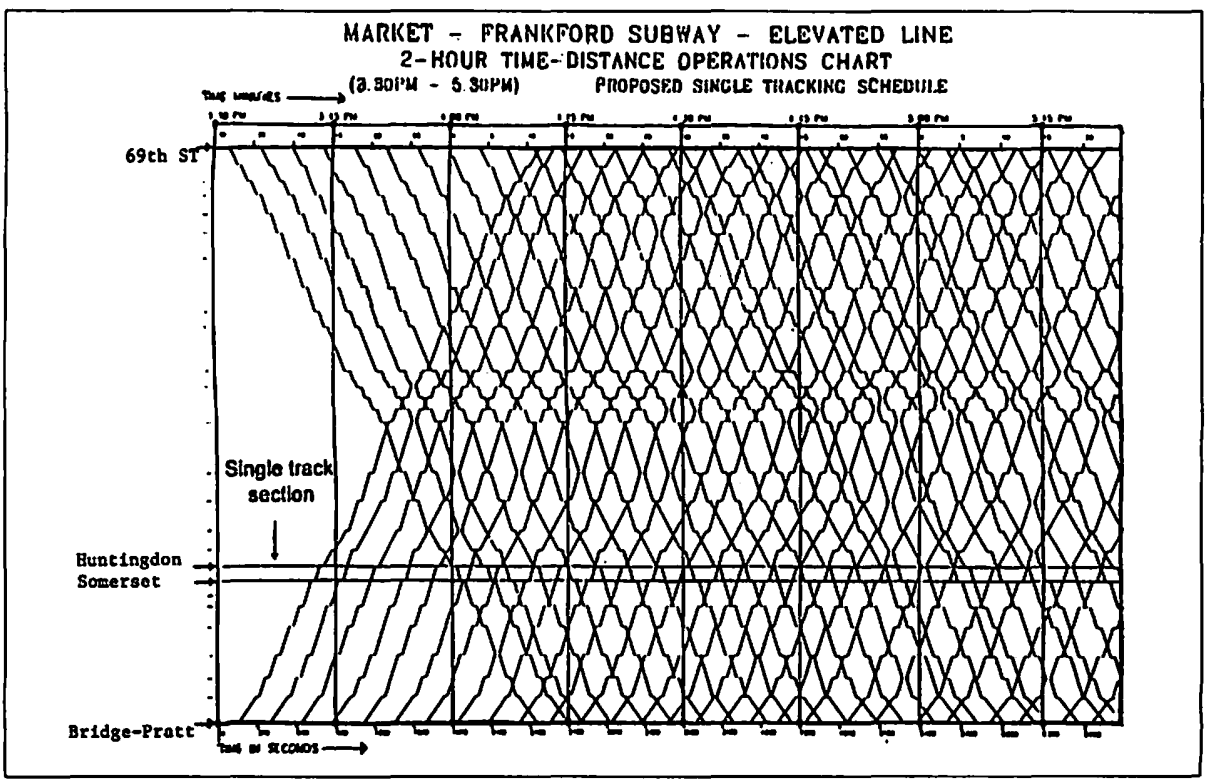

Figure 5. Application of time-distance diagram for scheduling high frequency service over a single-track section.

rapid transit line in Philadelphia, as described by Bruun and Salpeas (1991). The full peak period schedule was plotted using the incremental time-lost format to ensure that no trajectories crossed each other on the single-track section. For clarity and size, only part of the schedule is reproduced as Figure 5; the two solid horizontal lines show the single-track section.

\section{Applications in Scheduling}

The most common application of graphical schedules is for single lines. However, there are a number of cases where several lines that merge, diverge, intersect, or form a triangle can also be scheduled graphically, i.e., with application of timedistance diagrams. Several typical cases of different types of graphical schedules are described here.

\section{Single Line Operation}

Once average operating speed from terminal to terminal is known and desired headways are specified, development of the basic schedule for single routes is alge- 
braically and graphically simple. Its development involves only basic preliminary calculations, followed by adjustments to terminal times to maintain the integer constraint on fleet size. Even in this simple case, a time-distance diagram showing the detailed trajectory of each individual TU is helpful, because it reveals information on each individual terminal time, dwell times at different stations, average running speeds, etc. It is a simple method to clearly display deadheading, short turns, individual runs and fleet size on the line. All pull-ins and pull-outs, short-term storage on sidings, and other details can be shown. The diagram also is helpful for planning transitions between service plans during the day.

\section{Special Operations}

Once a basic pattern for the schedule has been established, variants can be easily plotted and analyzed. These include short turn, skip-stop, and partial express (also called zonal) operation. The modeling of each will be explained briefly.

Short turns can be treated as if they simply were intermediate terminals, although, for trains, the minimum terminal time may have to include allowances for maneuvering time shorter or longer than at the outer terminals, depending upon the length of line headways, short-turn cycle time and track layout. The simplest operation is when line headways are long and timing of a short-turning train such that the short-turning train can reverse at a station with center platform without conflict with regular trains passing in either direction, as shown in Figure 6a. In another case, the train has stopped and had sufficient dwell time to discharge passengers, it must wait before reversing. In this case, there is enough time for the operator to change ends and accept passengers, departing in reverse direction and crossing over to the opposite track prior to arrival of a following train in either direction, so that no delays occur.

It can happen, however, that the short-turning train cannot travel back immediately because the other track is occupied by a train passing in the opposite direction, or immediate turning would create irregular headways in the opposite direction. Then terminal time must be extended until a train in the reverse direction has passed before the short-turning train can travel back, as shown in Figure $6 \mathrm{~b}$. 


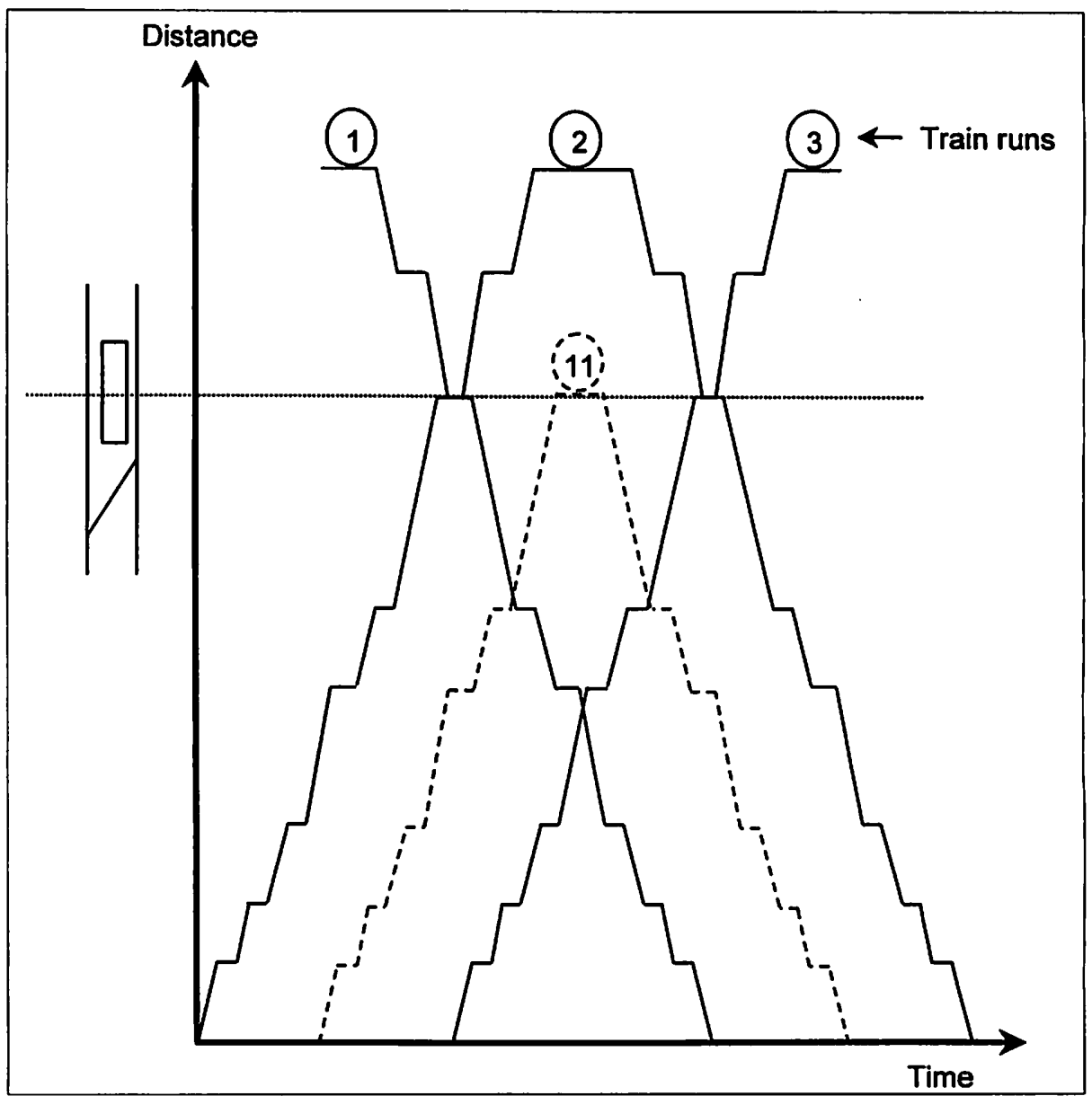

Figure 6a. Simple short turn.

As headways become shorter, it is likely that the TU cannot wait long enough to reverse without blocking traffic in its initial direction. In this case, either a different reversing location must be used, or an extra track for reversal must be provided. This situation is shown in Figure $6 \mathrm{c}$. The short-turning train must be moved promptly into the center track for reversing, so as to allow at least $h_{\min }$ for passing of the train that is following it in its initial direction. The center track then allows the reversing train to wait for the desired time to depart in the returning direction. Thus, any possibility of delays is eliminated and regular headway can be easily maintained. 


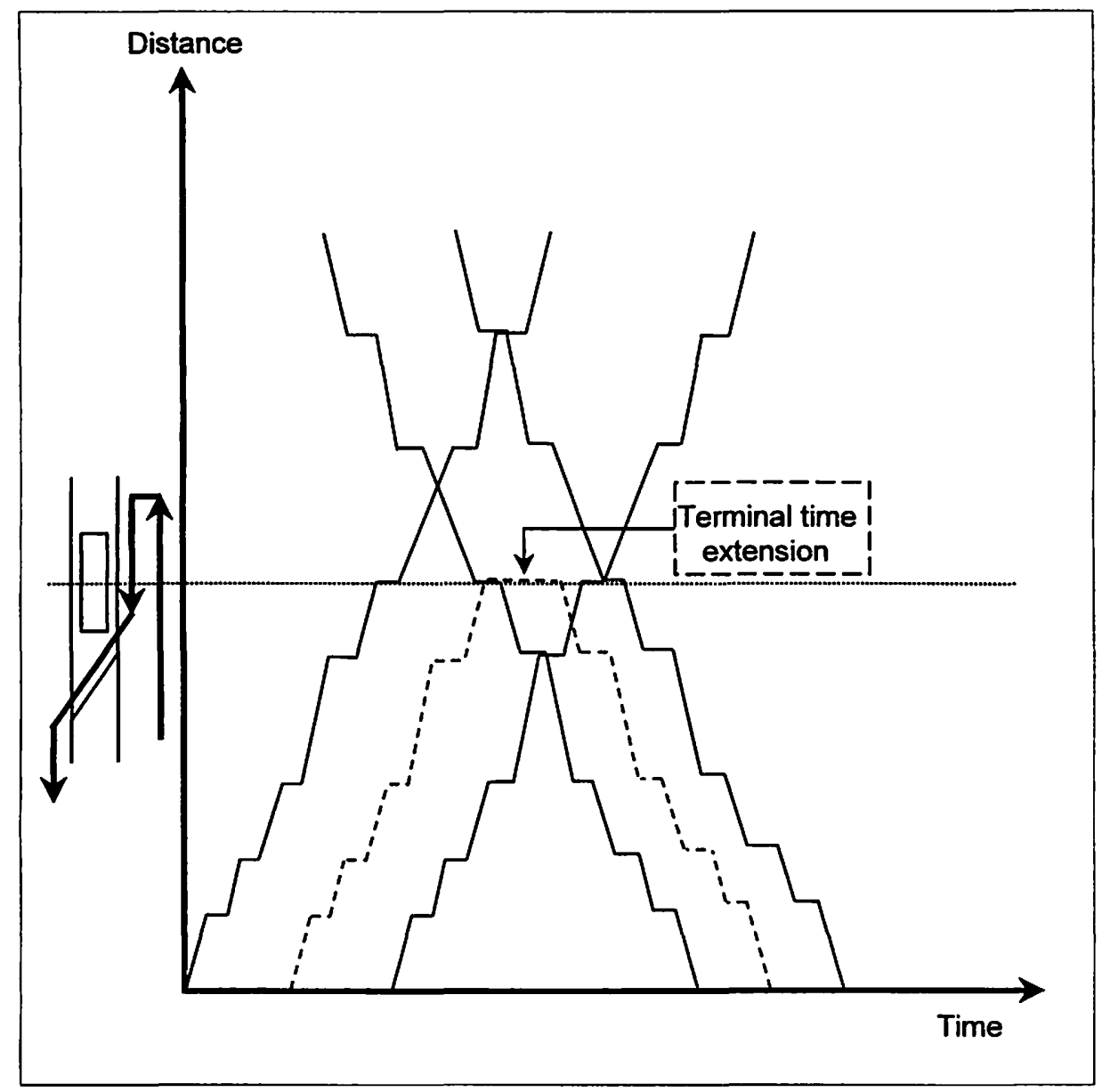

Figure $6 \mathrm{~b}$. Short turn scheduled between opposing train runs.

This example shows that a situation that is very complex to model algebraically due to several constraints and solution possibilities can be quickly analyzed graphically to see what type of solution(s) are actually feasible for a given basic headway, cycle time and track layout.

Skip-stop operations, described in Vuchic (1976), are such that at some stations, only alternating trains stop (typically called A and B stops). This is done generally only where the basic headway is short, as the stations where only alternating trains 


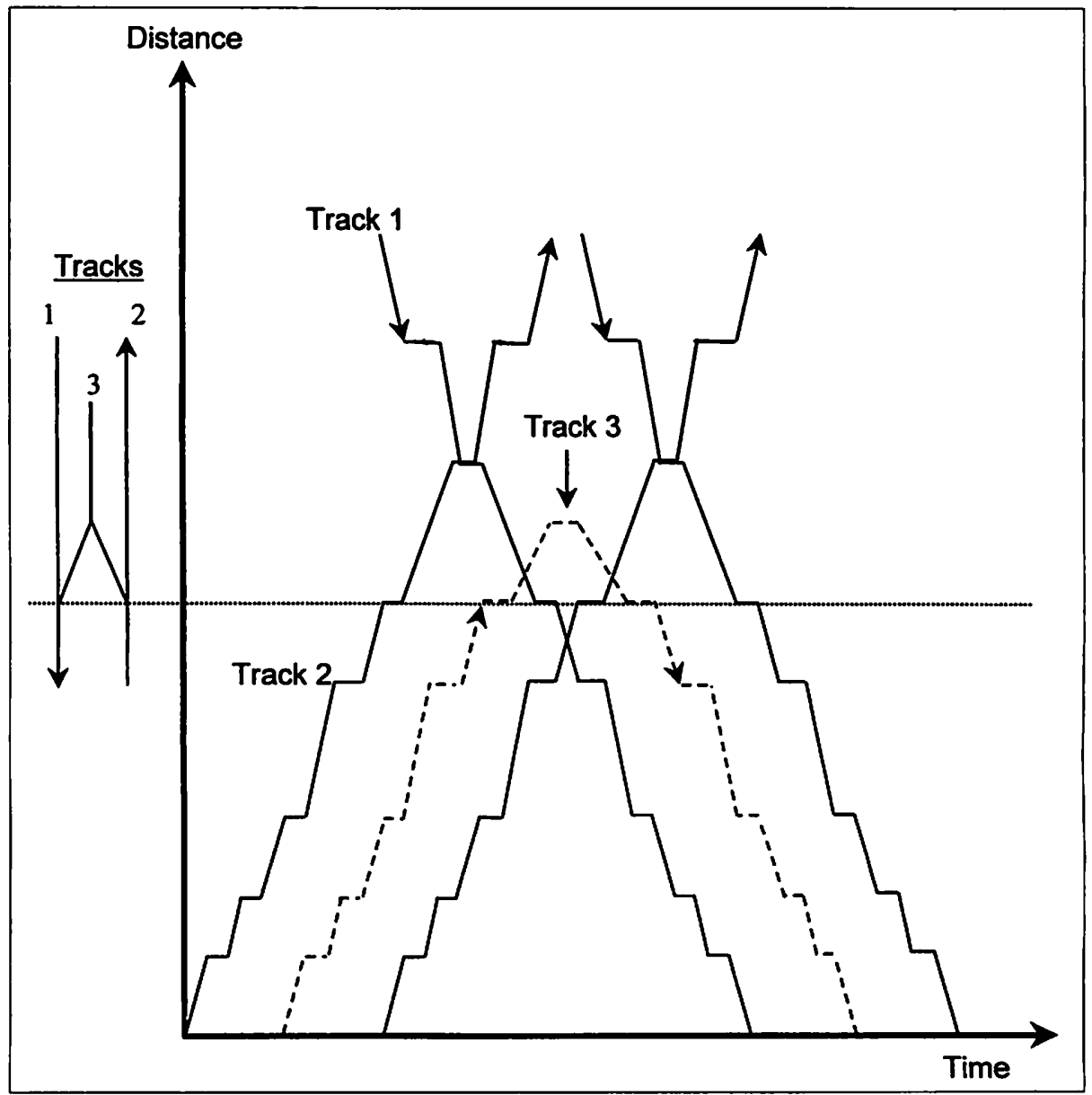

Figure $6 c$. Short turn with reversing track.

stop have doubled headways. Skip-stop service reduces operating time, so that either terminal times or dispatching times must be changed. Either possibility can be readily plotted and compared to regular operation. The horizontal separation between trajectories of trains that stop at a given station gives the headway passengers experience at that station. The diagram in that case shows that joint stations retain the same average headway as in regular, all-stop operation, while the A and B stations, being served by alternate trains, have twice longer headways. Since the joint stations have shorter headways, they remain critical for the line capacity. The diagram for skip- 
stop operation can also illustrate the increase in operating speed on the line achieved by skipping several stations.

Express operations on two-track lines require careful scheduling of local and express trains. Again, graphical scheduling is greatly superior to numerical methods, because inserting the trajectory of an express train between regularly scheduled train

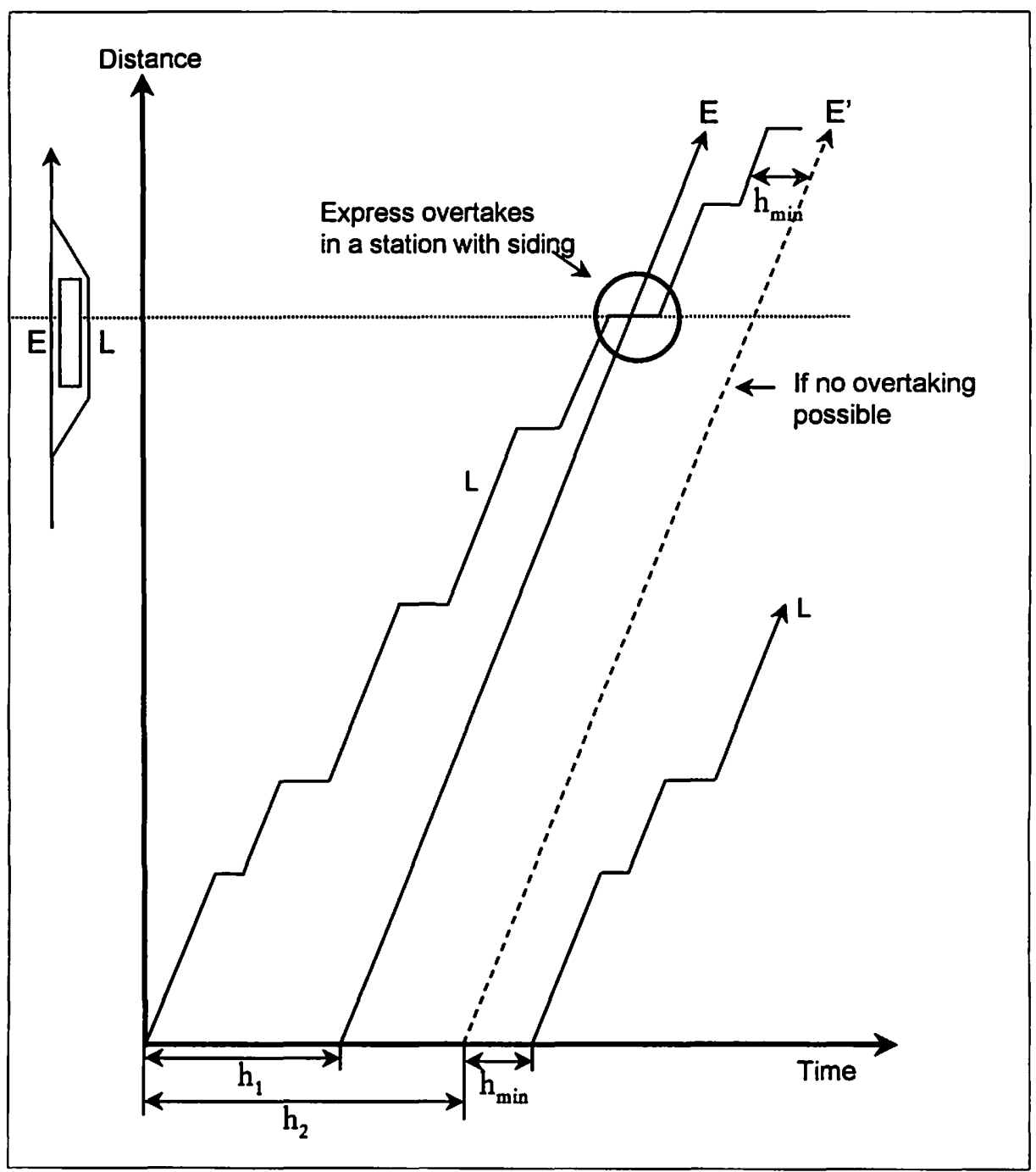

Figure 7. Synchronization of local and express trains. 
runs is visually very simple. As shown in Figure 7, the express, shown by trajectory $E$, should be scheduled so that it overtakes a local train in a station with siding; the initial headway between the local and express trains $h_{1}$ which is needed for this operation is easy to obtain graphically. If there are no stations with sidings, so that overtaking is not possible, trajectory of the express train is "slid" to the right until it reaches the dashed-line position on the right, E', where it "catches up" with the minimum headway behind the local train on the last interstation spacing. If it is important to utilize maximum line capacity achievable with this service regime, the express can be followed at the beginning of the line by another local train after a minimum headway, as shown on the diagram.

In general, express running is practical only when average headway on the line is considerably longer than the minimum one, so that the express train can skip several stations. The limits on express runs are imposed either by line capacity requirements or by the maximum acceptable headway.

\section{Trunk and Branch Operation}

Scheduling for a trunk line that divides into two or more branches is much more complicated than scheduling for a single line because it involves divergence and convergence of trains. The sequencing of TUs arriving from the various branches and the resulting regularity of the headway along the trunk section become important considerations. Algebraical coordination of schedules becomes quite complex, involving constraints on terminal times and merging sequences with multiple feasibilities, but not equally efficient solutions. Even when solved analytically, it may be difficult to visualize these solutions.

By contrast, using a graphical approach, feasible solutions can quickly be identified and compared. The method is to use the point of branch divergence $\mathrm{X}$ as a reference. The trajectories for all routes (each consisting of a trunk and a branch section) are shown together on the trunk section, while the trajectories along each branch section are shown on individual, vertically separated but synchronized timedistance diagrams. A vertical dashed line is drawn between corresponding diverging and merging points for each TU trajectory, as shown in Figure 8. 
To explain in more detail, a graphical diagram is started by plotting trajectories of successive TUs at given headways on the trunk line. At point $\mathrm{X}$, branch $\mathrm{A}$ is continued without interruption, while the following TUs, going to branches $\mathrm{B}$ and $\mathrm{C}$, are transferred vertically to the two respective diagrams. Terminal times on each

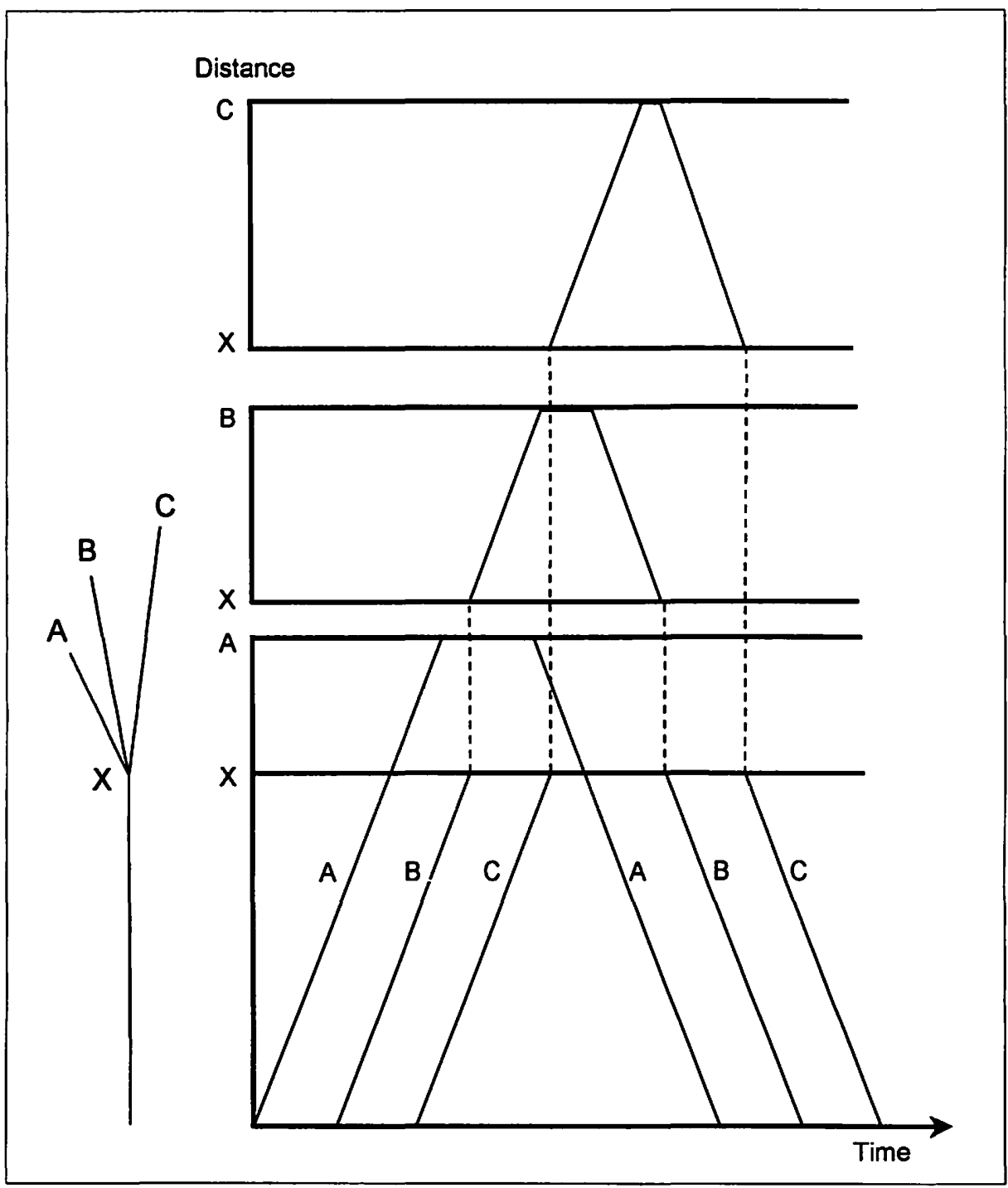

Figure 8. Time-distance diagram of a trunk with three branches. 
branch must be determined so that TUs merge at point $\mathrm{X}$ with equal headways. Graphically, these terminal times are obtained easily, and they can be visualized much more clearly than in numerical schedule tables. This solution, which provides even headways along the trunk, can be compared to alternate ones that would minimize terminal times and fleet size for each route, but, instead, have uneven headways along the trunk.

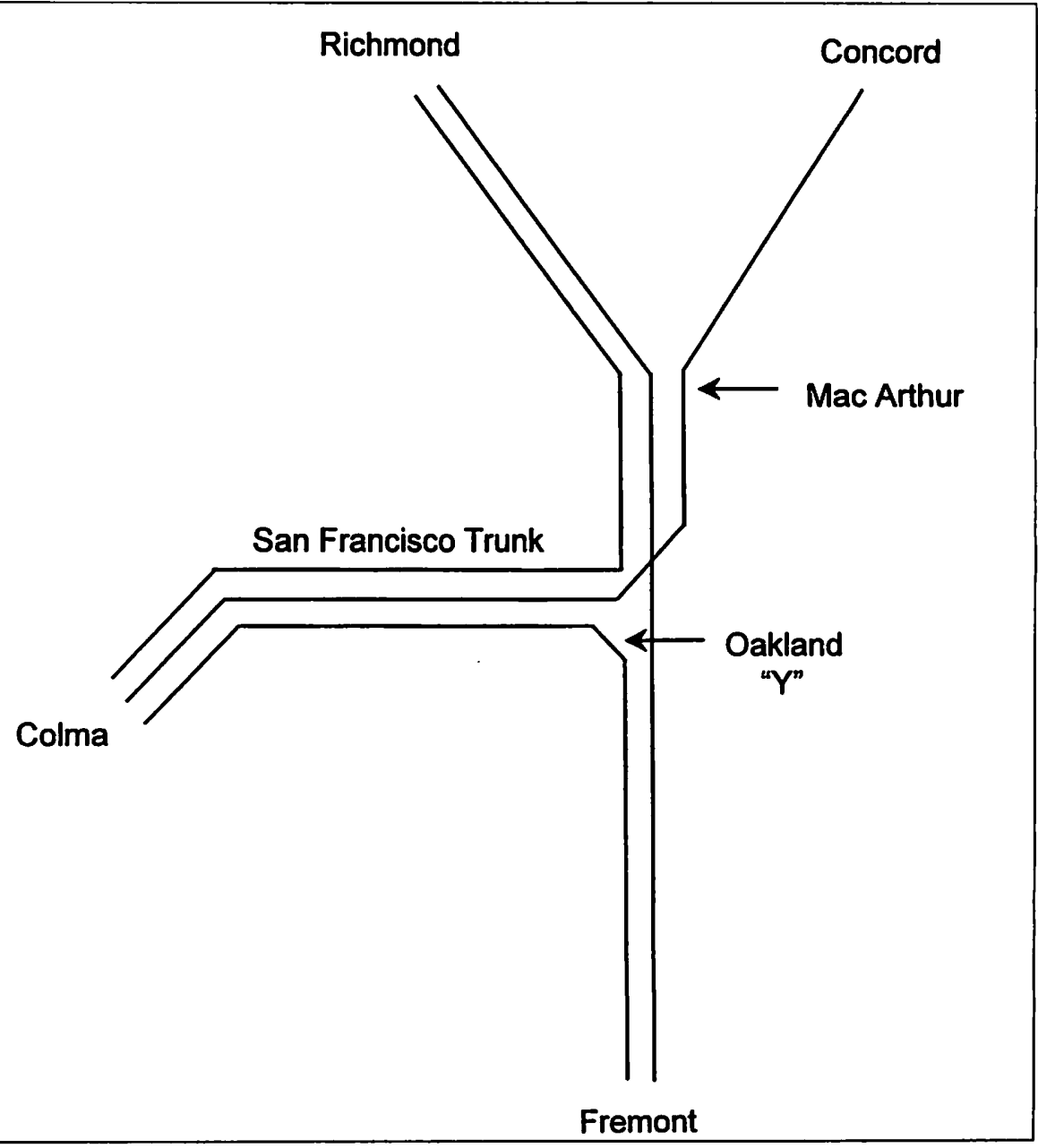

Figure 9. San Francisco BART network and lines (1996). 
In some complicated networks, analytic solutions can also become intractable. A good example is the Bay Area Rapid Transit (BART) network, which, until recently, consisted of three branches plus a "cross-connection" between two of the branches. Thus, the operation represents a triangle plus an additional trunk-andbranch line. The line pattern is shown in Figure 9. Although very difficult to model analytically, this network was successfully analyzed using a graphical method to arrive at several practical candidate scheduling solutions. This work was presented in several reports by Vuchic, Bruun and Krstanoski (1995-97).

Although space does not allow discussion of a complicated network like BART, application of graphical analysis to a network consisting of a trunk with two branches and crossline between the branches will be explained here. This network also can be interpreted as a three-leg network with lines between all three terminals, as shown in Figure 10.

Graphical presentation for this case, shown in Figure 11, is the same as for a trunk line with two branches: the main diagram shows the A-X-B

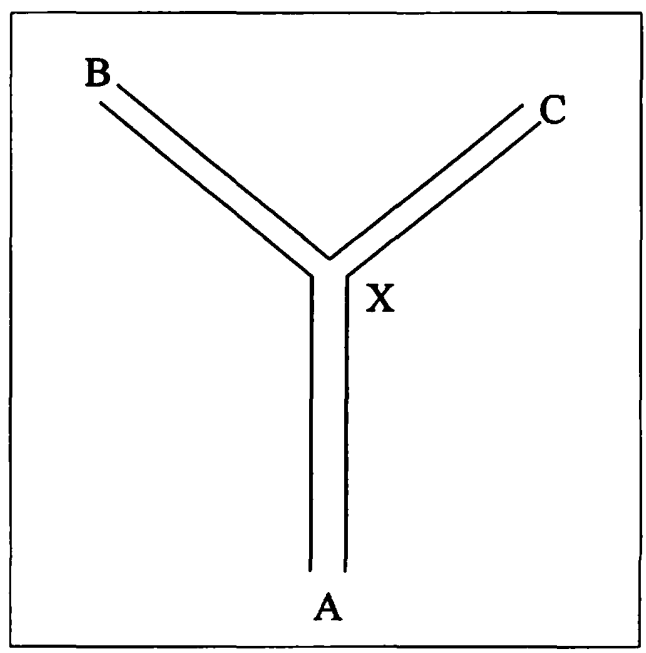

Figure 10. Simple two-branch network with cross-connecting line $B-C$. section, while the $\mathrm{X}-\mathrm{C}$ branch is shown above it. A-B and A-C trains are shown as in Figure 8. If the B-C trains are shown as inbound trains on the B-X section, then, when transferring to the X-C diagram, they are shown as outbound trains. Once understood, this diagram is very helpful in coordinating the schedules of the three branches. Because of the interdependency, such schedules usually cannot provide regular headways on all lines, and the graphical schedule can be very useful in making adjustments that make the best candidate sets of headways for the three branches. 


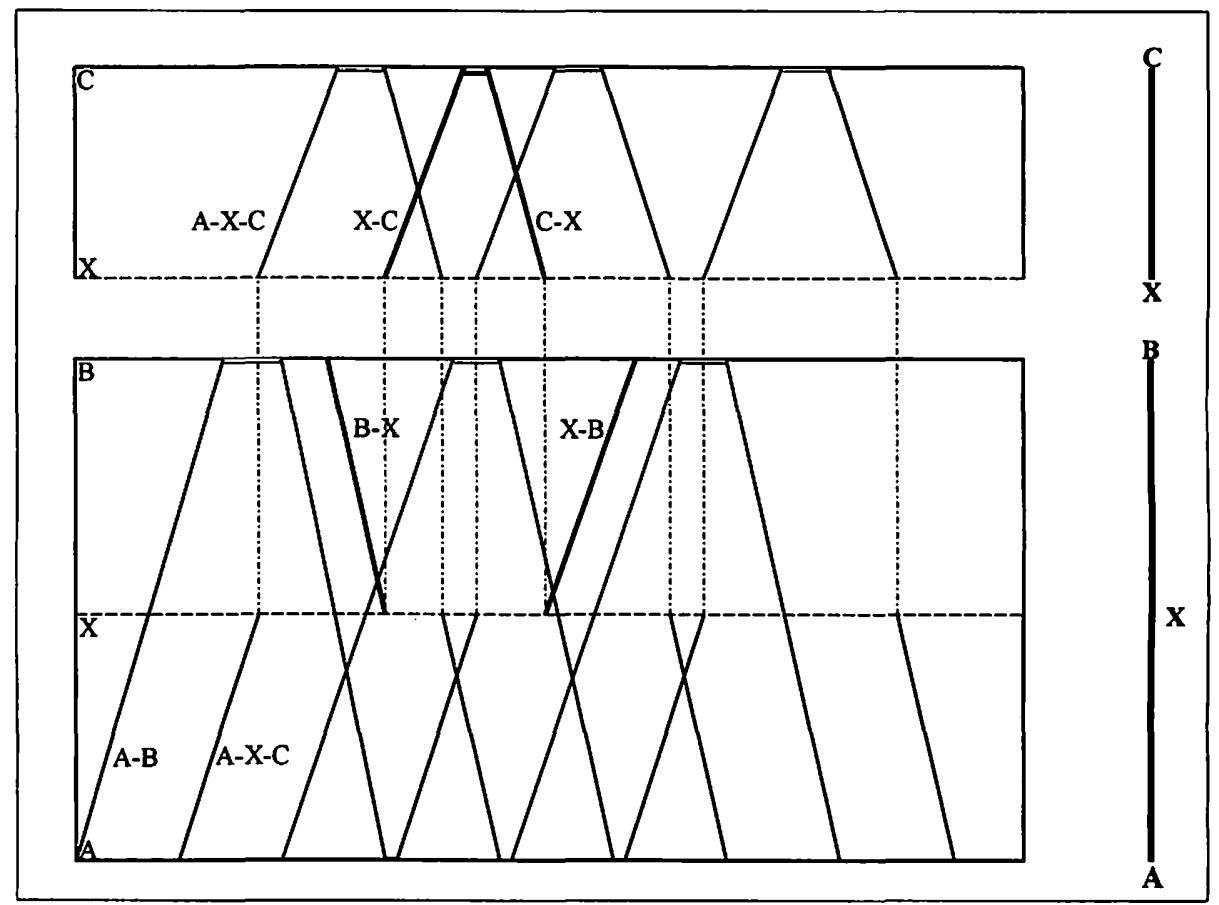

Figure 11. Time-distance diagram showing cross-connecting line between branches B and C (see Fig. 10).

\section{Use of Math Program Generated Schedules}

Several computer-based packages, using math-programming methods, have been in use for more than 20 years for scheduling transit services and crews. However, there are occasionally constraints that cannot be expressed well mathematically that may affect the practicality of the generated solutions. Examples include the operation of different rail services on shared trackage that do not fully cooperate in scheduling and dispatching, or transit lines that require large amounts of slack time in order to operate reliably. Interconnected lines, such as the above-discussed BART network, may also be more conducive to graphical than numerical scheduling and analysis.

Plotting the results generated by the program as a time-distance diagram will allow visualization of the latitude that is available for deviations from the schedule 
before a recovery strategy must be used to reposition TUs due to loss of slot in the schedule. This is done by checking the horizontal separation between the non-agencycontrolled vehicles and its own. The history of schedule adherence and delays along the shared section should provide some insight into the likelihood of delays serious enough to lose a slot as a function of the time slack available. Should the schedule appear too tight for reliable operation, the program can be rerun with changed constraints to include additional slack or "cushions" in the schedule.

An example application where a math-program-based schedule should be further analyzed is the Southeastern Pennsylvania Transportation Authority (SEPTA) Regional Rail Division. This is a regional rail network that includes not only SEPTAcontrolled tracks, but also major portions where Amtrak controls all train dispatching. By using a time-distance diagram, it is possible to see how tight the gaps are between the Amtrak and SEPTA trains at crucial locations along the network. Crucial locations are those where SEPTA trains are likely to be held when there are delays. Adjustments can be made to the schedule to provide recovery time or, if possible, to avoid tight scheduling in the first place. Such a diagram also allows quick visualization of the quality of connections between the various interconnected lines at key transfer points.

\section{Applications in Operations Control}

So far, the discussion has been in a planning context. Graphical analysis is useful in an operational context as well.

\section{Real-Time Oversight and Reporting}

Real-time oversight of train operations with elaborate control centers has been around for many decades, although, in some cases, the positional resolution is poor when signal blocks are long. Oversight of buses through Automatic Vehicle Location and other Intelligent Transportation Systems (ITS) technologies is a much more recent capability with generally high accuracy. In both cases, numerical schedules in spreadsheet format provide information with which to monitor adherence in realtime by displaying the numerical deviation, perhaps highlighted by a blinking or color-changing display when deviations become sufficiently large. For trains, a sys- 
tem schematic with lights indicating block occupancy is common. For buses, a GIS map showing vehicles of different colors (yellow-early, green —on time, red-late, for example) can also be used to highlight current status.

Spreadsheet-type displays have, however, some definite limitations. The bigger picture that might reveal how any deviations might be interrelated and where deviations are likely to propagate is not readily apparent with spreadsheets, schematics, or maps. A time-distance diagram where trajectories, or portions of trajectories change colors, used, for example, in the Italian Italtel bus dispatching/monitoring system, can readily reveal not only the current situation but impending deviations and conflicts. Even more importantly, as discussed in the next section, it provides some insight into when and where recovery strategies must be employed.

Moreover, when a real-time time-distance diagram is viewed on a high-resolution graphics terminal with a cursor ball, detailed information is instantly available. The horizontal cursor shows time information for any position along a route or common section. Every point where a trajectory crosses this cursor can be labeled with the time a vehicle passed or is projected to pass, which run number, vehicle, crew, etc. The vertical cursor provides position information at any particular time. Every point where the cursor crosses a trajectory can be labeled with the position coordinates (the precision of display depends upon the locating technology and update rate), run number, vehicle, distance separation from leading and following vehicles, etc. If there is more than one vehicle at a terminal, this is also readily shown automatically with more than one label.

Depending upon the ITS technologies in use, additional information about vehicle loading on a particular run, vehicle condition and other system attributes also can be instantly available. Thus, a graphical schedule is a means not only to track vehicles, but to monitor the entire operational status along a line or in a network, if desired. The data also can be stored, either temporarily or permanently. In the case of an incident a record is available, analogous to air-traffic control tapes or black boxes on airliners. Interesting records can be used for training purposes by replaying them to investigate control decisions that were taken. 


\section{Schedule Recovery Strategy Design}

A numerical format provides little assistance in designing a delay recovery strategy. A GIS display map on a computer terminal provides some visualization of the situation, but it does not provide an accurate picture of headway between vehicles as it shows distance between vehicles. Distance is not necessarily proportional to headway in urban situations where speeds vary widely over the course of a route. By comparison, an experienced dispatcher can quickly assess the status of an entire fleet operating on a route, or assess an entire sector in the case where dispatching responsibility is divided by region instead of by route.

Several recovery techniques can be tested on the time-distance diagram, alone or in combination. Ideally, likely delay scenarios should be studied beforehand so dispatchers can be trained in effective strategies, but it is also possible to investigate alternatives in real-time, at the cost of a few minutes of elapsed time (and the risk that the situation may deteriorate further).

The basic recovery technique is to simply delay the dispatching time of a following TU, which is done by "sliding" an entire trajectory. Another technique is to extend the dwell time at a station. By extending a dwell time, part of a trajectory can be shifted to represent holding a TU at a station to restore its headway separation from the first delayed one. In turn, the next TU can be held at another station to restore its headway separation. This process is repeated until scheduled headways are re-established. An example of a recovery strategy involving holding two TUs following delayed ones is shown in Figure 12. Other techniques include improvised shortturns, express running, and insertion of extra TUs. These concepts were already discussed, so it suffices to say that these techniques can also be readily tested on the diagram as recovery strategies as well as basic scheduling strategies.

\section{Real-Time Control}

Once the capability for oversight and for design of recovery strategies is in place, the capability is almost in hand to actively control operations. Instructions can, of course, be sent manually through verbal, either oral or written, messages. But it is also possible to automate the instructions, thereby shortening the response time and reducing the layers of supervision required. An example follows. 


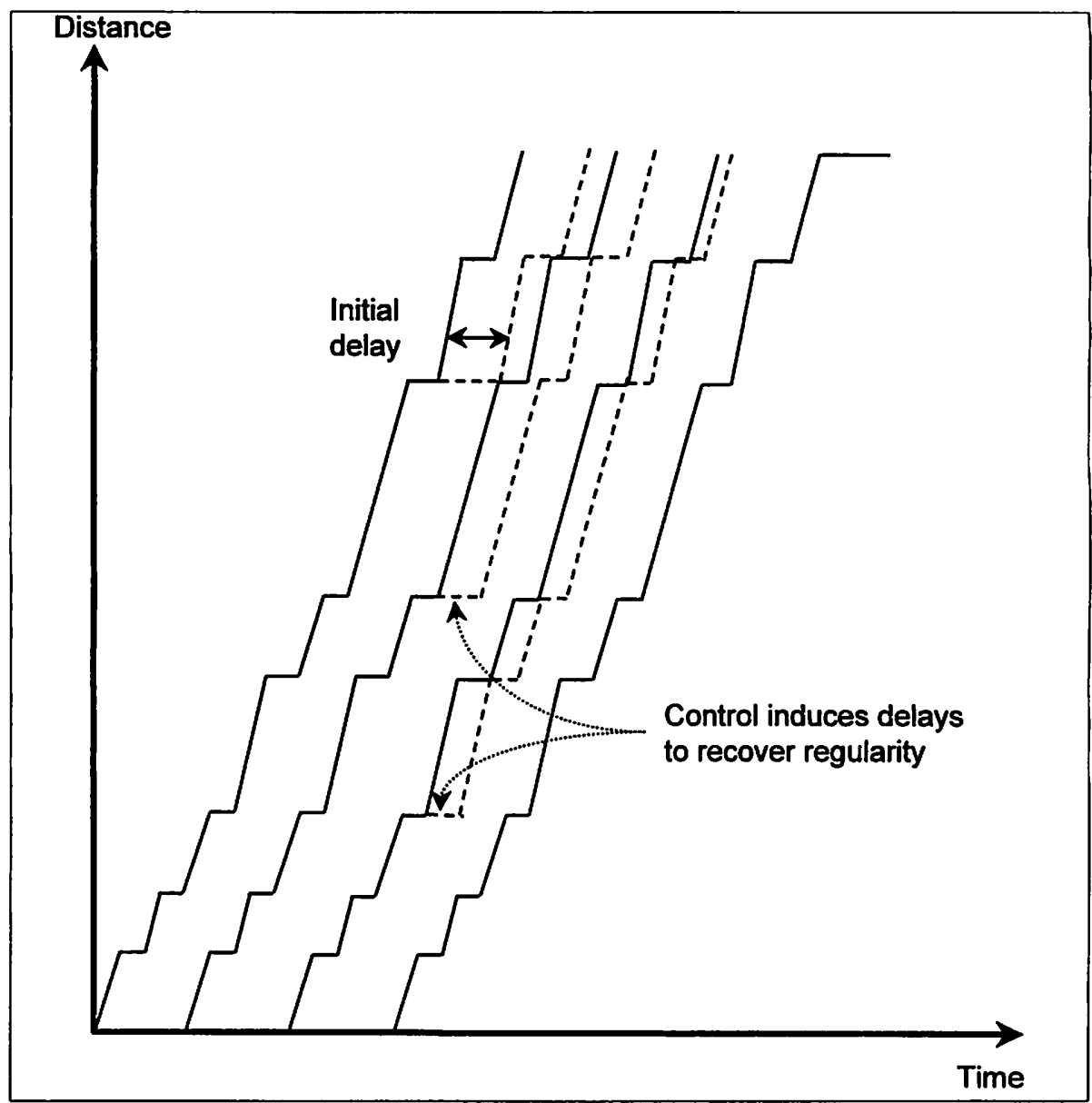

Figure 12. Schedule recovery by delaying two following trains.

Assume that a tentative schedule recovery strategy has been tried on the computer screen by clicking and dragging the dwell time of a particular train to prolong its stay at a station. The result is a tentative revised trajectory. A verification prompt could ask if the dispatcher would like to implement this plan. If answered in the affirmative, the command can automatically be issued to the in-vehicle control panel as instructions to the operator in the case of manually operated vehicles, or to the Automatic Train Operation (ATO) unit in the case of automatic operation. Further- 
more, the delay information can be automatically forwarded to the Passenger Information System and to the control centers for connecting modes. In turn, decisions can be automatically made with preset criteria whether to hold or dispatch connecting services, if desired.

\section{Conclusions}

Graphical scheduling is an old technique that has been neglected, or never acquired, in many North American transit agencies. Introduction of diversified and complex transit network operations in many cities creates potential for increasing applications of graphical methods in developing schedules, as well as in operations control. Actually, with modern computer graphics and ITS technologies it is more powerful than ever and deserves consideration where it is not currently being used. However, the latest dispatching/control software offered by transit ITS vendors in the U.S. does not take advantage of this approach.

Graphical scheduling retains its advantages in basic schedule design and analysis. It allows the solution of problems that are quite difficult to solve analytically. Even information about simple routes is enhanced by the detailed operating characteristics inherent in detailed vehicle trajectories and by the relative ease with which accelerated service and service recovery strategies can be investigated. It also can be used to confirm and refine solutions that are generated by analytic methods.

Graphical scheduling has additional advantages in operational control with the advent of modern ITS technologies. By movement of the cursor on a terminal screen, detailed information about any position along a route, or about all activity along a route at any particular moment, becomes available. An experienced dispatcher can gain a perspective on an entire route or geographic sector and anticipate problems at an early stage. In addition, it is possible to link the altering of trajectories through clicking and dragging to the automatic issuance of control commands and updates of passenger information.

\section{References}

Bruun, Eric C., and P. Takis Salpeas. 1991. Train operations computer simulation case study: Single-tracking operations for Philadelphia's Market-Frankford Subway Elevated Rail Rapid 
Transit Line. Transportation Research Record 1308, Transportation Research Board, Washington, D.C.

Vuchic, Vukan R. 1976. Skip-stop operation: High speed with good area coverage. UITP Revue No.

2, International Union of Public Transport, Brussels, Belgium.

Vuchic, Vukan R. 1981. Urban public transportation systems and technology. Englewood Cliffs, NJ: Prentice Hall.

Vuchic, V.R, E. C. Brnun, and N. Krstanoski. 1995-97. Schedule analysis of the BART system with SFIA-Millbrae Extensions, and other reports to BayArea Rapid Transit District. Oakland, CA: unpublished.

\section{About the Authors}

ERIC C. Bruun is Assistant Director for Advanced Technologies and Innovative Practices at the National Transit Institute, Rutgers University. He received his Ph.D. in Systems Engineering (Transportation focus) from the University of Pennsylvania in 1992.

VUKaN R. VuchIC is UPS Foundation Professor of Transportation Engineering at the University of Pennsylvania. He received his Ph.D. in Transportation Engineering from the University of California at Berkeley in 1966.

Yong-Eun SHIN is Assistant Professor at Dong-Eui University in Pusan, Korea. He received his Ph.D. in City and Regional Planning from the University of Pennsylvania in 1997. 


\title{
Stakeholder Preferences in Advanced Public Transportation System Planning
}

\author{
Jonathan Levine \\ Soonae Park \\ Steven E. Underwood \\ RichardR. Wallace \\ The University of Michigan
}

\begin{abstract}
Transportation planning in general and planning for intelligent transportation systems (TTS) in particular are notable both for multiple goals and for multiple constituencies. In response to complex policy environments such as this, multicriteria decision analysis often was utilized to assist in the evaluation of alternative investments or policy directions. This approach is extended here to assess stakeholder valuation of broad goals of an ITS planning process, the Suburban Mobility Authority for Regional Transportation (SMART) operational field test in the metropolitan Detroit area. Two levels of goals were considered: broad system-wide goals (e.g., energy savings, interagency coordination, congestion reduction) and specific service characteristics, such as advance reservations, scheduling, and reliability. Using a modified Analytical Hierarchy Process,

The authors wish to thank the Suburban Mobility Authority for Regional Transportation for research funding, and all of those who participated in our stakeholder interviews and focus groups. We also want to acknowledge the special assistance provided by the SMART staff who helped with access to facilities and participants. Finally, thanks to Tracy Gao and Zakia Shaikh of the University of Michigan for assistance in administering the survey questionnaires.
\end{abstract}


implicit preference weights for transportation planning goals were derived, and inter-and intragroup comparisons were made. Overall, there was less variation between groups in preferences than might be expected, indicating a fair degree of common ground in desired outcomes of transit planning. The ability to provide for the trips that people request, referring both to the accommodation of trips and the match between requested and scheduled times, were important goals across various stakeholder groups. Similarty, the provision of reliable service was generally valued highly. Information provision appears to be a lower priority. Thus, to the extent that automatic scheduling and dispatch assists improved scheduling, trip reservation, and routing, it is likely to meet stakeholders'preferences.

The study characterizes the various groups' preferences for transit service along a continuum ranging from "expansive" to "incremental." The expansive vision seeks to develop new forms of service for transit and paratransit customers better, while under the incremental view, consolidation of and improvements to existing service are a higher priority. The expansive position appears most clearly among citizens'groups, social service agencies, and business people. The business community is particularly interested in expansion of the hours of service, presumably to facilitate travel by customers or employees during evenings and weekends. The more incremental view is held by transportation professionals and SMART employees who are aware of the constraints under which they work.

\section{Introduction}

Advanced Public Transportation Systems (APTS) represent a diverse market basket of technologies and applications (Khattak et al. 1996). In planning for APTS adoption, public transportation organizations need to make decisions among technologies (e.g., automatic vehicle location, passenger counting, digital communication) and their application (e.g., paratransit routing and dispatch, traffic signal preemption, real-time information provision, fixed-route transfer coordination). Priority setting in this environment is likely to incorporate views regarding the preferences of different groups, with potential for both consensus and conflict. This study explores the interests of diverse stakeholder groups to a process of APTS implementation within metropolitan Detroit by the SMART (Suburban Mobility Authority for Regional Transportation) transit district. Within the national program of Intelligent Transportation Systems (ITS) field tests, SMART seeks to apply advanced technolo- 
gies, including automatic vehicle location and automatic scheduling and dispatch to its paratransit operations. As part of the evaluation of these efforts, this study aims to understand the relevant priorities of various groups in the region and how these may influence SMART's effort to improve services for its customers and communities by using APTS.

Given a public policy environment that is characterized by various objectives and constituencies, a search for a unitary social valuation within the SMART APTS deployment is probably futile. By reducing varied impacts to commensurate terms and masking actual variations in preferences, such analysis might limit the role of public debate regarding the directions of APTS deployment. For these reasons, a study of stakeholder groups and their preferences and priorities for system design is presented here. Information of this sort may be combined with knowledge regarding system outcomes to analyze the desirability of the systems from the perspectives of the various groups.

This study employs both qualitative and quantitative evaluations of stakeholder preferences. The former was designed as important input to the quantitative portion of the stakeholder preference analysis in that it established relevant groups and goals for further quantitative analysis. The study finds a relative consensus on the importance of transit mobility-related goals (as opposed to ancillary benefits such as interagency coordination or general congestion reduction) but disagreements on which mobility goals to pursue. In particular, some groups tend to focus on improving functions that are already being provided, while others will seek to use technological advances as a platform for broadening the scope of paratransit services.

\section{Preference Measurement in Transportation Evaluation}

The planning, marketing, and operations research literature abounds with approaches to multiattribute analysis in decisionmaking. Methodologies such as Multiattribute Utility Theory (Keeney and Raiffa 1976), Analytic Hierarchy Process (Saaty 1930; Saaty and Keams 1985), TODIM (Gomes 1989), and ELECTRE (Boy and Hugonnard 1982) share a similar underpinning: the notion that decisions entailing multiple objectives are aided by specifying quantified outcomes and preferencebased weighting schemes. The quantitative ratings generated by these methods are 
seen as tools for stakeholders and decisionmakers to compare simultaneously more alternatives and attributes than they would have been capable of otherwise, given the complexity of the information. Generically, these methods proceed according to five basic steps:

1. Identify relevant participants in the decision process. This can be a single decisionmaker, multiple decisionmakers, or "stakeholders"-the decisionmakers plus those groups affected by the decision (Edwards and Newman 1982).

2. Identify the dimensions, criteria, or goals that will characterize the alternatives.

3. Generate preference-based weighting schemes.

4. Develop measures by which each of the alternatives is assessed along each of the relevant dimensions.

5. Rank or rate alternatives based on measured outcomes and group preferences and perform analyses. These frequently include marginal analysis of costs and outcomes between alternatives, sensitivity analysis in which changes in the assumptions are tested for their capacity to alter final outcomes, and intergroup differences that compare the utility of different options to different groups and seek satisfying solutions.

Multiattribute studies traditionally have been used in transportation applications to select desired transportation improvements from among a series of proposed projects, or as an approach to predicting individual-level behavior under alternative policy options (Srinivasan et al. 1981; Bunch et al. 1993). Somewhat less common is the use of multiattribute analysis to assess trade-offs between broader goals of a transportation planning process (deNeufville and Keeney 1972). One approach for estimating people's preferences among trade-offs is the Analytic Hierarchy Process (AHP) (Saaty 1980) along with related techniques (Gomes 1989) in which the respondent is presented pairs of attributes and asked to rate the pair in terms of the relative importance of each of its elements.

In the rating scale developed by Saaty (1980), values range from 1/9 (for a case in which a goal is of extremely low importance compared to the other in the pair), 
through 1 (for cases in which the two goals are seen as equally important), to 9 (for cases in which a goal is of extremely high importance relative to the other in the pair). Classical AHP attaches verbal descriptors to the values, such as "moderate importance of one over another" or "demonstrated importance" (Saaty 1980). For the current study, these terms were judged not to be especially meaningful to respondents. Therefore, they were abandoned in favor of a simple row of boxes as shown in Figure 1.

The product of this approach is the estimation of a series of weights summing to unity that gauge the importance an individual places on the various competing goals. These weights may be gauged for consistency under the logic that under perfect consistency:

$$
a_{i k}=a_{i j} x a_{j k} \text { for all elements I, J and } K
$$

For example, if criterion I is seen as twice as important as $\mathrm{J}$ and $\mathrm{J}$ is 4 times as important as $K$, then I should be 8 times as important as $K$. Needless to say, individuals do not demonstrate such perfectly consistent ratios in their responses. AHP methodology thus develops a metric to gauge the distance of an individual's response

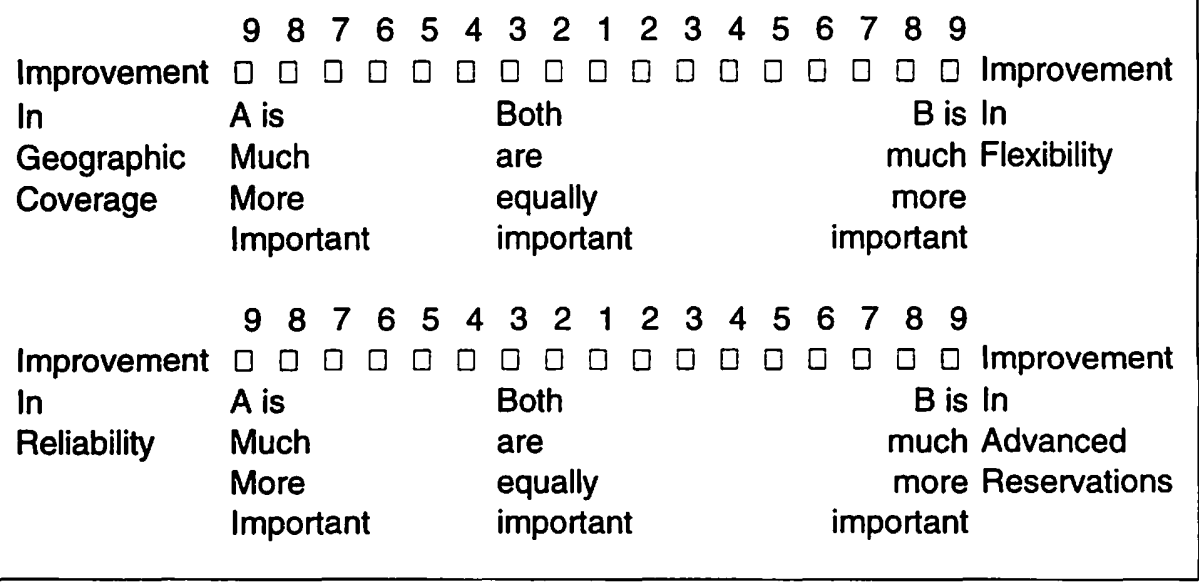

Figure 1. Sample questions from survey. 
set from randomness. A value of 0.1 , or sometimes 0.2 , on this metric (in which 0 indicates "perfectly consistent" and 1 signifies "random") is seen as reflecting adequate consistency to rely on results as reflecting an individual's considered judgment (Saaty and Vargas 1982). When the consistency ratio is higher than 0.2 , the analyst typically offers the respondent the opportunity to clarify some or all of his or her assessments.

\section{Study Methodology}

With the assistance of SMART, a list of groups with a vested interest in public transit in metropolitan Detroit was developed. Representatives of these groups were also involved in this identification process. Group members were contacted for initial phone-based interviews in order to assess (1) the objectives that these groups would define for an APTS implementation such as that planned by SMART, (2) other interest groups that should be represented in the evaluation process, and (3) other individuals associated with those groups that should be represented. Thus, a relatively small initial group expanded to encompass a broad range of individuals and groups with interest in SMART ITS policies and implementation. Through phonebased interviews, eight stakeholder groups were identified for this study, as shown in Table 1. The groups and representatives were selected for their likely interest in SMART policy, rather than for their representation of the population at large. Thus, no attempt is made here to infer to a larger population. The results represent the views of only the identified population of stakeholders in the SMART planning process. In all, 51 individuals were interviewed from groups 1 through 8 listed below.

This study consists of two surveys, each with somewhat different populations. First, subjects were drawn from identified stakeholder groups interested in SMART policy. Individuals were identified and selected within the eight groups listed in Table 1 . The second set of subjects of this study is paratransit passengers. Fifty-one passengers were interviewed on-board from 19 cities within the SMART service area. To select a representative group of passengers, a multi-stage cluster sampling technique was employed (Babbie 1990). Paratransit trips were stratified by service area based on each of four terminals, and by time. For sampled buses, all available passengers were interviewed. Three buses were selected from each terminal (for a 


\section{Table 1 \\ Stakeholder Groups in the SMART Evaluation Process}

Group 1: SMART

Group 2: Customer

Group 3: Local/regional public admin.

Group 4: Federal officials

Group 5: Agencies

Group 6: Business people

Group 7: Citizen groups

Group 8: Non-profit regional organizations
Customer operators, dispatchers, other SMART personnel

Active customers (i.e., board attendees)

City planning, city administration

FHWA, FTA

Agencies interested in using dispatch and related services

People who played key roles in recent millage election

Neighborhood and environmental groups

Urban development foundations, organizations

total of 12 buses) and roughly 4 or 5 passengers were interviewed on each bus (51 in total). Thus, about 13 riders from the service area of each terminal were interviewed.

Initial conversations with members of each of the stakeholder groups were conducted to identify a complete range of goals for SMART's APTS. Group members' stated goals appeared to break down into two dimensions. The first set of goals, identified in Table 2 as "system" goals, pertained to the broadest objectives for SMART system improvements, including ridership expansion, enhancement of interagency cooperation, energy savings, congestion mitigation, and cost reduction. A second set of goals focused more narrowly the dimensions of SMART's paratransit service; these are labeled the "service" goals and are described in Table 3. Two questionnaires were developed for this study; the first addressed five broad policy goals shown in 


\begin{tabular}{|ll|}
\hline \multicolumn{1}{|c|}{$\begin{array}{c}\text { Table } 2 \\
\text { System Goal }\end{array}$} & $\begin{array}{c}\text { Sentified SMART System Goals and Their Definitions, } \\
\text { as Presented to Respondents }\end{array}$ \\
\hline Increase ridership & Increase overall community transit ridership levels \\
Improve coordination & $\begin{array}{l}\text { Improve coordination between SMART and other } \\
\text { transit providers (for example, DOT and other } \\
\text { paratransit) }\end{array}$ \\
Save energy & $\begin{array}{l}\text { Reduce total gasoline and diesel consumption in } \\
\text { motor vehicles in the SMART service area }\end{array}$ \\
Improve cost effectiveness & $\begin{array}{l}\text { Deliver transportation services at a lower cost per } \\
\text { service } \\
\text { Reduce the amount of congestion on the arterials } \\
\text { and expressways in the SMART service area }\end{array}$ \\
\hline
\end{tabular}

Table 2, while the second considered the seven goals directly related to SMART's operations, as shown in Table 3.

The notion of a trade-off between goals is central to the design of this study, as ITS goals and outcomes can have mutually reinforcing or counteracting effects. For example, some strategies that increase ridership may impede cost effectiveness. Similarly, pursuing service goals such as the potential for spontaneous travel may detract from other goals, such as reliability (Levine and Underwood 1996).

To elicit information on stakeholders' valuations of such tradeoffs, a modified AHP approach was employed in this study. Accordingly, the respondent was presented with pairs of goals (Figure 1). To elicit valuation of the service goals, each goal was described by presenting data approximating the current situation and some target for ITS-based improvement in the future (Table 3). This quantitative specification of the goals was a departure from classical AHP, which would typically present two goals - for example, "advance reservations" and "scheduling"-and ask the respondent to compare the goals' relative importance. Faced with this choice, however, 


\begin{tabular}{|c|c|c|}
\hline \multicolumn{3}{|c|}{$\begin{array}{c}\text { Table } 3 \\
\text { Identified SMART Service Goals and Their Definitions, } \\
\text { as Presented to Respondents }\end{array}$} \\
\hline Transit Service & Before Improvement & After Improvement \\
\hline $\begin{array}{l}\text { Advance } \\
\text { reservations }\end{array}$ & $\begin{array}{l}50 \% \text { of advance } \\
\text { reservation requests met }\end{array}$ & $\begin{array}{l}75 \% \text { of advance } \\
\text { reservation requests met }\end{array}$ \\
\hline Scheduling & $\begin{array}{l}\text { Can schedule a ride within } \\
60 \text { min of requested time }\end{array}$ & $\begin{array}{l}\text { Can schedule a ride within } \\
30 \text { min of requested time }\end{array}$ \\
\hline Information & $\begin{array}{l}\text { Takes an avg of } 6 \mathrm{~min} \\
\text { to request a trip }\end{array}$ & $\begin{array}{l}\text { Takes an avg of } 2 \mathrm{~min} \\
\text { to request a trip }\end{array}$ \\
\hline $\begin{array}{l}\text { Weekend \& } \\
\text { evening rides }\end{array}$ & $\begin{array}{l}\text { Cannot get a ride on } \\
\text { evenings \& weekends }\end{array}$ & $\begin{array}{l}30 \% \text { of the time can get a ride } \\
\text { on evenings \& weekends }\end{array}$ \\
\hline $\begin{array}{l}\text { Geographic } \\
\text { coverage }\end{array}$ & $\begin{array}{l}\text { 6-mile limitation to } \\
\text { transfer-free coverage }\end{array}$ & $\begin{array}{l}\text { 10-mile limitation to } \\
\text { transfer-free coverage }\end{array}$ \\
\hline Flexibility & $10 \%$ of ASAP requests met & $30 \%$ of ASAP requests met \\
\hline Reliability & $\begin{array}{l}80 \% \text { of time vehicle } \\
\text { arrives within desig- } \\
\text { nated time window }\end{array}$ & $\begin{array}{l}95 \% \text { of time vehicle } \\
\text { arrives within desig- } \\
\text { nated time window }\end{array}$ \\
\hline
\end{tabular}

the respondent might legitimately wonder: "How much improvement in advance reservations versus how much improvement in scheduling?" Thus, the respondent might have difficulty formulating an appropriate response (Harker and Vargas 1988). The specification of specific, quantified improvements in all goals was an attempt to reduce this ambiguity for the respondent.

Respondents completed the questionnaire on computers in the presence of an interviewer. After all questions were answered, each respondent was shown a figure indicating the initial calculations of his or her weights regarding both the five system goals and the seven service goals described in Tables 2 and 3. All respondents were shown their initial consistency statistics and were given the opportunity to confirm their satisfaction with the initial calculation of weights. At this time, some respon- 
dents revised answers to improve the overall consistency of their responses or to adjust the relative weights of goals to better reflect their preferences.

\section{Preferences of Individuals and Stakeholder Groups}

Depending on one's view of the decisionmaking process, it is possible to view the respondents in this study either as individuals or as members of relevant stakeholder groups. This study adopts both approaches. First, information on the individuals comprising the population as a whole is presented to examine ranges of prevailing opinions on SMART policy among the population studied. Next, individuals are examined for their tendency to represent groups of common interests.

\section{Analysis of Individual Results}

The output of the modified AHP approach described above is an index of the relative importance that each individual implicitly attaches to each goal in the study. The values for an individual sum to unity; i.e., "1" represents the total importance placed on all goals together. Though the primary result of such an analysis is a set of weights for each individual in the study, aggregation of scores is presented as a convenience to avoid presentation of what would otherwise be an indigestibly large amount of data. Means, rather than medians, are generally used to ensure that weighting for groups, like those pertaining to individuals, sum to unity.

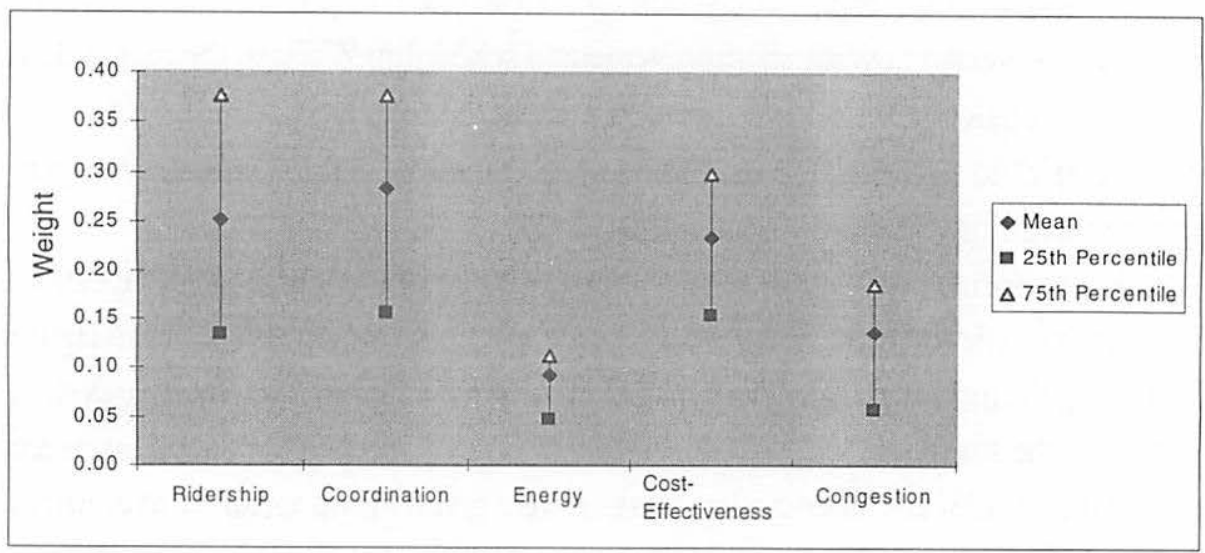

Figure 2. Weight for system goals: means and 25 th and 75 th percentiles. 
Figure 2 presents the means and the 25 th and 75 th percentile weights for each of the five goals across all respondents. For example, the mean weight of the "reduce congestion" goal was 0.14 and the interquartile range was from 0.06 to 0.19 . The greatest weight was placed on improving coordination between SMART and other transportation agencies as the desired system goal, followed by increasing ridership and improving cost effectiveness.

This result agrees well with earlier focus group discussions held with the respondents, as the highest weighted goals tended to dominate the discussions. The goal rankings also seem reasonable when considering the stakeholder groups involved in this survey. Most of the groups and respondents have intimate concerns about transitbased mobility in southeast Michigan. As a result, they are more concerned about immediate system improvements for transit in southeast Michigan than about a range of environmental concerns.

Figure 3 presents parallel findings for the specific service goals. The highest preference was given to reliability, which has a mean value of 0.19 . Interestingly, respondents accorded a relatively high weight to reliability, despite the fact that the base case-i.e., prior to improvement - was quite good ( 80 percent of vehicles arriving within the time window). The lowest rank was placed on information, with a mean value of 0.09 . The respondents appear to be more concerned about time sched-

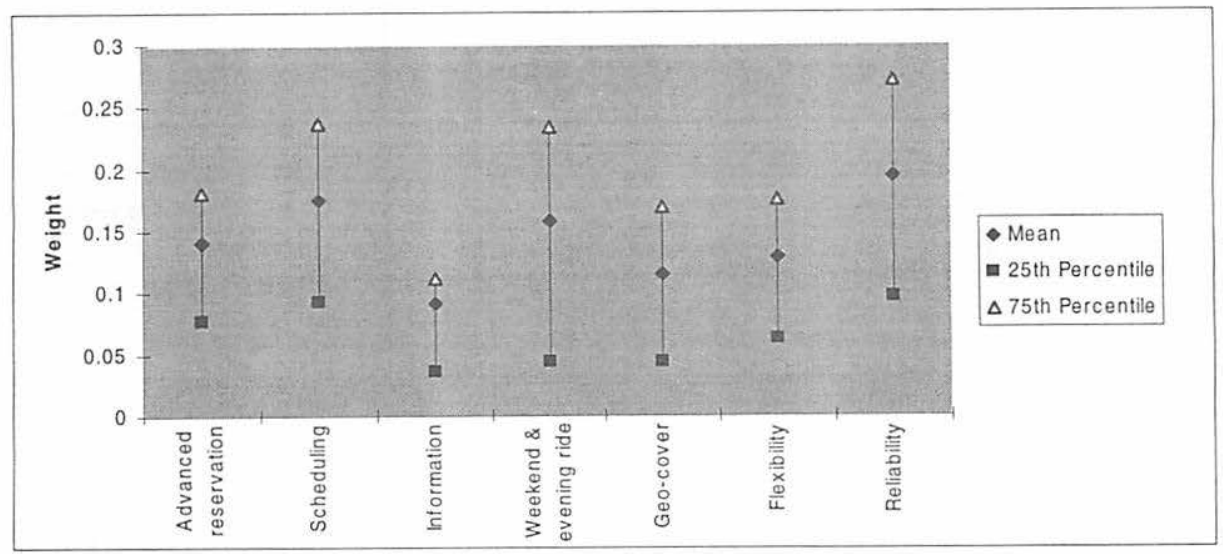

Figure 3 . Weights for service goals: means and 25 th and 75 th percentiles. 
ules and do not want to wait or to be late. Scheduling, weekend and evening rides, and advance reservations show relatively high mean values ( 0.14 to 0.17 )

Flexibility (i.e., immediate service request), expanding the transfer-free distance, and reducing waiting time for trip requests were all somewhat less emphasized, with mean values around 0.10 . In summary, respondents in this study are more concerned about faster and more reliable transportation service, and less concerned about service expansion in terms of geography or time. Of course, potential ridersas opposed to current riders-were not surveyed. Current riders, almost by definition, are having their basic mobility needs met by SMART, at least to some extent. People who have regular needs for travel outside of the constraints of the current SMART system, however, may weight goals differently.

\section{Analysis of Identified Stakeholder Groups}

An implicit assumption of a planning process that explicitly involves stakeholder groups is one of similarity of interests within identifiable groups. Under this framework, these groups - as groups, not as aggregations of individuals - are presumed to be major players in the process of policymaking. This section analyzes the extent to which the representatives form groups and the extent to which these groups match their identified affiliations. Figure 4 presents mean weightings for SMART

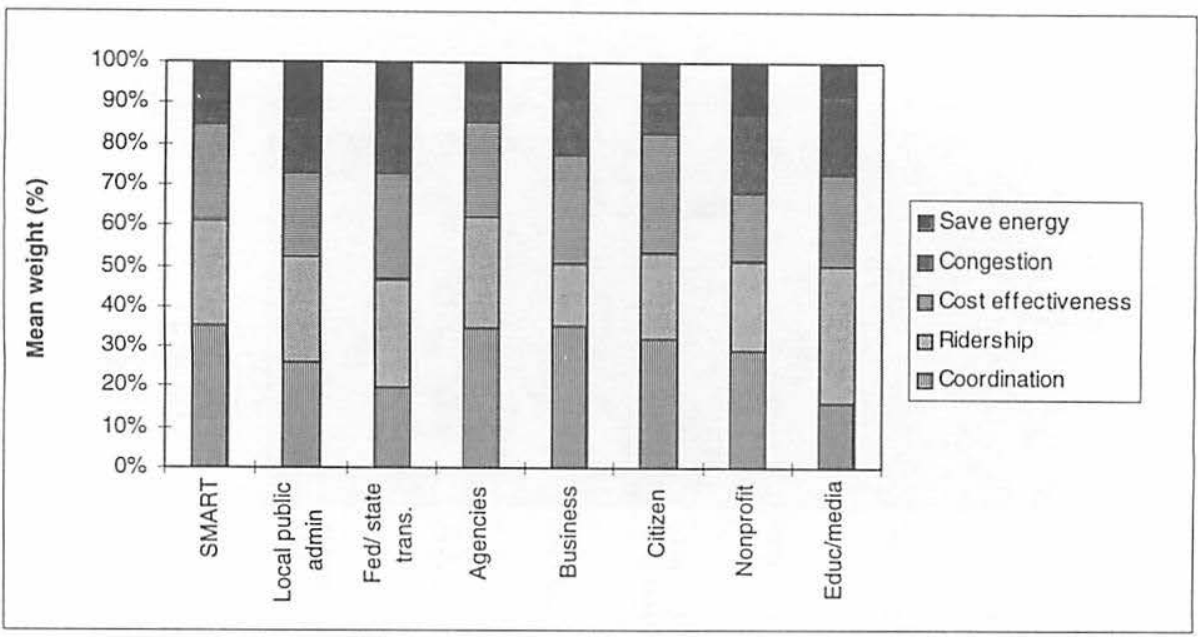

Figure 4. Valuation of system goals by stakeholder groups. 
system goals by the nine stakeholder groups. Each group's valuation of all goals combined is set to 100 percent. How each group divides up this total valuation among the various goals is represented by the heights of the bar segments.

Overall, there appears to be greater similarity than difference between the groups. Most of the groups rate improving coordination highly, though SMART, agencies, and business groups tend to give it a higher rating than others. The federal/ state transportation and media/education groups rate increasing ridership and cost effectiveness highly compared to others. Improving cost effectiveness and increasing ridership were rated similarly among various groups. Most groups give energy savings the lowest value, but non-profit organizations and local public administrators give higher ranks than other groups for both goals. Regarding congestion, the media/education, non-profit, and federal/state transportation groups indicate higher values compared to other groups.

The valuation of quality of service goals appears to have more differences among groups compared to system goals. Most groups rate improving reliability highly-around a mean value of 0.20 -while top ranking by passengers was given to scheduling ( 0.20$)$, by businesses to weekend and evening rides $(0.31)$, and by citizen groups to geographic coverage (0.25). Compared to other groups, passengers gave the lowest value to reliability. Given that most passengers on paratransit buses are seniors and persons with disabilities, many of whom are not currently employed, this outcome may be due to a fair amount of flexibility in their schedules. Perhaps the most notable result of this analysis is that business groups place a high value on weekend and evening rides, with a group mean of 0.31 . Other groups (e.g., SMART officials and the public sector) show less interest in this goal. Business groups may prefer extending service hours for their employees, as well as their customers.

Geographic coverage receives a high valuation from citizen groups but other groups appear somewhat less interested in this goal. Most groups rate information as their lowest value but the federal/state transportation group gives it a relatively higher value (0.13) compared to other groups. SMART employees tend to give lower values to both weekend and evening rides and geographic coverage while giving higher ranks to reliability, advance reservations, and scheduling. Passengers give 
higher ranks to scheduling, weekend and evening rides, and advance reservation factors related to ridership. The federal/state transportation groups indicate higher values for scheduling and flexibility, similar to the valuation given by the local and regional public administration group. Valuation of geographic coverage and improving scheduling varied widely among groups, while reliability and information showed similar values among groups.

Emerging from this breakdown of preference is a distinction between desired improvements on the basis of the respondent's affiliation. Families of improvements may be categorized as expansive (i.e., expanding service in the dimensions of time, geographic coverage, or flexibility) or incremental (i.e., improving service that is already provided, in terms of scheduling or reliability). Citizens' groups, businesses, and agencies appear to be more expansive in their vision, while SMART personnel appear to prefer a more incremental approach. Current passengers' valuations also appear more incremental in tone. This outcome probably is attributable to the self-

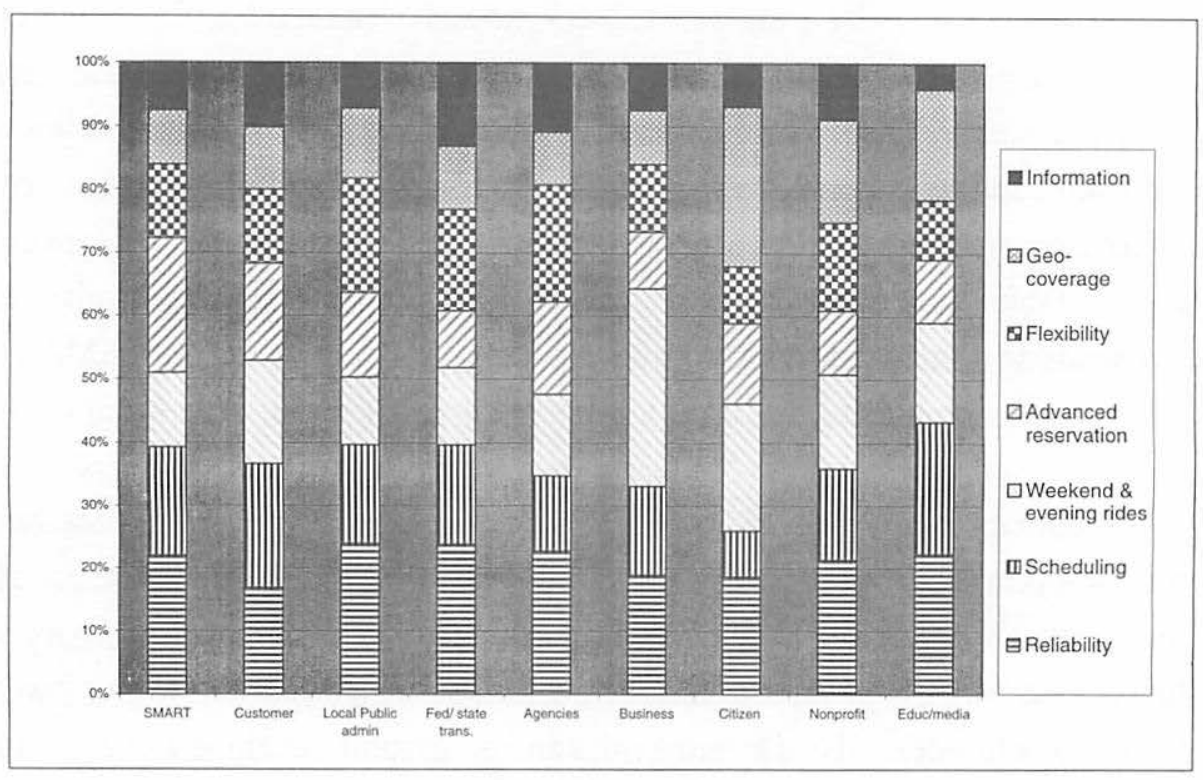

Figure 5 . Valuation of service goals by stakeholder groups. 
selection that occurs among riders - those who are current customers are those whose basic destination and travel times are being served through current service.

\section{Impact of Group Affiliation on Transit Preferences}

To further explore the significance of group membership on policy valuation, stepwise multiple regression was performed in an attempt to predict valuation of service improvement goals on the basis of individuals' characteristics, as well as stakeholder group affiliation. Table 4 presents the regression result for the four (out of seven) service goals for which at least 10 percent of the variance could be explained by group membership and demographic characteristics. The results tend to support the findings reported above: for only four goals was stakeholder group affiliation a statistically significant predictor of valuation of SMART service goals $(\mathrm{p}<0.05)$.

First, SMART affiliation and age are positively associated with improving advance reservations. Thus, SMART staff and older people appear to be more interested in improving than in expanding current service. Second, views on scheduling seem to be positively associated with membership in the customer group; this finding may have a similar interpretation to that associated with advance reservations. Third, the business group shows an interest in improving weekend and evening rides relative to other groups. Conversely, transportation groups as a whole (including SMART, lo$\mathrm{cal} /$ regional public administration, and federal/state transportation officials) show a negative association with weekend and evening rides. The focus group discussions help explain this result: these groups are concerned about spreading resources too thinly over expanded service. Finally, the citizens' groups and nonprofit organizations show an interest in improving the geographic coverage of transfer-free travel. In other words, they appear interested in allowing their clients to travel greater distances with less hassle. Quite possibly, such an improvement would allow these organizations to extend the geographic extent of their service provision.

Among demographic variables, only age was included as a statistically significant predictor variable. Age is positively associated with valuation of advance reservations, while showing a negative relationship with valuation of weekend and evening rides. It may be that older people are more concerned about improving paratransit 


\section{Table 4}

Stepwise Regressions Predicting Valuation of Service Improvement Goals (t-statistics in parenthesis)

\begin{tabular}{|c|c|c|c|c|}
\hline & & Dependent & Variables & \\
\hline $\begin{array}{l}\text { Independent } \\
\text { Variables }\end{array}$ & $\begin{array}{c}\text { Ln Improving } \\
\text { Advance } \\
\text { Reservation }\end{array}$ & $\begin{array}{l}\text { Improving } \\
\text { Scheduling }\end{array}$ & $\begin{array}{c}\text { Ln Improving } \\
\text { Weekend \& } \\
\text { Evening Rides }\end{array}$ & $\begin{array}{c}\text { Ln Improving } \\
\text { Geographic } \\
\text { Coverage }\end{array}$ \\
\hline Constant & $-2.92(-14.09)$ & $0.16(11.38)$ & $-1.31(-3.7)$ & $-2.60(-33.19)$ \\
\hline Age & $0.14(3.67)$ & & & $-0.18(-3.03)$ \\
\hline \multicolumn{4}{|l|}{ Dummies: } & \\
\hline Customer & & $0.04(2.09)$ & & \\
\hline \multicolumn{5}{|l|}{ Major agencies } \\
\hline Business group & & $\underline{0.66(1.48)}$ & & \\
\hline Citizen group & $-0.09(-2.09)$ & & $1.20(3.84)$ & \\
\hline Non-profit org. & & & $0.66(2.10)$ & \\
\hline Transportation & & $-0.32(-1.30)$ & & \\
\hline $\mathbf{R} 2$ & 0.16 & 0.11 & 0.12 & 0.16 \\
\hline Adjusted R2 & 0.14 & 0.09 & 0.09 & 0.14 \\
\hline
\end{tabular}

* When the skewness of dependent variable is greater than 1 , natural log transformation was performed. Based on the natural log estimations described in above Table 8 , the models may be presented in the following fashion:

Estimated Improving Advance Reservation: $0.05 * \mathrm{e}^{0.14 A_{z e} *} \mathrm{e}^{0.67 \text { SMART }}$

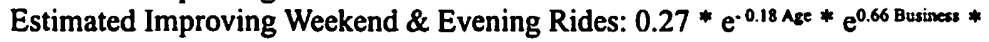
$\mathrm{e}^{-0.32 \text { Trans. }}$

Estimated Improving Geographic Coverage: $0.07 * \mathrm{e}^{1.20 \text { Citizen }} * \mathrm{e}^{0.66 \text { Non-Profin }}$

* Underlined dummy variable in Weekend \& Evening Rides are statistically significant only when $\mathrm{P}<0.2$.

* Media/education is the omitted stakeholder group dummy variables. 
within its current time limitations, while younger people prefer extending temporal coverage. In general, the results of stepwise regression are consistent with the results of means comparisons.

\section{Conclusion}

This study aims to understand how SMART and similar transit organizations may improve services for their customers and communities by using APTS. Several major themes emerge from the analyses above.

\section{Use of Stakeholder Preference Data in the APTS Planning Process}

This evaluation does not presume that there exists a single set of values upon which a judgment of efficacy of a transit organization can rest. Rather, the evaluation acknowledges the heterogeneity of interests in the planning efforts of a transit organization, the constituencies that influence it or may be impacted by its decisions, and the more general audience for which the evaluation will have some appeal. Transit officials are interested in tracking the political environment, including the viewpoints of riders, the U.S. DOT, and national transportation policy leaders. The evaluation was designed to capture these multiple interests through the application of multiattribute value and integrative analysis techniques. These techniques are designed to clarify similarities and differences in values between individuals and groups, to explore the potential for creating new implementation options, and to evaluate new and baseline options in terms of the stakeholders' values.

\section{Relative Consensus Among Groups}

Although stakeholders were drawn from a broad range of interest groups, including riders, SMART employees, the business community, agency representatives and more, there was less variation among groups in preferences than might be expected. Statistically significant differences among groups were rare, indicating a fair degree of common ground in desired outcomes of transit planning. This may be good news for decisionmakers trying to forge system goals meeting the needs of a broad array of groups. 


\section{Importance of Scheduling and Advance Reservations}

The ability to provide for the trips that people request, referring both to the accommodation of trips and the match between the requested and the scheduled times, were important goals across various stakeholder groups. Similarly, provision of reliable service was generally valued highly. Information provision, a focus of much of SMART's efforts in the early phase of the project, appears to be a lower priority. Thus, to the extent that automatic scheduling and dispatch assist improved scheduling, trip reservation, and routing, it is likely to meet stakeholders' preferences. If systems focus largely on information provision, then stakeholders' goals will not be met as well.

\section{Focus on Mobility-Related Goals}

Two levels of goals were considered here: broad system-wide goals (e.g., energy savings, interagency coordination, congestion reduction) and specific service characteristics such as advance reservations, scheduling, and reliability. Emerging from the broader perspective is a view that SMART's planning activities need to be oriented to effective mobility provision, per se, rather than related goals of energy savings or congestion reduction. Large numbers of people in the SMART service area are dependent on SMART and other providers for their mobility needs, and intelligent transportation systems are seen as potential elements of meeting those needs. Furthermore, given transit's low mode share in the region, in the near term, incremental changes in transit policy can have little effect on energy use or congestion.

\section{Expansiveness versus Incrementalism}

The goals discussed in both the quantitative and qualitative analyses can be divided into two principal families:

1) those goals that pertain to operating current service more effectively, and

2) those goals that pertain to expanding the types of service that SMART is able to offer.

The former view can be referred to as the incremental view, while the latter may be seen as the expansive position. The expansive position appears most clearly among citizens' groups, social service agencies, and business people. These groups are keenly 
interested in expansion of the geographic range that is accessible by SMART paratransit and expansion of the flexibility with which trips can be requested. Notably, the business community is particularly interested in expansion of the hours of service, presumably to facilitate travel by customers or employees during evenings and weekends.

The more incremental view is held by transportation professionals and SMART employees who are aware of the constraints under which they work. Current passengers also appear to be more incremental than expansive. At first glance this may be surprising, given that passengers are largely dependent on transit for their mobility needs. It seems that a process of selection has already occurred; current passengers are those for whom SMART more or less serves needed destinations and travel times. Furthermore, as current customers, passengers may also share an understanding of system tradeoffs and constraints.

Assessment of the appropriate balance between the expansive and the incremental views will be a continuing process that will undoubtedly occupy transit organizations for years to come. Methodologies established in the current study can assist in this process by identifying relevant views and perceptions of groups and individuals who are intimately involved in and concerned with the provision of transit and paratransit-based mobility.

\section{References}

Aldenderfer, M. S., and R. K. Blashfield. 1984. Cluster analysis. Beverly Hills, CA: Sage Publications, Inc.

Babbie, E.A. 1990. Survey research methods, 2nd edition. Belmont, CA: Wadsworth Publishing Co.

Bunch, D. S., M. Bradley, T. F. Golob, and R. Kitamura. 1993. Demand for clean-fuel vehicles in California:A discrete-choice stated preference pilot project. Transportation Research 27A: 237-253.

Chen, K., and S. E. Underwood. 1988. Integrative analytical assessment: A hybrid method for facilitating negotiations. Negotiation Journal, April 1988: 183-197. 
de Neufville, R., and R. L. Keeney. 1972. Use of decision analysis in airportdevelopment in Mexico City. In A. W. Drake, R. L. Keeney, and M. P. Morst (eds.), Analysis of public systems. Cambridge, MA:MIT Press.

Downs, A. 1992. Stuck in traffic: Coping with peak-hour congestion. Washington, D.C.: Brookings Institute; Cambridge, MA: Lincoln Institute of Land Policy.

Edwards, W., and J. R. Newman. 1982. Multiattribute evaluation. Newbury Park, CA: Sage Publications.

Giuliano, G. 1985. A multicriteria method for transportation investment planning. Transportation Research 19A:29-41.

Gomes, L. F.A. M. 1989. Multicriteria ranking of urban transportation system alternatives. Journal of Advanced Transportation 23: 43-52.

Gordon, D. 1992. Intelligent vehicle/highway systems: An environmental perspective. In J. L. Gifford, T.A. Horan, and D. Sperling, eds. Transportation, information technology and public policy: Institutional and environmental issues in IVHS. Proceedings of TVHS Policy:A Workshop on Institutional and Environmental Issues. Fairfax, VA: The Institute of Public Policy, George Mason University.

Harker, P. T., and L. G. Vargas. 1988. The theory of ratio = scale estimation: Saaty's analysis hierarchy process. Management Science 33: 1383-1403.

IVHS America. 1992. Strategic plan for Intelligent Vehicle-Highway Systems in the United States. Report NumberIVHS-AMER-92-3.

Keeney, R. L., and H. Raiffa. 1976. Decisions with multiple objectives: Preferences and value tradeoffs. New York: Wiley Publishing Company.

Khattak, Asad J., H. Noeimi, and H.Al-Deek. 1996. A taxonomy for advanced public transportation systems. Journal of Public Transportation 1(1):39-102.

Lister, M., C. L. Schweiger, and I. Keaveny. 1995. Getting smarter with ITS: Improved paratransit operations using integrated scheduling and dispatch and automatic vehicle location at SMART. Prepared for ITS America Fifth Annual Meeting, Washington, D.C.

MITRE. 1995. Assessment of ITS benefits: Early results. Report No.: FHWA/JPO-96/00, Federal Highway Administration, U.S. Department of Transportation, Washington, D.C.

Roy, B., and J.C. Hugonnard. 1982. Ranking of suburban line extension projects on the Paris Metro System by a multicriteria method. Transportation Research 16A:301-312.

Saaty, T. L., and L. G. Vargas. 1982. The logic of priorities: Applications in business, energy, health and transportation. Boston: Kluwer-Nijhoff Publishing. 
Saaty, T.L. 1980. The analytic hierarchy process: Planning, priority setting, resource allocation. NewYork:MoGraw-Hill.

Saaty, T. L. 1976.Axiomatic foundation of the analytic hierarchy process. Management Science 32: 841-855.

Saaty, T. L., and K. P. Kearns. 1985. Analytical planning: The organization of systems. NewYork: Pergamon Press.

Sebenius, J.K. 1984. Negotiating the law of the sea. Cambridge, MA: Harvard University Press.

Shladover, S. 1993. Potential contributions of Intelligent Vehicle/Highway Systems (IVHS) to reducing transportation's greenhouse gas production. Transportation Research 27A: 207216.

Srinivasan, V., P. G. Flachsbart, J. S. Dajani, and R. G. Hartley. 1981. Forecasting the effectiveness of work-trip gasoline conservation policies through conjoint analysis. Journal of Marketing 45: 157-172.

Underwood, S. 1994. FAST-TRAC: Evaluating an integrated Intelligent Vehicle-Highway System. In Proceedings for Fourth Annual Meeting of IVHSAmerica, April 17-20 1994,Atlanta, GA.

\section{About the Authors}

Jonathan LeVINE is an Associate Professor in the Urban and Regional Planning Program at the University of Michigan

SOONAE PARK is an Instructor in the Public Administration Department, Sang-Myoung University, Korea.

STEVEN E. UnderwOOd is an Assistant Research Scientist in the Department of Electrical Engineering and Computer Science at the University of Michigan.

RICHARD R.WALLACE is a doctoral candidate in Urban, Technological, and Environmental Planning and a researcher with the Intelligent Transportation Systems Laboratory, both at the University of Michigan. 


\title{
The "Ins and Outs" of APCs: An Overview of Automatic Passenger Counters
}

\author{
Michael R. Baltes \\ Joel R. Rey \\ University of South Florida, Tampa
}

\begin{abstract}
Experience has shown that manual data collection via ridechecks is one of the most costeffective data collection methods for most transit systems when evaluating ridership levels and system performance. Unfortunately, this manual method of collecting ridership data and system operational information produces both limited system wide and route specific reports due to the amount of manual ridechecking required and the manual data processing involved. This is especially true for larger transit systems. One possible alternate solution for a transit system to meet its need for reliable, accurate, detailed, up-to-date, and cost-effectively-obtained ridership data is through the use of automatic passenger counters, or APCs. Unlike manual ridechecks, anAPC system provides a transit system with an automated method for collecting information on the number of passenger boardings and alightings at a variety of system levels including route, route segment, or specific bus stops by time of day and by day of week, for example. This paper provides a general overview of APC systems. Included is a discussion of APC components, a review of typical transit system data needs, a list of current worldwide APC vendors, the results of a survey of North American transit systems related to APC usage, and a summarization of important issues for transit systems to consider when contemplating integrating APC systems on board their vehicles.
\end{abstract}




\section{Introduction}

Efficient and effective public transit service delivery depends on the interplay of a multitude of internal and external factors, but in large part depends on accurate information collected about transit ridership and overall transit system operations. When provided with information about the transit system, the system's overall performance and performance of individual routes and route segments can be assessed with great accuracy by system planning, scheduling, and management staff. Accurate and comprehensive ridership data will indicate areas of strength and weakness in transit operations and will support and justify the corrective efforts established by transit agency staff.

Historically, the data most appropriate for examining the performance of a transit system have been obtained from manually-derived passenger ridechecks (a ridecheck is a ride, usually on a transit bus, on which staff manually tabulates the number of passenger boardings and alightings at each stop by time of day, tracks ontime performance, and observes the operator's skills and compliance with rules and standards). Generally, these ridechecks reveal peak passenger loads by bus stop and run times on a specified route. The ridechecks also show the demand for the service at the time, location, and direction of that demand using these data. Frequency and running time decisions can be made so that the supply of service corresponds precisely with the actual demand for that service. This will provide optimal economies to the transit system and, hopefully, improve the provision of transit service to the system's customers.

Experience has shown that many transit systems use labor-intensive manual ridechecks during specific service periods to collect ridership (number of boardings and alightings at the stop level) and operational data such as run times. Currently, this is one of the most cost-effective data collection methods for most transit systems. Unfortunately, this manual method of collecting ridership data and system operational information produces both limited systemwide and route specific reports due to the amount of manual ridechecking required and the manual data processing involved. This is not to say, however, that processing this limited amount of manually-collected information into reports does not provide beneficial information to 
support decisions by transit system staff. Nevertheless, the limited information obtained associated with collecting and processing information into a comprehensive database by manual ridechecks has persuaded some transit systems to pursue the utilization of an automated alternative data collection method.

One possible alternate solution for a transit system to meet its need for reliable, accurate, detailed, up-to-date, and cost-effectively-obtained ridership data is through the use of automatic passenger counters, or APCs. Unlike manual ridechecks, APCs provide a transit system with an automated method for collecting the number of passenger boardings and alightings at a variety of system levels including route, route segment, or specific bus stops by time of day and by day of week, for example. Unlike the limited information available via manual ridechecks, APCs provide the transit agency the opportunity to automatically collect a host of additional information about operations, as well. In addition, APCs also enable transit systems to automatically upload the passenger and run time data that were collected through various electronic means, thus eliminating the errors that can accompany manual data entry.

\section{What is an APC System?}

As stated above, an APC system provides an automated method for collecting passenger and system data. Among the additional parameters that can be measured by an APC system are maximum and minimum load points, boarding and alighting rates, vehicle dwell times, door cycles, wheelchair lift cycles, distance traveled, and vehicle average speed.

An APC system can be seen as akin to a microscope in that it permits transit system staff to intently focus on the productivity and quality of their system's performance at various levels, ranging from individual bus stops or route segments, to time point segments, and to the overall transit system as a whole. Just as the development of new technologies such as the Internet has increased knowledge about the world around us, an APC system will allow transit staff to identify problems that may not have been possible to identify when analyzing data gathered via manual ridechecks and to create innovative strategies for improving their transit system's performance. 


\section{Basic Components}

To collect ridership data such as load levels and their locations, a number of APC hardware components are required including:

- counting sensors (treadle mats, I-R beams, etc.);

- an odometer sensor for location referencing;

- a clock to determine the time that the passenger activity occurred (usually in the microprocessor);

- a data processing unit to tabulate, accumulate, and store passenger activity data onboard the bus;

- data storage devices consisting of either integrated circuit semiconductor memory; cassette tape; or 51/4-, 31/2-inch computer diskettes, or hard drive (all three usually contained in the data processing unit);

- a power supply to convert primary bus voltage (usually 12 or 24 volts DC nominal) to the APC system;

- engine sensors to register engine dwell and idle times;

- wheelchair lift sensors to register wheelchair lift activity;

- door sensors to register door openings and closings; and

- either radio signposts or some type of global positioning system (GPS) technology to improve the confidence in the location referencing of odometer readings.

The current state-of-the-art methods of automatic passenger counting currently in use can be divided into several technologies: infra-red (I-R) beams, treadle mats, optical sensors, and low ultrasonic frequency sensors. (These latter two technologies have specific application on low-floor buses, which present a special problem for APC I-R beam and treadle mat technologies when counting passenger activity due to the width, height, and design of the buses' front door. However, at the time of this writing, these two technologies were not being widely used in North American transit systems. For this reason, in-depth information about these two technologies has not been included herein.) To illustrate, the APC technology that utilizes I-R beams computes the total number of boardings and alightings by tabulating the number of times the beam is "interrupted" by a passenger entering or exiting the bus. Generally, 
the I-R beams are placed at the waist height of passengers. Algorithms are specifically built into the APC's proprietary software to take into account the under- and over-counting of passengers created by multiple passengers crossing the beam simultaneously and passengers exiting through the front door on a two-or-more-door bus (accomplished through the sequence in which the I-R beams are broken).

APC treadle mat technology tracks passenger boardings and alightings through passenger foot pressure on sensing contacts/switches positioned in the "tread" of the bus's stairwell steps. The APC's treadle mats are designed to replace the bus's existing stairwell mats. Proper fit of the treadle mats is critical for safety reasons and to properly determine the stream of passenger activity in each stairwell. Similar to the APCs that utilize I-R beams, the APC's software is tailored to account for the underand over-counting of passengers.

Optical sensors are a non-contact vision system that optically detects passenger activity. This specific APC technology was designed for application on low-floor buses. A single overhead optical sensor is mounted in each doorway of the vehicle to detect passenger boardings and alightings. One of the strengths of this type of system over APCs that use treadle mats or I-R beams is its ability to detect multiple passengers in doorways and simultaneous bi-directional passenger flows (particularly useful on vehicles with only one door).

Ultrasonic frequency sensors are acoustic in nature and track passengers by transmitting and receiving ultrasonic pulses, i.e., pulses of sound that are above the range of human hearing (typically 30 to $100 \mathrm{kHz}$ ). At the time of the project upon which this paper is based, ultrasonic frequency sensor technology for specific application on low-floor buses was still in the beta test stages. Therefore, specific information about this APC technology could not be included herein. Currently, however, this technology is being tested at OC Transpo in Ottawa-Carleton, Canada.

For each of the APC technologies, the location of the bus when the APC system is performing actual counts of passenger boardings and alightings while in revenue service is inferred by using an odometer. Confidence in the position of the bus is improved by using either electronic signposts or GPS. Signpost technology has been in use for many years by a number of transit agencies in conjunction with APC 
systems and other technologies such as automatic vehicle location (AVL), but GPS is a relatively new technology that is now being more widely incorporated with APCs and other technologies such as AVL to greatly improve locational accuracy of transit vehicles. Signposts are commonly ground-based, short-range radio transmitters located throughout a given transit system's service area that provide a number of accurately known locational references. Between signposts, the bus's location is deduced by the APC's data processing unit by correlating the distance traveled provided by the odometer with the route the vehicle is traveling while in revenue service.

Unlike the ground-based signpost technology used with some APC systems, APCs that utilize GPS technology make use of satellites positioned around the earth to determine, with great accuracy (usually within a few meters), the location of the transit buses that are affixed with GPS receivers. The GPS satellites transmit signals that permit, with tremendous accuracy, the identification of the global position of the GPS receiver(s) placed on the transit buses, therefore also allowing for the precise determination of the location of the transit buses within the transit agency's service area. Specifically, the GPS receiver(s) placed on the transit buses use the GPS satellites as reference points for triangulating a precise position on earth. Two satellite measurements determine an intersection of two spheres and a third measurement identifies two points common to the spheres, while a fourth measurement determines the specific point. One point that should be noted is that, despite the improved accuracy of location determination using AVL/GPS technologies, it is still possible for location errors to occur, e.g., weakened signal or complete signal loss resulting in positional inaccuracies of, or total loss of positional information for, specific time point/bus stop location(s).

To clarify the workings of an APC system for the reader, a simple flow diagram contained in Figure 1 illustrates a hypothetical APC system. It should be pointed out that APC systems (both hardware and software) currently in use at transit properties throughout North America have been customized a great deal to fit the particular data needs of these transit agencies as well as the design problems related to the installation of an APC system that are created by a transit agency's bus fleet being composed of different bus types from a variety of manufacturers. Therefore, no two 
APC systems in operation are identical and, also, for these reasons, an "off-the-shelf" APC system does not truly exist that can be easily integrated into and satisfy the diverse needs of a particular transit system. It is also for these reasons that detailed information related to the per unit cost of APCs could not be obtained and included.

Once the boarding and alighting data are collected by an APC system, they can either be stored in integrated circuit semiconductor memory, on a cassette tape, or on a $5 \frac{1}{4-\text { or }} 3 \frac{1}{2}$-inch computer diskette. The current methods for data transfer from the APC's data processing unit consist of the following:

- Transit agency staff manually retrieves collected data from either a cassette tape, diskette (51/4- or 31/2-inch), or magnetic data card (other forms of storage media may be available).

- Transit agency staff manually retrieves the collected data by linking to the APC's data processing unit via a portable laptop computer which transfers the data to a diskette or hard drive in the laptop.

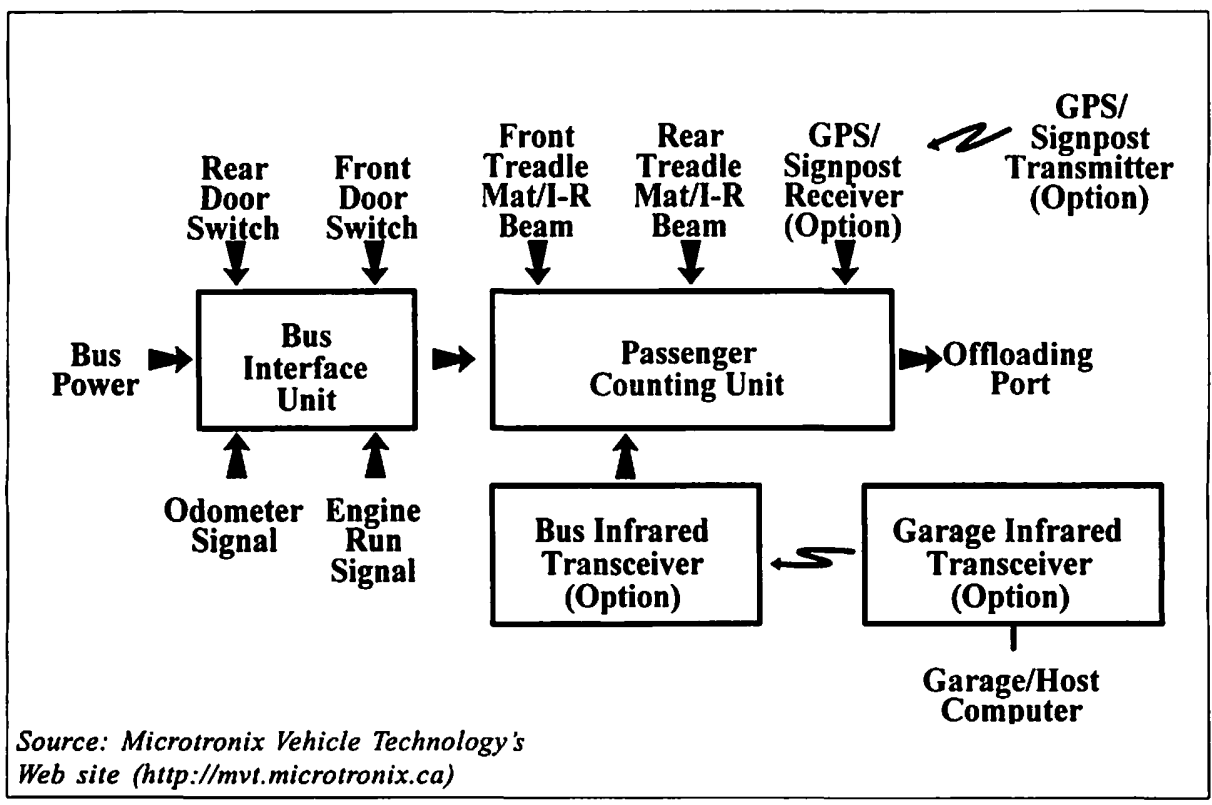

Figure 1. Illustration of a hypothetical APC system and related components. 
- Transit agency staff manually links, usually using a telephone line, the APC's data processing unit to a wayside computer located at the transit system's garage, for example.

- Equipment is used to automatically transfer data from the APC's data processing unit via the vehicle radio or a communication system such as AVL to a central computer located at the transit system's garage or central facility. The ridership data can be transmitted in real time with the vehicle location provided by the AVL system.

- An optical link (I-R beam) to automatically transfer data from the APC's data processing unit to a wayside computer at the transit system's garage, for example.

In addition to the basic APC components listed previously, a transit system that is evaluating the potential use of APCs will also have to consider additional equipment for the storage and processing of the resulting APC obtained data. This equipment may include computer equipment (laptops, PCs, mainframe, LAN), long-term storage devices, and supplemental analysis software such as SPSS or SAS.

\section{Typical Data Needs}

For a transit system to effectively and objectively evaluate its performance and identify potential areas for service improvement, a significant amount of information about passenger boardings and alightings is required at both the micro- and macro-level. Collecting and evaluating this information is critical for a transit system to make effective decisions about changes in service provision that will translate into increased operating efficiencies and improve the provision of transit service to the general public. In deciding whether or not to implement an APC system, a transit system first needs to evaluate its data needs and the intended use(s) of the data by its service planning and scheduling departments once it has been collected by the APC system. This is a critical first step since the data an APC system gathers can be tailored to meet the specific data and report generation requirements specified by a transit system. 
Typical data needs can be grouped into several general categories as follows:

- Data for Service Planning - data related to the daily variation in total passengers, boarding and alighting distributions, county of operation, overcrowding(standees) times/locations, and actual run times compared to scheduled times by route and route segment, by time period and day of week. From these data, a transit system can monitor the minimum and maximum passenger loads by direction, determine average speeds for the purpose of restructuring routes and headways, and derive various other measures for comparison with its route- and system-level service standards. In addition, these data can also be used to discover if there are any seasonal variations in ridership and run times. The need here is to conduct frequent enough data collection so that the statistical significance of the daily variations can be identified with a high degree of confidence.

- Data for Scheduling - data related to individual stop and trip boardings and alightings, run times, dwell times, deadheading times, time point arrival and departure times, and on-time performance. From these data, for example, run time analyses can be performed to monitor and adjust trip cycle times to maximize both cost efficiencies and passenger comfort.

- Data for Transportation Management-data related to the daily exceptions to the scheduled time point and stop arrivals and departure times of buses, passenger loads at important locations, and compliance with National Transit Database (NTD, formerly Section 15) reporting requirements.

\section{APC Studies}

To identify current information on APC technologies, an in-depth review of available APC literature was conducted, as was an Internet search using key words and phrases such as "automated passenger counting systems" and "vehicle technology." Unfortunately, the APC literature available for review is sparse and is not as current as originally thought. However, documentation from several APC demonstration projects conducted by transit systems were identified and reviewed. 
One of the primary concerns about the data that are obtained from an APC system is the accuracy of the passenger boardings and alightings. Overall, the APC information indicates that, for routes with higher volumes of passenger activity, APCs have a tendency to undercount rather than overcount passenger activity. Regarding specific activity, the literature points out that passenger boardings tend to be counted more accurately than alightings. The most likely explanation for this is that passengers boarding a transit vehicle tend to do so in a more orderly fashion (i.e., one at a time in a queue) than when alighting, particularly on buses with two or more rear doors. When evaluating APCs, transit agencies that use manual data collection methods must weigh this problem of APCs under- and over-counting passengers in certain situations against the errors that can typically occur during manual data entry of the ridecheck collected data. However, it should further be noted that the problem of under- and over-counting passengers can also occur during manual data collection, especially during heavy passenger loads.

In 1991, the Washington Metropolitan Area Transit Authority (WMATA) conducted a six-week test of APC systems to determine their feasibility for collecting data for the conduct of economic route analyses (WMATA 1991). The route selected for the APC test represented a typical bus route in the WMATA service area. Three buses were equipped with APC systems using I-R beams. In addition to the on-bus APC systems, nine radio signposts were installed as well to improve the location accuracy of the passenger counting. During peak hours, the route offered six-minute headways, requiring 13 buses. At the time the tests were conducted, weekday ridership was about 7,700 passengers. The accuracy of the APC-collected data was measured at the route, route segment, and bus stop level. Manual ridechecks were performed with persons on the APC-equipped buses simultaneously as the APCs recorded passenger activity.

During the WMATA tests, the ridecheckers recorded more than 17,000 boardings and an almost equal number of alightings. On average, the boardings recorded by the APC systems varied by less than one percent (about 99 percent accurate) from the manually-recorded data. With respect to alightings, the average variance between the APCs and manually-recorded data was less than two percent (about 98 percent 
accurate). In addition, maximum load data between the APC systems and manuallycollected data compared favorably. Overall, the tests concluded that the APC systems performed equal to that of the manual ridecheckers. It should be mentioned that communication with several APC vendors and transit systems that are currently using APC technology determined that the counting accuracy for both boardings and alightings, even during peak loads, is consistently above 90 percent regardless of APC system configuration (i.e., sensor type used, etc.).

A study of APC systems at OC Transpo located in Ottawa-Carleton, Canada, uncovered some of the reasons why APC systems that use I-R beams may inaccurately count passenger activity (OCRTC 1986). Some of the reasons listed include mistakenly counting umbrellas or waving arms of passengers that crossed the I-R beams as stairwell activity, missing very small children who walked under the I-R beams, undercounting groups of passengers who boarded or alighted very close together, counting passengers more than once who swayed back and forth while in the stairwell, mistakenly counting a boarding passenger as alighting or vice versa (particularly problematic on one-door buses), counting errors arising from dirt accumulating on the front door windows which distorted the I-R beam when the door was open, and cold weather adversely affecting the performance of the I-R sensors. These problems were ameliorated by simple routine maintenance such as cleaning the front door windows, heating the I-R beam sensor heads during cold weather, disabling the counting mechanism when the doors are closed, and optimally locating the sensors at the front and rear doors. It should be noted that correction algorithms will still need to be developed and utilized to account for any remaining error(s).

In addition to the problems encountered with I-R beams inaccurately counting passenger activity, treadle mats also have difficulty accurately counting passengers in a variety of situations. These situations usually occur when passengers behave inconsistently when boarding or alighting vehicles. For example, young passengers or commuters rushing to catch the bus will sometimes skip a step in the vehicle's stepwell; confused individuals will sometimes walk partway up the steps to ask a driver for information while stepping on the mat, then back out of the vehicle after a response has been given; and passengers waiting in line to board a vehicle will 
sometimes rock back and forth with a heel-to-toe motion on one or more of the vehicle's steps thereby creating confusion in the APC system as to the direction of travel (boarding vs. alighting) (Microtronix 1997).

In addition, treadle mats are more susceptible to environmental/climatic conditions than I-R beams, according to a demonstration project of APCs at Denver Regional Transportation District (RTD) (Denver RTD 1985). These include excessive vibration caused by poor road conditions which can loosen the mats from the vehicle steps, and the seepage of water and/or salt (especially in winter climates) into the mat(s) when punctures occur due to rocks, grit, glass, etc. However, it should be noted that the RTD study also concluded that I-R beams are susceptible to vibration as well, which can cause misalignment of the beams. In addition, the study noted that the misalignment of the I-R beams can also occur due to vandalism.

In addition to being able to collect transit system data automatically, APCs also offer significant data collection cost savings. In at least one study of the economic feasibility of APCs conducted by WMATA, it was noted that between a 66 and 90 percent cost savings can be realized via the use of APCs over manual ridecheckers.

The review of APC information and an Internet search developed a list of APC vendors, as shown in Table 1. From these sources, a list of 41 transit systems that have in the past used or are currently using APCs in North America was also compiled. A survey of these particular transit systems was conducted to gather information about their experiences with APC systems.

\section{Transit System Survey}

To identify current APC technologies/vendors, a brief 13-question APC-related survey was developed and faxed to 41 transit agencies in the United States and Canada to determine if they have ever used or are currently using APC technology, the type of technology employed (if applicable), the vendor of the technology, uses for the ridership data once collected by the APC system, and the accuracy of the ridership data collected by the APC system, among other information. The survey was sent to the planning director or applicable position or the APC technician, where identified, within each transit agency. Of the 41 transit systems surveyed, nine were Canadian properties. 


\section{Table 1 \\ APC Vendors}

\section{U.S. Vendors}

Urban Transportation Associates (UTA) (I-R Beams, GPS Locator, Proprietary APC Data Analysis Software), 700 East McMillan, Ste. 302, Cincinnati, OH 45206, (T) 513/961-0099, (F) 513/751-2821

\section{Canadian Vendors}

Microtronix Vehicle Technologies (MVT) (Treadle Mat and Optical Sensor, Signpost or GPS Locator), 200 Aberdeen Drive, London, Ontario N5V 4N2, (T) 519/659-9500, (F) 519/659-8500,mvt@microtronix.com

ILI Technologies, Inc. (Treadle Mat \& Low Ultrasonic Frequency, Signpost, Proprietary APC Data Analysis Software), 830, 407 - 2nd Street S.W., Calgary, Alberta T2P 2Y3, (T) 403/291-9161, (F) 403/291-9660, ilitech@telusplanet.net

Wardrop Applied Systems, Inc. (Proprietary APC Data Analysis Software), 6006725 Airport Road, Mississauga, Ontario L4V IV2, (T) 416/673-3788, (F) 416/ 673-8007

Red Pine Instruments, LTD. (I-R Beams, Signpost/GPS Locator, Proprietary APC Data Analysis Software), RR 1, Denigh, Ontario K0H 1L0, (T) 613/3332776, (F) NA

\section{European Vendors}

Dilax AG (information on APC technology available), Seepanorama, $\mathrm{CH}-8559$, Fruthwilen Lankwitzer Strasse 3, D-12209, Switzerland (T) (+41) 716637575 , (F) (+41)7166375 76,dilax@paus.ch

INIT (Passive I-R Detector Array, Signpost or GPS, Proprietary APC Data Analysis Software), Haid-und-Neu-Strasse 7-9, D-7500 Karlsruhe, Berlin, Germany, (T) 0-721-69-10-73-76, (F) 0-721-69-68-08, postmaster@init-ka.de

Note: This table is provided for informational purposes only; it is not intended to be an endorsement of the APC vendors or their equipment. The information contained in the table was collected in March 1999. MVT and Wardrop Applied Systems, Inc. work jointly to provide APC systems. 
A total of 25 surveys was returned, with 14 of the responding transit systems indicating that they currently use or have in the past used APC systems. With regard to the different types of APC technology employed by each, three systems indicated that they use(d) treadle mats, and the rest use either dual, multiple, or passive I-R beam technology. Discussions with staff at several of the responding transit systems revealed the fact that an APC system's counting technology (e.g., treadle mat, I-R beam, etc.) is not as critical to the quality of the passenger and system data collected as is the APC system's software. The transit staff that were interviewed noted that the APC system's software is the most critical link to obtaining quality passenger count and other system data. In addition, the transit system staff specifically noted that there is a nominal difference with regard to accuracy between the differing APC counting technologies. Also, several of the transit system staff commented that signpost technology works better in a highly urban environment, particularly in a metropolitan downtown setting with high-rise buildings, and that, overall, there is only a marginal difference between signpost and GPS technology for use in improving the confidence of an APC system's odometer readings.

On the survey, transit systems were also asked to provide information about their use(s) for the data collected by their APC systems. Responses to the survey show that the majority of the transit systems use APC-collected data primarily to create, evaluate, and adjust schedules and run times, and plan and justify route changes, as shown in Table 2. Other, less common uses of the APC-generated data are for the purpose of NTD reporting requirements, monitoring driver performance, and determining the location of bus stops. Approximately 93 percent of the transit systems that indicated that they use(d) an APC system are satisfied with the system's overall reliability and about the same percent are satisfied with the accuracy of their obtained passenger information; the vast majority of these transit systems noted that they are achieving accuracy levels of 90 percent and above regardless of the APC counting technology employed. Last, of the 14 transit systems that reported that they use(d) an APC system, 12 noted that they periodically verify the accuracy of the information collected by their APC systems via only manual ridechecks while the other two transit systems use a combination of manual ridechecks and GFI fareboxgenerated information. 


\begin{tabular}{|lc|}
\hline \multicolumn{2}{|c|}{ Table 2} \\
Transit System Uses for APC Systems \\
\hline Uses for APC Systems & $\begin{array}{c}\text { Number of } \\
\text { Responding } \\
\text { Transit Systems }\end{array}$ \\
\hline Create/evaluate/adjust run times/schedules & 14 \\
Plan/justify route changes & 13 \\
Evaluate marketing strategies & 3 \\
Estimate expected revenue & 1 \\
Determine fleet needs & 2 \\
Monitor driver performance & 3 \\
Determine location of stop facilities & 5 \\
NTD reporting & 6 \\
Other & 2 \\
\hline
\end{tabular}

\section{Important Considerations}

In sum, there are many aspects to consider when contemplating the implementation of APCs by a transit system. Specifically, a number of important issues were revealed during the course of this research related to integrating APCs into a transit system. These important considerations are as follows.

1. It is critical that scheduling, planning, management, and maintenance staff all embrace their system's APC program in order to ensure that the resulting data will be properly utilized and that the APC units will be properly maintained.

2. For any APC system to perform up to expectation it is critical, in conjunction with other factors, that a transit agency have a very detailed bus stop inventory that includes the number of bus stops and the exact mileage between the bus stops at the individual route level for the entire system, assuming that all routes will be 
sampled using the APC system, prior to APC system installation. This will allow for precise analysis of passenger activity at the bus stop and route segment levels as well as on-time performance for both individual routes and the system as a whole.

3. Agency staff must be prepared to handle and analyze the voluminous amount of information gathered by the APC systems in comparison to the typically scant information obtained from manual ridechecks. This may require additional training of planning and scheduling staff.

4. Agency staff should prepare a detailed sampling plan that specifies exactly how and when the APC-equipped buses will collect passenger data prior to APC system installation. This becomes especially important if the APC-equipped buses will be used to satisfy NTD reporting requirements or for the statistical validity of data collected for other reasons.

5. Environmental conditions in which a transit system operates should be taken into account prior to selecting an APC counting technology since rain, dirt, snow, salt, and extreme fluctuations in temperature may adversely affect the operation of a specific counting technology. For example, treadle mats have a slight tendency for water to seep into the mats which can lead to corrosion of the mat's internal switches, particularly in climates that experience prolonged winters or rainy seasons.

6. Agency staff should consider carefully their particular data needs and the purposes for which they will be utilizing APC-generated information when determining how many vehicles to outfit with APCs. APC systems can be quite costly, especially with custom modifications, and putting units on more vehicles than a system actually requires is an unnecessary waste of funds. The rule of thumb suggested by a number of APC vendors and transit systems currently using APCs is to outfit 10 percent of a system's active vehicle fleet with APC units (since sampling is typically used when collecting ridership data [both manually and automatically], it is not necessary to equip a larger percentage of a system's fleet with APCs).

7. Consideration should also be given to the fleet mix on which the APCs will be installed to make sure that routes requiring buses with smaller turning radii or buses with large seating capacities (articulated) be accommodated. 
8. The portability of the APC units between buses of varying types and the wiring of additional buses to accept APC systems should be another consideration at the time of initial unit installation. This is important since a particular bus may break down while in revenue service for a variety of reasons and it may be necessary to transfer the APC system to another bus of the same type.

9. Agency staff should be familiar with and account for the Transit Communications Interface Protocols (TCIP) family of standards including SAE J1708 (supports communication among devices installed on a transit bus) and J1587 (an extension of J1708 which defines data and message identifiers) prior to APC system installation so that subsequent integration with other advanced technologies for transit (e.g., AVL) will be possible.

10. Care should be taken in the placement of APC counting sensors and central processor units. Treadle mats need to be perfectly fitted on the vehicles steps to ensure that all passenger activity is recorded and that there are no extended mat edges that can create a hazard to boarding/alighting passengers or make the mat more susceptible to damage or vandalism. Similarly $\mathrm{I}-\mathrm{R}$ beam sensors should be as unnoticeable to passengers as possible and completely out of the passenger stream so that inadvertent bumping and/or vandalism will not occur that could possibly effect sensor alignment and, therefore, their counting accuracy. If possible, the APC system central processing unit or other modular components should also be located in a hidden and "out-of-the-way" location to prevent damage and/or vandalism.

Based on these observations, it is apparent that the decision to utilize APCs requires more than just selecting and installing a particular APC technology. Considerable planning needs to occur prior to, during, and after the installation of APCs, even if only for demonstration purposes. Only with this planning and proper preparation can the efficient and effective collection of accurate information about transit ridership and overall transit system operations be realized using APCs.

\section{Acknowledgments}

The authors wish to thank Mark Lowenstine of Microtronix Vehicle Technologies LTD, Steve Gallant of Wardrop Engineering Inc., Tom Kowalski of Urban Trans- 
portation Associates Inc., and Horst Gerland of INIT for sharing their vast knowledge and experiences about APCs. In addition, the authors would like to thank Dennis Hinebaugh and Victoria Perk of CUTR for their editorial comments regarding content.

\section{References}

IBI Group. 1985. Automatic passenger counting demonstration-Evaluation report. Regional Transportation District, Denver.

Microtronix Vehicle Technologies LTD. 1997. Informational memorandum sent to CUTR.

Ottawa-Carleton Regional Transit Commission. 1986.APC at OCTranspo-A new dimension.

Washington Metropolitan Area Transit Authority. 1991. An evaluation of automated data collection systems and their use in conducting an economic route analysis.

Washington MetropolitanArea TransitAuthority.(nd).APC economic feasibility.

\section{About the Authors}

Michael R. Baltes and Joel R. Rey are Senior Research Associates at the Center for Urban Transportation Research (CUTR) at the University of South Florida in Tampa. 


\title{
Development and Evaluation of Transit Signal Priority Strategies
}

\author{
Michael Garrow \\ Barton-AschmanAssociates, Inc. \\ Randy Machemehl \\ The University of Texas atAustin
}

\begin{abstract}
Research describing the effectiveness of providing signal priority to transit vehicles is presented. Results from previous studies indicate that the effectiveness of transit signal priority depends on a number offactors, including the type of transit route, the transit usage level, and the time of day. This research describes and evaluates several transit signal priority provision methods during both peak and off-peak times. Results indicate that providing signal priority during off-peak times is often justified, due to excess capacity available within the transportation network. However, during peak times, transit signal priority use is justified only when the transit usage level is high.
\end{abstract}

\section{Introduction}

In recent years, rising population levels coupled with low density development outside center cities has created a large increase in demand placed upon transportation networks in many urban areas. Building additional infrastructure to meet these increasing demand levels is expensive and time consuming and often encourages more travel. Therefore, in recent years, transportation professionals have shifted 
their efforts from building additional transportation infrastructure to operating the existing infrastructure more efficiently.

Encouraging travel in high occupancy vehicles, such as public transit, is one way to meet growing levels of travel demand while building little or no additional transportation capacity. However, low public transit usage plagues many urban areas, especially urban areas with low density development. In low density urban areas, travelers do not share many common origins or destinations, making it difficult for public transit to provide service levels competitive with the private automobile.

Therefore, policies providing priority to high occupancy vehicles have been initiated in many urban areas. Priority for public transit vehicles has been initiated in many urban areas over the past 25 to 30 years. Traditionally, priority for transit vehicles has been provided through signal timing advantages at signalized intersections. However, methods for providing signal priority for transit vehicles that consider the well-being of the transportation network as a whole should be developed.

This study examines work that previously has been performed in the transit signal priority arena, and proposes and evaluates methods of providing transit signal priority, during both peak and off-peak times.

Based on past transit signal priority studies, conditions favorable for transit signal priority success and strategies for its use are identified. These strategies were tested with both peak and off-peak traffic levels along a case study arterial network using computer simulation. Results from the computer simulation are evaluated over the entire arterial network to determine whether the various transit signal priority strategies provide an overall arterial network benefit.

\section{Literature Review}

Strategies for awarding priority for transit vehicles have been developed and tested in the field or using computer simulation over the past 20 to 30 years. Several signal priority algorithms are identified in a 1995 report by Sunkari of the Texas Transportation Institute (TTI) (Sunkari et al. 1995). These include both passive and active priority strategies. With passive priority, signalization plans are not affected by the presence or absence of transit vehicles. Shortening cycle lengths and splitting phases are examples of passive priority strategies. These algorithms are explained in 
greater detail in a related report by Urbanik (1977), also from TTI. Urbanik notes that shortening the cycle length along an arterial reduces stopped time delay to both transit vehicles, and private vehicles. However, the merits of a shortened cycle length must be weighed against the capacity reduction along the arterial.

Splitting phases refers to splitting transit's signal phase into multiple phases whose total time equals its original duration. This reduces the cycle length for the transit vehicle's approach, without altering the overall intersection cycle length.

Urbanik notes that active priority algorithms are different than passive priority algorithms, in that active priority measures are only taken in response to a transit vehicle signal priority request. Green extensions and red truncations are forms of active priority that steal green time from cross street approaches to be added to the end and beginning of the transit approach's green phase, respectively.

Active priority measures can be grouped into two categories: 1) unconditional priority, and 2) conditional priority. With unconditional priority (or preemption), a priority measure is granted whenever the transit vehicle calls for priority, subject to safety considerations. When using conditional priority, a transit vehicle is not necessarily given priority at an intersection every time priority is requested. Instead, the well-being of cross streets is considered before priority is granted to the transit vehicle's approach.

Bowen et al. (1994) describes how several parameters must be established before signal priority can effectively be granted to buses. The degree of intersection saturation below which priority may be granted is a highly important parameter. If this cutoff value is set too high, the usefulness of green extensions or red truncations will be lost when used in heavily congested environments. In addition, the intersection level of service may be further sacrificed through the excessive use of signal priority. However, if this cutoff value is set too low, buses that could have benefited from signal priority will not be granted a green extension or a red truncation. Green extension and red truncation lengths are also highly important variables. According to Bowen, the amount of priority should vary from intersection to intersection based on the amount of spare intersection capacity. 
Hounsell et al. (1996) tested active bus priority using simulation and determined that bus delay savings of 20-30 percent are possible without significant impacts to general traffic, when appropriate control settings (cutoff degree of saturation for priority use, etc.) are used with signal priority. Also, simulation showed increasing bus delay savings when signal priority was used with decreasing intersection saturation levels.

Hounsell also found that the use of green extensions alone, without red truncations, had the best overall impact upon traffic. The delay savings to transit are increased by supplementing green extensions with red truncations, but at a high cost to the general traffic.

In a separate paper, Hounsell and Wu (1995) identified additional issues involved with signal priority. The frequency of bus arrivals was identified as a key variable in determining appropriate signal priority strategies. In London, when buses were operated with one-minute headways, providing green extensions only was identified as the optimum strategy. When operating at headways shorter than one minute, adjusting signal timings to allow for bus progression was recommended.

A study conducted by the Municipality of Metropolitan Toronto (1991) found that streetcar delays and travel times decrease with the introduction of signal priority. Due to high transit usage in Toronto, this reduction in delay translates into substantial savings in passenger-minutes of delay. In addition, negative impacts to the cross streets resulting from priority were minimal. Further, green extensions were far more effective than red truncations. Often, red truncations were "lost" or could not be used by the streetcars along Queen Street.

Al-Sahili and Taylor used TRAF-Netsim to test the effectiveness of active signal priority (1995). Results indicate that arterial traffic suffered from overall increased delays whenever signal priority was initiated. Since the arterial traffic volumes were rather high, upon receiving signal priority, signal progression along the arterial was lost, resulting in increased downstream intersection delay. Therefore, along heavily traveled arterials, signal progression, rather than signal priority, appears to be of prime importance. 
The sensitivity of transit signal priority success to the ratio of arterial and cross street traffic volumes also was examined. The ratios of arterial traffic volumes to cross street traffic volumes selected for the analysis were 2:1, 3:1, and 5:1.

Results of the simulation indicate that negative impacts (in terms of increased delay per vehicle) introduced through the various signal priority techniques are significant at low volume ratios (2:1), but insignificant at high volume ratios (5:1). However, benefits from signal priority in terms of reduced bus travel times and delays decreases with increasing volume ratios because, at high volume ratios, signals are already timed to favor the bus approaches.

These past studies indicate the success of transit signal priority appears to depend on a number of factors, including the traffic characteristics at intersections where priority is used and the characteristics of the transit service itself. This study evaluates the effectiveness of signal priority and establishes guidelines for its use based on these traffic and transit service characteristics.

\section{Traffic Simulation Model-Based Data Collection}

The TRAF-Netsim simulation program was used as the analysis tool for this study. Since TRAF-Netsim is a link-node based micro-simulation model (USDOT 1998), it simulates all vehicles individually as they respond to traffic controls and other vehicles in the network.

TRAF-Netsim provided a useful tool for modeling transit signal priority. Passive transit signal priority was modeled using TRAF-Netsim by simply changing the signal timing characteristics in the simulation to reflect passive transit signal priority. TRAF-Netsim also proved to be very effective in modeling active signal priority, since it allows one to use multiple time periods within each simulation. Within each time period, one can alter input parameters such as signal timings, traffic volumes, lane channelizations, and turning percentages. With active signal priority, an intersection signal timing is temporarily altered to provide priority for a transit vehicle, then restored to its original timing upon the transit vehicle's departure. Active signal priority can be modeled within TRAF-Netsim by using the signal priority timing within a time period corresponding to the transit vehicle's arrival at the intersection. 
The intersection's original timing plan can be restored in the subsequent time period as the transit vehicle departs the intersection.

The graphical animation feature in TRAF-Netsim is also helpful when evaluating transit signal priority strategies. The animation feature displays a plan view of the network, where traffic movements and signal indications can be observed over the simulation duration. This graphical animation feature allows one to track the progress of buses through the network to determine where and when active signal priority is needed. Once a need for signal priority is identified, a time period can be inserted to initiate active signal priority.

Figure 1 shows the link-node representation of the Guadalupe-N. Lamar case study arterial in Austin, Texas, used for the transit signal priority analysis. Nodes 1 through 11 represent signalized intersections along the arterial, which extends roughly $4.1 \mathrm{~km}$ from the Koenig Lane and Lamar Boulevard intersection to the 27th Street and Guadalupe Street intersection. Buses share their right of way with private vehicles while operating along both northbound and southbound directions of the Guadalupe-N. Lamar arterial. Typically, two northbound and southbound lanes, as well as a continuous left turn lane, are present throughout the arterial.

\section{Off-Peak Time Period Transit Signal Priority}

Use of transit signal priority during the off-peak hours is promising because excess capacity available within the transportation network can be used for transit's advantage. In this study, the effectiveness of reduced signal cycle lengths and split phasing were examined in conjunction with local transit service, while unconditional priority was examined with respect to express transit service.

Using short cycle lengths as a passive transit signal priority strategy is appealing for several reasons. First, benefits to transit can be realized with little monetary cost. Implementing a policy of short cycle lengths along an arterial is a passive form of transit signal priority and is, therefore, in effect even in the absence of transit vehicles. Therefore, vehicle detection equipment is not necessary.

In addition, unlike most forms of active transit signal priority, a policy of short cycle lengths does not penalize vehicles along the cross streets by using a portion of their green time to favor transit vehicles. 


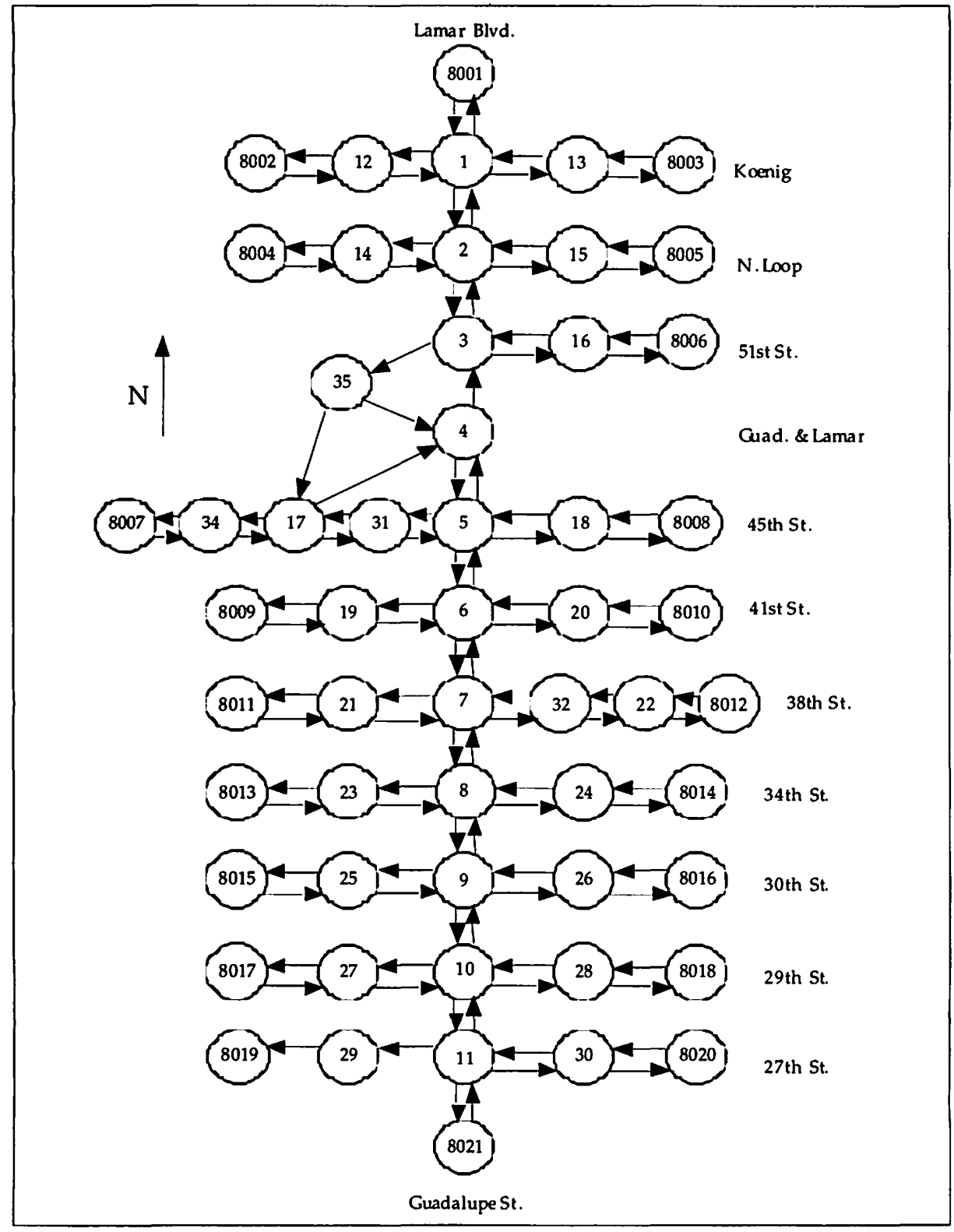

Figure 1. Link-node representation of Guadalupe-N. Lamar arterial. 
The effectiveness of granting passive signal priority to local transit vehicles with shortened cycle lengths was evaluated using TRAF-Netsim by comparing the performance of the Guadalupe-N. Lamar arterial under existing and passive priority signal control. Existing off-peak cycle lengths along the Guadalupe-N. Lamar arterial is 100 seconds. There is no evidence that shows that these 100 -second off-peak cycle lengths are optimal to process off-peak traffic volumes. Therefore, passive priority was implemented by reducing these cycle lengths to 70 seconds. Three replicate simulation runs lasting one hour each were performed.

Simulation results indicate that a 70 -second cycle length benefited buses by reducing their average travel time. Average bus travel times along the northbound route decreased from 797 seconds with the use of 100 -second cycles to 768 seconds with the use of 70-second cycles. Benefits to the Southbound bus route were even more impressive, as the average travel time dropped 11 percent, from 814 seconds to 725 seconds with 70-second cycle lengths.

Meanwhile, cumulative delay statistics along cross street and arterial links generated by TRAF-Netsim showed that the overall performance of these links improved with shorter cycle lengths. This analysis shows that both buses and private vehicles benefit when the cycle length along an arterial is pushed closer to its optimum value in response to lower off-peak traffic volumes.

\section{Split Phasing}

Split phasing was also examined using TRAF-Netsim by splitting bus phases at most intersections along the Guadalupe-N. Lamar case study arterial and comparing the resulting delays and bus travel times to those of the base case.

Splitting phases refers to splitting transit's signal phase into multiple phases whose total time equals its original duration. This reduces the cycle length for the transit vehicle's approach without altering the overall intersection cycle length. The concept of split phasing is illustrated in Figure 2. As shown in Figure 2, under normal phasing, if a bus arrives at the intersection on a red signal indication, it may have to wait the length of phases $B$ and $C$ before it receives a green indication with phase $A$. With split phasing, if a bus receives a red indication, it will only wait at most the length of phase $\mathrm{B}$ or phase $\mathrm{C}$ before receiving its green indication. 

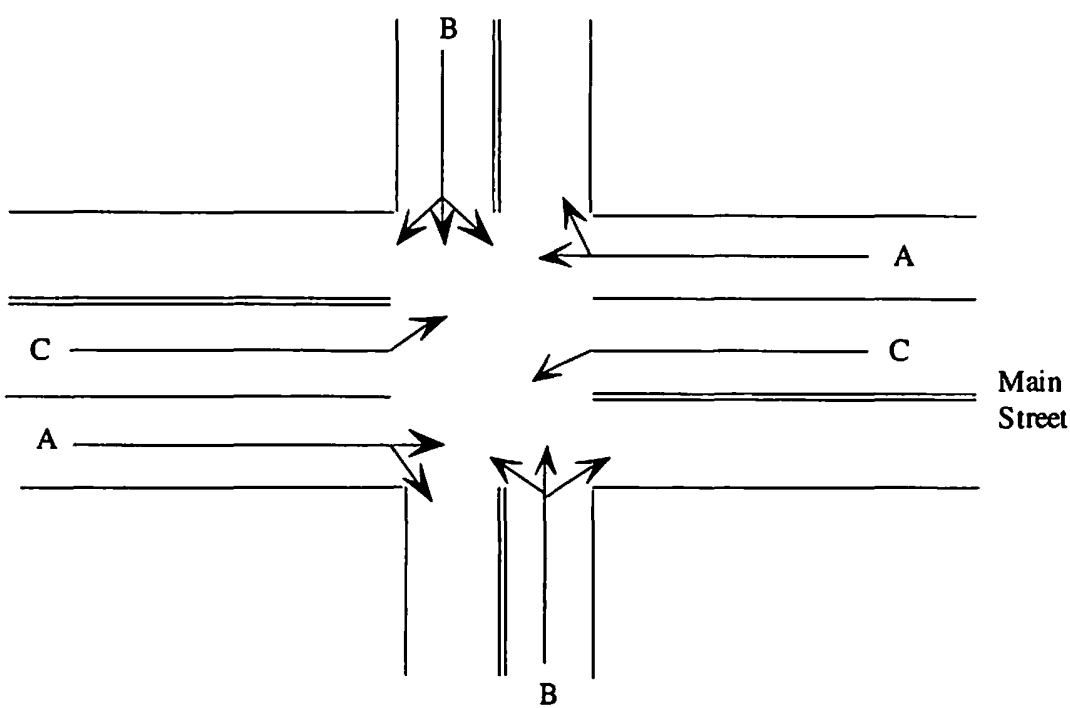

Cross

Street

Normal Phasing

A

B

C

Split Phasing

\begin{tabular}{|l|l|l|l|}
\hline A & B & A & C \\
\hline
\end{tabular}

Figure 2. Passive transit priority with split phasing.

Split phasing was evaluated using TRAF-Netsim and one-hour simulations. To account for variability and produce more robust results, three separate observations of the effects of split phasing and three base-case observations were performed using TRAF-Netsim. 
The impact of split phasing on local bus performance was mixed. The Northbound bus benefited from split phasing, as its average travel time dropped by nearly 10 percent, from 841 seconds to 757 seconds. However, the Southbound bus received no benefit as the average travel time increased slightly from 751 seconds to 767 seconds.

Meanwhile, split phasing had a minimal impact upon delay along both cross street and arterial links. Since split phasing does not impact the overall cross street or arterial green time, this result is not surprising.

\section{Unconditional Priority}

Unconditional priority is an active transit signal priority strategy where transit vehicles receive green extensions or red truncations whenever needed regardless of cross street queue lengths or the time since priority was last granted (Urbanik and Holder 1977).

While unconditional priority offers significant potential for transit, vehicles traveling on cross streets may feel severe negative impacts. Therefore, the use of unconditional priority should be reserved for express bus service during off-peak hours. Express bus service uses longer headways than local bus service, resulting in fewer priority calls over time, while off-peak traffic volumes enable cross streets to recover from each priority call more quickly than during the peak period.

The cross street degree of saturation (or saturation level) and the length of green extensions or red truncations made available to express buses are critical parameters to the success of unconditional priority.

The impact of unconditional priority on cross streets with various saturation levels was determined by performing several analyses using TRAF-Netsim. The first analysis examined how often unconditional priority would likely be triggered at the intersections along the Guadalupe-N. Lamar case study arterial. Unconditional priority was implemented along the northbound and southbound bus routes on the Guadalupe-N. Lamar arterial using the time period feature within TRAF-Netsim and the graphical animation. Three separate TRAF-Netsim simulations were performed in this manner for each direction. Therefore, a total of six buses (three northbound 
and three southbound) approached most intersections along the arterial within the analysis.

Results of this analysis indicated are shown in Table 1. As shown in Table 1, results indicate that unconditional priority will more likely be necessary at high volume intersections, such as 38th Street and 45 th Street intersections. Where the cross street volume is light, unconditional priority will rarely be triggered by the bus because the bus approach already receives a large fraction of intersection green time. Such is the case at the 51 st Street intersection.

The next analysis examined the effects of varying green extension and red truncation lengths and cross street saturation levels at several intersections.

The Eastbound approach of 38th Street, a cross street with heavy traffic, was examined first. Green extension or red truncation lengths available to the buses included 10 seconds of additional green, 20 seconds of additional green, and an unlimited amount of additional green as needed for the bus to traverse the intersection. In addition, the saturation level along the Eastbound approach of 38th Street varied from 0.62 (its existing saturation level) to 0.70 and 0.50 , respectively. To

\section{Table 1}

Percent of Time Priority Needed at Intersections

\begin{tabular}{lccc}
\hline \multicolumn{1}{c}{ Intersection } & $\begin{array}{c}\text { No. of Bus } \\
\text { Arrivals }\end{array}$ & $\begin{array}{c}\text { No. of } \\
\text { Priority Calls }\end{array}$ & $\begin{array}{c}\text { \% Priority } \\
\text { Needed }\end{array}$ \\
\hline $\begin{array}{l}\text { North Loop \& Lamar } \\
\text { (moderate volume cross street) }\end{array}$ & 6 & 2 & $33 \%$ \\
$\begin{array}{l}\text { 51st Street \& Lamar } \\
\text { (low volume cross street) }\end{array}$ & 6 & 1 & $17 \%$ \\
$\begin{array}{l}\text { 45th Street \& Guadalupe } \\
\text { (high volume cross street) }\end{array}$ & 6 & 3 & $50 \%$ \\
$\begin{array}{l}38 \text { th Street \& Guadalupe } \\
\text { (high volume cross street) }\end{array}$ & 6 & 6 & $100 \%$ \\
$\begin{array}{l}\text { 30th Street \& Guadalupe } \\
\text { (low volume cross street) }\end{array}$ & 6 & 2 & $33 \%$ \\
\hline
\end{tabular}


obtain robust results, three replicate simulations were conducted for each cell within this factorial experiment design.

Unconditional priority was simulated at the eastbound approach of 38th Street by taking green time from 38th Street in favor of the bus approach at 600 and 800 seconds into the simulation. Previous simulation results indicated that the Northbound bus typically requested priority at 38 th Street 600 seconds into the simulation, followed by a priority request from the Southbound bus 200 seconds later.

The second analysis examined the impact that unconditional priority had on the Westbound 45th Street approach, a cross street with only light to moderate off-peak hour traffic. This proceeded in a similar fashion to the last analysis (using three replicate runs per cell in the experiment), except saturation levels of $0.25,0.38$ (existing saturation level), and 0.50 were simulated. Also, because this is not a high volume intersection, simulation revealed that only 1 signal priority call would likely be necessary.

Results indicate that, placing a 10-second limit on the added green time, which the bus approach receives from the cross street, limits the impacts to the eastbound approach of 38th Street. Placing a 20-second limit on each signal priority call resulted in significant delay increases along the cross street, as delay levels hover in the range of 45 seconds per vehicle for roughly 500 seconds.

Similar results were encountered when the Eastbound 38th Street approach saturation level was lowered to 0.62 and 0.50 , when a 10 -second limit on the signal priority time protected the cross street from significant delay increases.

When unconditional priority was simulated along the Westbound 45th Street approach with a saturation level of 0.50 , unlimited priority increased the cross street delay producing effects lasting about 5 minutes. Both 10 -second and 20-second priority calls, however, had little impact upon delay. Similar results were encountered when the saturation level along the Westbound 45th Street approach was lowered to 0.38 .

However, when the cross street saturation level was reduced to 0.25 , enough excess capacity was available along the Westbound 45th Street approach to enable it to recover from even an unlimited priority call. Although the cross street delay 
increase resulting from an unlimited priority call (taking 30 to 40 seconds of green away from the cross street) was greater than when limits were imposed on signal priority, the cross street was not severely impacted.

Therefore, when the cross street intersection saturation levels drop below 0.25 , one might consider using unlimited signal priority because present signal timing should already heavily favor the bus approach. Therefore, the bus will rarely need to request priority, and the priority time needed will typically be fairly small.

The results of the analysis of unconditional priority at the Eastbound 38th Street approach and the Westbound 45th Street approach are summarized in Table 2.

\begin{tabular}{|lc|}
\hline \multicolumn{1}{|c|}{$\begin{array}{c}\text { Table } 2 \\
\text { Guidelines for Use of } \\
\text { Unconditional Priority } \\
\text { During Off-Peak Hours }\end{array}$} \\
\hline $\begin{array}{l}\text { Cross Street } \\
\text { Saturation Level }\end{array}$ & $\begin{array}{c}\text { Recommended Green } \\
\text { Extension or Red } \\
\text { Truncation Length }\end{array}$ \\
\hline Below 0.25 & Unbounded \\
0.25 to 0.35 & 20 Seconds \\
0.35 to 0.70 & 10 Seconds \\
\hline
\end{tabular}

\section{Peak Time Period Transit Signal Priority}

Implementation of transit signal priority during peak time periods is more difficult than during off-peak time periods. Because both cross streets and arterials are likely to be operating at higher degrees of saturation than during off-peak times, less excess transportation network capacity is available.

\section{Impact of Transit Signal Priority on Cross Street Delay}

To observe the effects of transit signal priority on cross street delay during the peak time period, the delay calculated within TRAF-Netsim at several cross streets was monitored as green time was taken from these approaches and given to the bus approach in the form of a green extension. 
Cross street saturation levels and green time taken from the cross street and provided to the bus approach were varied over the simulation runs. The resulting impacts were observed at two cross streets-the eastbound 38th Street approach and the westbound 45th Street approach.

The total simulation time used for every run was one hour and three replicate simulations were conducted for each cell within the factorial experiment. Within each run, a transit signal priority cycle was inserted in place of the normal signal timing at the particular intersection under examination once every 10 minutes. This mimics the arrival of a bus requesting priority once every 10 minutes (the assumed bus headway).

Results indicate that when 10-second green extensions were used in conjunction with a cross street saturation level of 0.8 , signal priority did not result in substantial increases in delay per vehicle along the cross street approaches.

When the cross street saturation level was raised to 0.9 in conjunction with the use of 10-second green extensions, the cross streets began to feel more substantial delay increases, causing the use of priority to become questionable. Increases in delay felt by cross streets did not readily dissipate with time.

When cross street saturation levels were raised to 1.0 and 10 -second green extensions were used, simulation results at both approaches revealed increasing delay levels over time with each signal priority initiation. This indicates that green time should not be taken from cross streets operating at saturation levels of 1.0 to award priority to transit vehicles along an arterial.

When the green extensions awarded to the bus approach were increased from 10 seconds to 20 seconds per priority call, larger delay increases were encountered along the cross streets.

However, when the cross streets were operating at saturation levels of 0.8 , enough excess capacity was available to allow them to recover from the impacts of the priority signal timing within two to three signal cycles following each priority call. However, it is unclear whether the benefits to transit from signal priority outweigh the increases in delay incurred by vehicles along the cross street. A more comprehensive analysis is required. 
As the saturation level of the Eastbound approach at 38th Street is increased to 0.9 , substantial increases in cross street delay relative to the base case were felt over the majority of these simulations, indicating that signal priority should not be used in this context.

The results of this analysis are summarized in Table 3. Under conditions where only minimal negative impacts are felt by cross streets due to signal priority, the use of signal priority may be appropriate. Should transit signal priority be used under conditions which generate moderate negative impacts along the cross streets, the resulting increases in delay along the cross streets should be closely scrutinized, while transit signal priority should be avoided under conditions that generate significant negative impacts to the cross streets.

\begin{tabular}{|lcc|}
\hline \multicolumn{3}{|c|}{$\begin{array}{c}\text { Table } 3 \\
\text { Negative Impacts Accruing on Cross Streets Due to } \\
\text { Signal Priority (Assumed Bus Headway }=10 \text { Minutes) }\end{array}$} \\
\hline $\begin{array}{l}\text { Cross Street } \\
\text { Saturation }\end{array}$ & $\begin{array}{c}\text { Green Extension } \\
=10 \text { Sec. }\end{array}$ & $\begin{array}{c}\text { Green Extension } \\
=20 \text { Sec. }\end{array}$ \\
\hline \begin{tabular}{lcc} 
Saturation Level $=0.8$ & Minimal & Moderate \\
Saturation Level $=0.9$ & Moderate & Significant \\
Saturation Level $=1.0$ & Significant & Significant \\
\hline $\begin{array}{l}\text { Minimal Impacts-Signal priority appropriate. } \\
\text { Moderate Impacts-Signal priority should be used with } \\
\text { caution; delays on side streets should be closely monitored. }\end{array}$ \\
Significant Impacts-Signal priority should be avoided.
\end{tabular} \\
\hline
\end{tabular}

\section{Arterial Street Impacts Upon Signal Priority Effectiveness}

This analysis examined how different characteristics of the bus arterial affect the success of active transit signal priority. In particular, two characteristics were examined: 1) the location of bus stops along the arterial (near-side versus far-side) and 2) the saturation level of the bus approach. 
TRAF-Netsim was used to examine the success of a green extension in allowing buses to traverse a test intersection without stopping in a variety of traffic conditions. In particular, the bus stop location, bus approach saturation level, and green extension length were all varied within simulation runs. For each scenario examined within the factorial experiment, 8 to 10 replicate observations were made using TRAF-Netsim.

Green extensions were triggered with the aid of TRAF-Netsim's graphical interface. Upon approaching the intersection, the graphics display would indicate whether the bus was in need of signal priority. If so, a time period would be inserted within the simulation that contained the signal priority signal timing. The outcome of this signal priority timing was then observed using TRAF-Netsim's graphical animation. Bus dwell times at the bus stop were simulated within TRAF-Netsim based on a dwell time distribution modeled within the simulator. This dwell time distribution was based on field data collected along the Guadalupe-N. Lamar corridor in Austin.

Tables 4 and 5 summarize the results of this analysis for near-side and far-side bus stops, respectively. For each scenario, a success rate for the green extension used is given. Success in this context indicates that the green extension enabled the bus to

\begin{tabular}{|lcccc|}
\hline \multicolumn{5}{c|}{ Table 4} \\
Success & Rate of Green Extensions (Near-Side Bus Stop) \\
\hline $\begin{array}{c}\text { Green } \\
\begin{array}{c}\text { Extension } \\
\text { Length }\end{array}\end{array}$ & $\begin{array}{c}\text { Bus Approach } \\
\text { Saturation } \\
\text { Level }\end{array}$ & $\begin{array}{c}\text { No. of } \\
\text { Attempted } \\
\text { Extensions }\end{array}$ & $\begin{array}{c}\text { No. of } \\
\text { Successful } \\
\text { Extensions }\end{array}$ & $\begin{array}{c}\text { Success } \\
\text { Rate }\end{array}$ \\
\hline 10 Seconds & Saturation $=0.8$ & 10 & 2 & $20 \%$ \\
10 Seconds & Saturation $=0.9$ & 10 & 1 & $10 \%$ \\
10 Seconds & Saturation $=1.0$ & 10 & 0 & $0 \%$ \\
20 Seconds & Saturation $=0.8$ & 10 & 3 & $30 \%$ \\
20 Seconds & Saturation $=0.9$ & 10 & 3 & $30 \%$ \\
20 Seconds & Saturation $=1.0$ & 10 & 0 & $0 \%$ \\
\hline
\end{tabular}




\begin{tabular}{|lcccc|}
\hline \multicolumn{5}{c|}{ Table 5 } \\
Success Rate of Green Extensions (Far-Side Bus Stop) \\
\hline $\begin{array}{c}\text { Green } \\
\begin{array}{c}\text { Extension } \\
\text { Length }\end{array}\end{array}$ & $\begin{array}{c}\text { Bus Approach } \\
\text { Saturation } \\
\text { Level }\end{array}$ & $\begin{array}{c}\text { No. of } \\
\text { Attempted } \\
\text { Extensions }\end{array}$ & $\begin{array}{c}\text { No. of } \\
\text { Successful } \\
\text { Extensions }\end{array}$ & $\begin{array}{c}\text { Success } \\
\text { Rate }\end{array}$ \\
\hline 10 Seconds & Saturation $=0.8$ & 8 & 5 & $63 \%$ \\
10 Seconds & Saturation $=0.9$ & 9 & 6 & $67 \%$ \\
10 Seconds & Saturation $=1.0$ & 10 & 5 & $50 \%$ \\
20 Seconds & Saturation $=0.8$ & 8 & 7 & $88 \%$ \\
20 Seconds & Saturation $=0.9$ & 9 & 8 & $89 \%$ \\
20 Seconds & Saturation $=1.0$ & 10 & 6 & $60 \%$ \\
\hline
\end{tabular}

avoid a red signal indication at the intersection, which it would have otherwise received.

As can be seen in Table 4, the presence of a near-side bus stop greatly hinders the effectiveness of green extensions. Near-side bus stops limit the success of green extensions because a significant portion, if not all, the green extension is wasted while passengers board and deboard at the near-side bus stop.

Table 5 shows the success rate of green extensions when used with a far-side bus stop configuration. Transit signal priority is much more successful when used with far-side bus stops, rather than near-side bus stops. With far-side bus stop configurations, the success of signal priority is no longer a function of the bus dwell time.

Table 5 further shows that the success rates of both the 10 - and 20 -second green extensions remain relatively constant as the bus approach degree of saturation increases from 0.8 to 0.9 . In particular, the success rate of the 20 -second green extensions along bus approaches with saturation levels of 0.8 or 0.9 looks extremely promising from the bus's viewpoint. However, as shown in the previous analysis, the use of 20-second green extensions causes moderate to significant increases in delay along cross streets operating at saturation levels above 0.8 . 
These findings identify the direct conflict arising between the success of signal priority and the negative impacts along cross streets resulting from signal priority. To determine whether the use of signal priority is justified, a comprehensive analysis that examines the overall net effect of signal priority upon an intersection is needed.

\section{Effectiveness of Signal Priority at an Isolated Intersection}

This analysis addresses the questions raised previously regarding whether signal priority can be justified by evaluating the overall net impact of transit signal priority at a single intersection.

The intersection of 38th Street and Guadalupe Street was simulated using TRAFNetsim. This intersection was chosen because the cross street volume along 38th Street is significant and, therefore, a definite conflict exists between arterial traffic along Guadalupe Street, which stands to benefit from signal priority, and the cross street traffic, which is negatively influenced by signal priority.

Based on the results of the last analysis, a far-side bus stop configuration is assumed. Also, a 10-minute bus headway is assumed and transit signal priority is assumed to only be used by buses traveling in the peak period direction (the northbound intersection approach).

The criteria that is used to address the effectiveness of transit signal priority at a single intersection is the travel time per person over all individuals approaching the intersection over a given time frame.

The time frame used for this analysis began 600 seconds into each TRAFNetsim simulation and ends 10 minutes later, at 1200 seconds. A green extension was used at the intersection 600 seconds into the simulation, and the effects of this green extension were examined over the following 10 minutes.

The analysis of signal priority effects at a single intersection was broken into the following three components: 1) the analysis of signal priority effects on travel time per person along non-bus approaches, 2) the analysis of signal priority effects on travel time per person for non-bus traffic along the bus approach, and 3) the analysis of signal priority effects on travel time per person on-board the bus.

The effects of signal priority along the non-bus approaches were monitored by acquiring cumulative travel time and vehicle counts along the three non-bus links 
600 and 1200 seconds into each simulation. These data were collected in conjunction with both 10 -second and 20-second green extensions, with each simulation accompanied by a base case where no signal priority was used. Three replicate runs were performed for each scenario described above.

Whereas the volumes along the non-bus approaches were fixed at the volumes consistent with peak period volumes from the Guadalupe-N. Lamar case study network, the bus approach volume was varied to create approach saturation levels of 0.8 , 0.9 , and 1.0. The effect of signal priority on non-bus traffic along the bus approach was also monitored by acquiring cumulative travel time and vehicle counts for nonbus traffic along the bus approach at 600 and 1200 seconds into each simulation. Three replicate runs were performed for each scenario described above.

Finally, data concerning the effect that signal priority had on the bus travel time along its approach were obtained by collecting the bus travel times from TRAFNetsim, using three replicate runs for each scenario tested.

Having collected statistics regarding the total travel times and number of vehicles processed along all 4 approaches of the 38th Street and Guadalupe Street intersection, the overall travel time per person at the intersection was calculated by assuming occupancy rates for the bus and the automobiles.

Upon assuming an auto occupancy of 1.2 and a bus occupancy of 25 , the measures of travel time per person shown in Table 6 were obtained.

As can be seen in Table 6, signal priority does not appear to significantly impact the overall travel time per person at the intersection. This result stems from the small bus share of roughly 2.9 percent of the total person-trips at the intersection. As a result, reducing the travel time for this small fraction of users had a negligible overall impact upon the travel time per person over the entire intersection.

In addition, when looking at Table 6 , one notices the superior performance of the 10-second green extension over the 20 -second green extension across all bus saturation levels. This finding indicates that a signal should accommodate its users. Larger green extensions place the signal timing of an intersection farther away from the original timing intended for individuals in autos, the intersection's major group 


\section{Table 6}

Travel Time per Person (Seconds/Person) at 38th Street and Guadalupe (Auto Occupancy = 1.2, Bus Occupancy $=25$ )

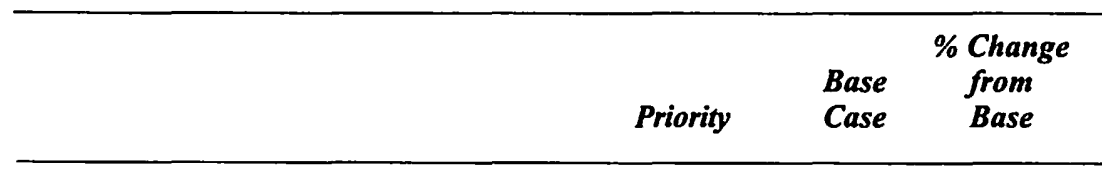

\section{0-Second Green Extension}

Bus approach saturation level $=0.8$

47.5

47.6

$-0.2$

Bus approach saturation level $=0.9$

49.1

49.9

$-1.7$

Bus approach saturation level $=1.0$

53.0

55.0

\section{0-Second Green Extension}

Bus approach saturation level $=0.8$

49.8

Bus approach saturation level $=0.9$

Bus approach saturation level $=1.0$

of users in this analysis. Similar results were encountered even when a bus occupancy of 50 passengers was assumed.

It is important to note that the findings from this analysis are based on 10minute headways and heavy automobile volumes taken from traffic counts at the 38th Street and Guadalupe Street intersection. Had the transit mode share been higher, the effectiveness of signal priority would likely increase.

\section{Effectiveness of Signal Priority within an Arterial Street Network}

The previous analysis showed transit signal priority to be largely ineffective at an isolated intersection with high cross street traffic volumes. However, in reality, transit signal priority systems are not operated only at isolated intersections, but along transit corridors, such as the Guadalupe-N. Lamar arterial. Only by looking at the overall impact of transit signal priority upon the entire arterial and its cross 
streets can one clearly determine whether the use of transit signal priority can be justified along the corridor.

The users of the Guadalupe-N. Lamar arterial network can be broken into three categories.

1) non-bus users traveling along the cross streets,

2) non-bus users traveling along the arterial, and

3) bus users traveling along the arterial.

Previous analyses have clearly indicated that non-bus users traveling along the cross streets suffer increased delays with the use of transit signal priority.

However, the effect that transit signal priority has upon non-bus users traveling along the arterial remains somewhat unclear. This group of users stands to benefit from the effects of transit signal priority as their overall green time increases with the use of transit signal priority. However, signal coordination along the arterial is also very important to the success of this user group. It is still unclear how transit signal priority affects signal coordination along an arterial.

Finally, bus users should realize improvements in service levels with the use of transit signal priority. However, as shown in the previous section, the benefits to this small group of users might not justify the negative impacts to cross street users or potential negative impacts to automobiles traveling along the arterial.

To determine the overall effect of transit signal priority upon the Guadalupe-N. Lamar arterial, this analysis quantifies the effects that transit signal priority has on the three user groups.

The transit signal priority implementation strategies which will be tested within this analysis are as follows:

Case 0: Transit signal priority not used (base case).

Case 1: Transit signal priority available in equal amounts (20-second green extensions) at all intersections along the arterial.

Case 2: Transit signal priority available in a limited fashion (10-second green extensions) at high volume cross street intersections with 20 -second green extensions available at all other intersections. 
Case 3: Transit signal priority unavailable at high volume cross street intersections, with 20-second green extensions available at all other intersections.

As with the previous analysis, far-side bus stop configurations and 10-minute bus headway were assumed. In addition, transit signal priority is only used by buses traveling in the peak period direction, the northbound direction.

The time frame used for this analysis began 6 minutes after the beginning of each TRAF-Netsim simulation and concluded 18 minutes after the beginning of each simulation. This analysis time frame was chosen because the northbound bus enters the network about 6 minutes after the beginning of each simulation and exits the network about 18 minutes after the beginning of each simulation.

To account for the variability that occurs over different simulation runs, each of the 4 cases was simulated twice. As a result, a total of eight simulations were run, with the results of two simulations averaged for each of the four cases.

The criterion that was used to compare the various transit signal priority strategies was the total travel time occurring along the cross street and arterial links during the analysis time frame.

Finally, the occupancy of the bus and autos was taken into consideration by multiplying the travel times (in vehicle minutes) by the occupancy rates (passengers per vehicle) to obtain the travel time along each link in terms of total person-minutes.

Table 7 shows the results of this analysis when bus occupancy is assumed to be 10 passengers per bus, accompanied by an average auto occupancy of 1.2 passengers.

As can be seen from Table 7, the base case outperformed all the cases where transit signal priority was used. As expected, the cross streets suffered with the use of transit signal priority, with the greatest increase in cross street travel time occurring with Case 1 . When priority is limited and restricted at the high volume cross street locations the travel times along the cross streets are reduced relative to Case 1, but are still greater than the base case.

The travel time that auto traffic experiences along the arterial fluctuates over the four cases with no apparent pattern. In addition, none of the changes are very 


\section{Table 7}

Total Travel Time (Person-Minutes) Within Arterial Network (Bus Occupancy $=10$, Auto Occupancy $=1.2$ )

\begin{tabular}{lrrrr}
\hline & Case 0 & Case 1 & Case 2 & Case 3 \\
\hline Auto travel time along arterial & 4405 & 4379 & 4376 & 4417 \\
Auto travel time along cross streets & 2899 & 3193 & 3023 & 2985 \\
Bus travel time along arterial & 108 & 89 & 96 & 99
\end{tabular}

Total Travel Time within Arterial Network7412 $\quad 7661 \quad 7494 \quad 7501$

Case 0 -Transit signal priority not used (base case).

Case 1-Transit signal priority available in equal amounts (20-second extensions) at all intersections.

Case 2-Limited transit signal priority available (10-second extensions) at high volume cross street intersections with 20 -second extensions available at all other intersections.

Case 3-Transit signal priority unavailable at high volume cross street intersections, with 20 -second green extenşions available at all other intersections.

large with respect to the base case. In fact, over the four cases, auto travel times along the arterial all fall within 1 percent of one another. This indicates that transit signal priority has little effect on the performance of automobile traffic traveling along the arterial which receives priority.

TRAF-Netsim's graphical animation showed that arterial traffic in the vicinity of the bus benefited from the bus's first priority call. However, after receiving priority, the bus typically stopped at a far-side bus stop, which caused it to lose coordination with the arterial traffic which benefited from the first priority call. As a result, the impact of signal priority upon arterial traffic may come in the form of increased number of stops and start up delay.

Finally, Table 7 shows that bus travel time is reduced relative to the base case over all three signal priority strategies, with the shortest bus travel time occurring with Case 1 . However, although bus travel time is reduced by significant percent- 
ages, the absolute travel time savings that the bus receives is minor compared with the absolute travel time increases imposed upon the cross streets when signal priority is initiated.

With 10-minute bus headways and significant automobile traffic volumes, bus mode share is extremely small. When bus occupancy is assumed to be 10 passengers, the bus's share of the total travel time within the network over the analysis period is only 1.5 percent (for the base case). Therefore, even improving the bus's performance significantly (on a percent basis) fails to provide the overall transportation network with significant absolute gains. In addition, the disruption caused to the network with the use of the signal priority timings overwhelms any small benefits realized by bus passengers.

Similar results were encountered when bus occupancy was assumed to be 25 and 50 passengers. Even with these occupancies, the bus's share of overall travel time was extremely small, causing the benefits of signal priority to be overshadowed by the resulting increased travel times along the cross streets.

This analysis leads to several conclusions. First, in areas where transit enjoys only a small mode share, transit signal priority is not recommended. However, in areas where transit enjoys a higher mode split, active signal priority may be feasible. In addition, the well-being of general traffic can be considered while using signal priority by compensating cross streets for lost green time or monitoring the saturation levels of cross streets. It is important to note, however, that if transit enjoys a high mode split within a particular transportation network, the network signal timings will almost certainly reflect the needs of the transit vehicles to begin with (perhaps in the form of passive priority). Therefore, under these circumstances active signal priority may not provide significant incremental transit benefits.

\section{Conclusions}

Reducing signal cycle lengths and split phasing are passive priority techniques that may be useful during off-peak times with local transit service. Reducing the cycle lengths along an arterial reduces transit delay and delay to general traffic if the arterial is operated with a generous amount of excess capacity. Split phasing, however, enjoyed only modest success. 
Unconditional signal priority during off-peak times offers express transit service significant potential benefits. However, its use should be regulated by placing limits on green extension and red truncation lengths, especially at intersections with busy cross streets.

During peak times, active transit signal priority should be used with caution. Active signal priority may cause disnuptions along highly saturated cross streets that do not dissipate before the next priority call. Far-side bus stops should be used with active signal priority to ensure that signal priority calls are not wasted as transit vehicles dwell at bus stops. Also, the success of transit signal priority during peak times is proportional to the transit mode share within the network. Only when transit gains a significant share of trips within the network will transit signal priority have an overall positive network impact. However, providing transit signal priority will improve transit service. Enhanced transit service promotes a more sustainable transportation mode within any transportation network and may, therefore, result in longterm benefits by encouraging transit use.

\section{References}

Al-Sahili, Khaled, and William C. Taylor. 1995. Bus preemption signal (BPS): An application, executive summary. Michigan State University.

Bowen, G. T., R. D. Bretherton, J.R. Landles, and D. J. Cook. 1994. Active bus priority in SCOOT. 7th International Conference on Road Traffic Monitoring and.

Hounsell, N. B., and J. P. Wu. 1995. Public transport priority in real-time traffic control systems. Applications of Advanced Technologies in Transportation Engineering.

Hounsell, N. B., F. N. McLeod R. D. Bretherton, and G. T. Bowen. 1996. PROMPT: Field trial and simulation results of bus priority in SCOOT. 8th International Conference on Road Traffic Monitoring and Control Priority in SCOOT.

Mainline Traffic Signal Priority Study. 1991. Phase 5-Demonstration project, final report. Municipality of Metropolitan.

Sunkari, Srinivasa R, Phillip S. Beasley, Thomas Urbanik II, and Daniel B. Fambro. 1995. Model to evaluate the impacts of bus priority on signalized intersections. Transportation Research Record 1494. Washington, DC: Transportation Research Board. 
TRAF User Reference Guide, Version 5.0.1995. U.S. Department of Transportation: Federal HighwayAdministration.

Urbanik II, Thomas, and R. W. Holder. 1977. Evaluation of priority techniques for high occupancy vehicles on arterial streets. College Station: Texas Transportation Institute, Texas A\&M University.

\section{About the Authors}

MichaEl GaRRow is an associate with Barton-Aschman Associates, Inc. specializing in transportation planning, traffic engineering, transit planning, and airport ground transportation planning.

RaNDY MACHEMEHL is a Professor and Associate Chairman of the Department of Civil Engineering at The University of Texas at Austin and serves as Associate Director of the Center for Transportation Research for the Southwest Region University Transportation Center. 


\title{
The Advanced Technology Bus and the Evolution of Workplace Expertise
}

\author{
DavidW. Partain \\ MetropolitanAtlanta RapidTransitAuthority
}

\begin{abstract}
The purpose of this paper is to define and explore the immediate and long term effects and the resulting organizational dynamics of advancing technology on maintenance workplace expertise in transportation. In the past ten years the face of maintenance in the transportation workplace has completely changed as computerization has taken over the control of transmissions, engines, and bus/truck environmental systems and transformed them from "closed" stand alone components to an interdependent "open system" in a state of constant communication. The immediate future brings with it the advanced technology of the Intelligent Transportation System with its Geographic Information System, in-vehicle logic system, automated annunciation, signal prioritization, global positioning, and live audio and visual data links with a central control center.

This complexification of the transportation maintenance workplace is being compounded by the growing use of alternative fuels, and the resultant requirement for the maintainer to learn a new operational set of skills and competencies. This evolution of technology in transportation has caused a revolution in technical training for which the maintainers of transportation resources must reskill immediately to meet the demands of the technology invasion. The paper examines the need for an accelerated evolution of workplace expertise using a combination of motor skill and cognitive training competency based learning techniques to evolve the maintainer through the phases of basic operation, to systems expert, to system creator.
\end{abstract}


This evolution is accomplished through the use of a four step implementation strategy which begins with the determination of training sources, the development of an effective resource investment strategy, the development of a model trained cadre, and concludes with the expansion of this model to improve the overall baseline of workplace expertise.

\section{Introduction}

The post-World War II diesel mechanics maintained their skills with little technological upgrade training for 40 years, and then, with the advent of engine and transmission electronic controls, the world changed. No longer could the test light be used to troubleshoot every electrical circuit on the bus. Diagnostic equipment evolved through the multi-meter, the vacuum tube volt meter, the digital multi-meter, the laptop computer, and the digital diagnostic analyzer (Hannum 1990). Today, with Programmable Logic Controller circuits, mechanics must still be warned not use the test light, but they continue to do so, at considerable expense.

As a result of this nonstop integration of technology into our modern transit buses, and the resultant complexification of maintenance tasks (Casti 1994), the normal divisions between "manual " and "intellectual" labor are collapsing. As transit maintenance moves toward the mediation and control of work using automated tools and test equipment, a greater number of workers at all levels are being compelled to conceptualize work and troubleshoot problems using a very different group of competencies than before (Di Bello 1994). The foremost role and goal of technical training in the transit maintenance organization has become the development of mechanic "workplace expertise." Workplace expertise is both the productivity multiplier and road-call minimizer in our transit bus maintenance technical organization.

The problem of developing workplace expertise has been an issue of concern since the Industrial Revolution and the advent of Frederick W. Taylor and the "one best way" to do a job (Taylor 1911). Since 1900, the American workforce has been subjected to several conflicting methods of developing and maintaining workplace expertise. These methods ranged from "de-skilling" or compartmentalization of tasks that resulted in increased personnel requirements, to "re-skilling" or developing a higher number of skills in a fewer number of people (successfully implemented by 
the Israeli Air Force), to the promotion of highly skilled technical workers to the ranks of "foreman" (often done without investing training in the development of requisite management and interpersonal skills) (Partain 1994), to the advent of team directed maintenance, which, in itself, presupposes and requires an entire hierarchy of skills be present before team formation can begin and the desired results produced (Howard 1995).

It is becoming apparent that the classic on-the-job training (OJT) instructional method of task certification training is becoming ever more difficult to implement successfully with the acquisition of advanced technology in transit. It is one thing to teach the steps of rebuilding a diesel engine "by the book," and another to teach analytical methods for computer ladder logic. We have now evolved to a workertechnology interface that must encompass two distinct forms of training activity with very different cognitive consequences. These forms are "constructive activity systems," which specify the goals to be accomplished but leave the means unspecified, and "procedural activities" which, like task-oriented OJT, specify both the goal and the means to attain a goal or complete a task (Di Bello and Glick 1993).

It has become essential to define the environment in which learning is to take place; however, much development of workplace expertise has been done without the essential definitions of "What does the organization want the level of expertise to be?", "What does technology require the level of expertise to be?" (Leibowitz 1986), and "What must the mechanic know to make any particular technology effective?" (Di Bello and Spenser 1994).

The level of expertise in the garage-centered bus maintenance organization is a hierarchy of building-block levels constituting a five-rung ladder composed of:

1) Basic understanding: This is the core concept to understanding. It is the minimum baseline of knowledge and competency that will allow the individual mechanic to operate the system, i.e., drive the bus, service the bus, activate the in-vehicle logic system, and document problems. These are the basic operator requirements of the service person which require only a premechanical knowledge of the bus. 
2) Basic operational capability: This is the development of the core knowledge essential to understanding how components on the bus work together as a system. Can the individual engage and operate the major systems on the bus (i.e., engine, transmission, heating and air conditioning systems, brake and air systems, and general electrical system) from a mechanical and systems operation point of view, including the reading and understanding of service manuals and the removal and replacement of components? These are the basic operations of the apprentice and basic mechanic. The advanced technology bus expands the horizons of basic operational capability to include automatic passenger counting, enunciators, global positioning system and the on-vehicle logic system (Reynolds and Paquet 1996).

3) Analytical troubleshooting capability: This reflects a higher level of understanding of the operation of specific components and systems and how they interact with other components and systems on the bus. Can the individual read and understand schematic and system diagrams? Can the individual use troubleshooting and fault isolation trees and ladder logic diagrams. Can the mechanic use test equipment and arrive at an accurate interpretation of test equipment readings? These are the operations of the experienced mechanic.

These first three rungs are dedicated to the maintenance of the system. The next two are dedicated to changing, improving, and/or innovating the system.

4) Capability to improve on the existing system: Can the mechanic analyze system operation to the point that deficiencies in the system can be identified and suggestions for improvement offered? This level requires the visualization of circuits and systems, in-depth knowledge of technical specifications, the accurate performance of corrective maintenance procedures on literally hundreds of repeat discrepancies. It requires intuition to guide the mechanic past the obvious and into the world of root cause analysis where the question is, "If the system should work because all of the components work, then why does the system continue to fail?" These are the skills and competencies of the "lead" mechanic (Newby and Stepich 1987). 
5) Capability to create a new system: Can the individual compare performance requirements to current system capabilities and devise new systems to optimize performance? Can the individual devise improvements for systems that have not yet failed (Field 1994)? These are the competencies of the "systems" mechanic (Chi et al. 1988). It is at this level that learning becomes very self-motivated and self-directed (Grow 1991, Mezirow 1985).

These rungs portray levels in a hierarchy that define the degree of expertise required to perform the task or process. To achieve required performance goals, technical training must be aimed at the right technical and/or information system, at the appropriate performance level, and applied at the right time (Carey 1985). For example, having technical training aimed at the operational performance level with workplace performance expectations at the troubleshooting performance level is a common but serious problem in that it produces a "remove and replace" mechanic. Most maintenance supervisors can relate to a workforce that hovers in that area between levels 2 and 3 .

Technical jobs (and technical training) in the workplace often have been different for those who troubleshoot and for those who operate technical systems (the bus). This is true in a typical Authority's Bus Services operation on the macro level where bus drivers (those who operate the technical system) and bus maintainers (those who troubleshoot the technical system) are separated. However, for one to understand the scope of the issue at the maintenance level, one must focus on the micro level of the garage maintenance organization, where it becomes apparent that within a maintenance workforce there is disparity in expertise and competency levels separating "troubleshooters" from the other mechanics. There tends to exist in the garage that small group of mechanics who have developed (either formally or informally) those clusters of skills that cause them to be called on more frequently to perform specific maintenance tasks on engine, transmission, and electrical systems.

This natural selection of skill development is typical in any technical maintenance organization. A longevity study of this phenomenon in the U.S. Air Force (USAF) revealed this same characteristic (DOD 1982). The USAF identified these mechanics as "Maintenance Heroes" and used them to demonstrate a desired perfor- 
mance standard. This study resulted in changes in USAF technical training that raised skill and capability standards to develop a greater pool of "Heroes" (increased workplace expertise).

The evolution in bus technology, which began in the mid 1980s with the move to electronic engine and transmission controls, began the dilution of post-World War II diesel mechanic workplace expertise that served transit and long-haul trucking well until the encroachment of automated systems into the diesel environment. This encroachment has continued to evolve to even more complex computer control and monitoring systems such as the integration of Programmable Logic Controllers (PLC) into bus systems. The investment in this evolution was and will continue to be an expensive and strategic business investment, especially in light of the commitment to adopt alternate fuel technologies. However, the fact is that the scope of technical training has not tended to evolve along with the new bus technology. This lag is now driving the (reactive) process of developing adequate technical workplace expertise (and technical training) to the top of Authority investment priorities for both funds, equipment, and personnel.

Artificial intelligence will continue to be increasingly built into our bus systems, as PLC's and other "in-vehicle logic (smart) systems" will be able to diagnose and troubleshoot themselves. For the mechanic, this causes an evolution from the maintenance of a purely mechanical system to the understanding, troubleshooting, and maintenance of a mechanical/intelligent hybrid system. The new systems rely on computer-assisted, problem-solving methods as opposed to previous maintenance methods of removing and replacing components sequentially in a system until the defective component is (finally) discovered. This evolution is compounded by the adoption of alternative fuel technology.

To develop the "smart systems" mechanic, a three-element technical training method has been proven successful:

1) The use of computer-based communications skills, by the use of a computer and specialized diagnostic software, to interface the mechanic with the mechanical systems host computer. This requires the mechanic to acquire new skills in computer operation and understanding. Troubleshooting the PLC 
system, for example, requires not only that the mechanic know how to connect and operate the computer, but also requires that the mechanic understand true/false ladder logic diagrams (Newby 1987).

2) The elevation of technical training content from component specific to total systems understanding to ensure adequate expertise to meet advanced technology maintenance and performance standards (Chi et al. 1988). This requires a long-term strategic investment in training and equipment and leads to the evolution from mechanic or instructor to internal technical consultant.

3) The development of a baseline "common core of experience" for the introduction of new systems and technologies (Rosow1988). This may require general re-skilling and upgrade of the workforce in the areas of basic electronics, systems operations, and computer diagnostic skills.

The advent of computerized bus technology has had a profound change on the basic mechanical principles practiced and applied at the garage level. Previously, the bus could be viewed as a series of closed systems, where the engine, the transmission, and the air conditioning and electrical systems could, to a great degree, be worked on by the mechanic as separate and independent mechanical/electrical entities. With the initial evolution to computerized engine and transmission systems, the separate mechanical entities combined. Troubleshooting became more sophisticated as did the test equipment. With the continued evolution of computerized bus electronic control systems, the four basic closed systems became connected and formed into an "open system" requiring far more sophisticated test equipment and troubleshooting abilities (Hannum 1990). As a result, the hierarchy of skills for a capable bus mechanic in the 1990 s has been completely restructured and redefined compared to those skills required of the bus mechanic in the 1980s (Business Week 1994). But, while millions of dollars have been and are being invested in procuring buses with the new technology, little has been invested in bringing increasingly obsolete 1980 s workplace expertise (Johnston 1987) in line with 1990s technology and skills requirements.

The increasing complexity of bus systems, compounded by the addition of the Intelligent Transportation Systems Initiative that incorporates geographic informa- 
tion and geographic positioning systems technology on the buses, as well as the introduction alternative fuel systems, will continue to drive the demand for (and complexity of) technical training (Rothwell 1994, Clark 1989). The requirement to provide a level of training that brings workplace expertise up to the current level of bus technology and complexity requires a strategic investment in training for productivity enhancement (Waldrop 1992).

Based on the documented results of technical training and productivity enhancement studies, targeted training for workplace expertise against a specific level of technology could raise the overall level of workplace expertise and resultant productivity of the workforce from 20 to 200 percent (Carnevale 1990).

With approximately 50 percent of bus maintenance work orders (MARTA 1996) oriented to the "electrical system" (not including programmed maintenance work orders), it is reasonable to project that the level of maintenance activity in this area will increase as our mechanics are forced to react to new electrical/electronic system problems being generated by the "open system" of newer buses. To compound this situation, add a highly-pressurized CNG fuel system or a very-low-temperature LNG fuel system with its own set of electronic system controls and monitoring devices, working in conjunction with its companion engine electronic control and monitoring system.

The corrective action to the current issue of electrical/electronic systems workplace expertise is reactive. These "lessons learned" must be applied to the training and preparation for the integration of open systems and alternative fuels technology on our urban transit buses. This training and preparation must be proactive (or predictive) as well as self-motivated and self-directed on the part of the individual mechanic (Mezirow 1985).

\section{Resolution Strategy}

It is easy to say, "Now that we have defined the problem, let's fix it." It is infinitely more difficult to bring the "fix" into reality, especially since training technology provides no "magic bullet" or 17-minute videotape to solve the problem. The answer is: We must do it with innovation. Innovation must be incorporated into 
a set of sequential steps (Quinn 1985) to systematically increase workplace expertise in open (computerized) systems and to develop a uniform base of electrical/electronic and alternative fuel knowledge in preparation for the arrival of new technology and fuel buses.

1) Identify who will solve the problem, and empower them to do so. Identifying the individuals or groups who will maintain the emerging technologies integrated into transit buses may require authorities to develop completely new career development paths for mechanics (Liebowitz et al.1986) as well as restructuring on-the-job training concepts to stress cognitive and analytical skills (Jacobs and Jones 1995).

2) Determine whether to do the job in-house or with external resources. Determine the resources required to implement the program and establish the methodology to secure the resources (Horne 1982).

3) Develop a small cadre of experts who will "lead the force" in resolving the problem. Select a core group of individuals who have the capability and motivation to learn new systems and methods. Use these individuals to provide worker input in the designing of the training program (Sonnefield 1986).

4) Identify and train the small number of mechanics in each garage that do systems work well. Using the training model developed in \#3 above, implement the training and begin to develop internal expertise (Feuer 1986).

5) Invest the time and resources for additional training for these mechanics. As new technologies are integrated into the bus, train the experienced cadre (\#4) first because of their cumulative background and expanded core of experience and competencies (Hewitt 1988).

6) Expand the training to other mechanics, thus enlarging the pool of workplace expertise in the mechanics of a bus as a system. This is the long-term fix to develop the skills and competencies required for the integration of new technologies. This phase implements competency-based learning for the long term (Davies 1973). 
The above methodology can also be applied to the development of workplace expertise in the area of CNG/LNG. The significant difference is that the formation of the training cadre and the major bulk of the training must be accomplished prior to the receipt of this technology. After-the-fact training on the bus $\mathrm{CNG}$ system is not acceptable, since there is little prior experience base or common core of experience on CNG/LNG propulsion, refueling, and electrical systems by transit bus mechanics.

Two priority issues for maintainers - electrical/electronic (open) systems workplace expertise and the development of alternative fuels workplace expertise-are progressing side by side and must be addressed simultaneously. While the short-term fix for electrical systems may be implemented within one year by realigning existing in-house resources or with the assistance of outside resources, the long-term fix is instituted through increased resources by the establishment of a professional instructor cadre or through cooperation with a local educational institution. The issues of alternative fuels, co-generation, and fuel cell technical training, however, are not so easily addressed. Given the limited technical core of experience in urban transit alternative fuel systems, this expertise will have to be secured and developed as an addition to current training capabilities and resources (Hamburg 1985).

In developing training systems for advanced technology, the training manager may wish to apply the T-5 concept of evaluating the capability of a new training program. Utilizing T-5, the following elements must be in place:

- Technical Data: Accurate maintenance technical manuals and schematic diagrams for training and troubleshooting.

- Test Equipment: Any test equipment peculiar to the new components or systems.

- Training Aids: High fidelity training aids using actual system components and capable of supporting fault insertion and fault isolation.

- Tools: Any special tool peculiar to the new components or systems.

- Training: Vendor/manufacturer training of the instructor cadre.

Absence of any of the " $T$ " elements may cause the training effort on the new technology to fail. 
As the transit industry experiences the near-term acquisition of more advanced technology buses, the strategic imperative to train mechanics and operators prior to new bus arrival becomes an obvious and sensitive issue. Given the lead time to secure and train such a resource, it appears that we are within the critical window to secure this resource so that training and manufacturer orientation can be completed and a training program be developed, in place, and in progress before technology leads training and the transit industry must play catch-up.

\section{References}

Business Week. 1994. Rethinking work. Business Week, October 17: 76-106.

Carey, M. L. 1985. How workers get their training. Washington D.C.: U.S. Department of Labor Statistics.

Carmevale, A.P., L. H. Gainer, and J. Villet. 1990. Training in America. San Francisco, CA: JosseyBass.

Casti, John L. 1994. Complexification: Explaining a paradoxical world through the science of surprise. NewYork: Harper Perennial.

Chi, M.T., R. Glaser, and M. J. Farr. 1988. The nature of expertise. Hillsdale, NJ: Earlbaum. Clark, Ruth C. 1989. Developing technical training. Phoenix, AZ: Buzzards Bay Press.

Davies, I. 1973. Competency-based learning: Technology, management, and design. New York: MoGrawHill.

Department of Defense 1982. Analysis of the characteristics of the aircraft maintenance technical workforce. Headquarters, United States Air Force (LEYY), The Pentagon, Washington, DC. Di Bello, L. 1994. Exploring the relationship between activity and expertise: A study of manufacturing workers learning MRP. Paper presented at the Second Naturalistic Decision Making Conference, June 13-15, 1994, Dayton, $\mathrm{OH}$.

Di Bello, L., and J.Glick. 1993. Technology and minds in an uncertain world. Paper presented at the 31st Annual Conference of the National Society for Performance and Instruction. April 12-16, Chicago, Il.

Di Bello, L. and Spencer, J.C. 1994. Constructive learning: A new approach to deploying technological systems into the workplace. NewYork: The CityUniversity of NewYork-Laboratory for Cognitive Studies.

Feuer, D. 1986. Growing your own technical experts. Training, July 23-26.

Field, Laurie 1994. Skills training for tomorrow's work force. San Diego: Pfeiffer \& Co. 
Grow, G. 1991. Teaching learners to be self-directed. Adult Education Quarterly41(3): 125-149. Hamburg, S.K. 1985. Training for new technology. NewYork: Work in America Institute.

Hannum, W. 1990. The application of emerging technology. Alexandria, VA:TheAmerican Society for Training and Development.

Hewitt, C. 1988. Education for the new technologies. London: Kogan Page.

Horne, R. 1982. Guide for implementing competency-based education in vocational programs. Blacksburg, VA: Virginia Dept. of Education, Division of Vocational and Adult Education.

Howard, Ann (ed). 1995. The changing nature of work. San Francisco: Jossey-Bass.

Jacobs, Ronald L., and Michael J. Jones. 1995. Structured on-the-job training: Unleashing employee expertise in the workplace. San Francisco: Berrett-Koehler.

Johnston, W. 1987. Workforce 2000: Work and workers for the twenty-first century. Indianapolis: Hudson Institute.

Leibowitz, Z.B., C. Farren, and B. L. Kaye. 1986. Designing career development systems. San Francisco: Jossey-Bass.

MARTA 1996. Annual analysis of maintenance indicators. Atlanta: Metropolitan Atlanta Rapid Transit Authority.

Mezirow, J. 1985. A critical theory of self-directed learning. In S. Brookfield (ed.), Self-directed learning: From theory to practice, New directions for adult and continuing education 25. San Francisco: Jossey-Bass.

Newby, T.J., and D.A. Stepich. 1987. Learning abstract concepts: The use of analogies as a mediational strategy. Journal of Instructional Development 10(2): 20-26.

Partain, D. 1994. Bus maintenance foreman training:A model for development and implementation.

Paper presented to the Metropolitan Atlanta Rapid Transit Authority, May 10, Atlanta.

Quinn, J.B. 1985. Managing innovation: Controlled chaos. Harvard Business Review, May/June: 73-84.

Reynolds, William J., and John F. Paquet. 1996. Can your bus be too smart for its chassis? Paper presented at the 1996 Bus Operations, Technology, and Management Conference of the American Public TransitAssociation, May 5-9, Kansas City, MO.

Rosow, J.M., and R. Zager, with Casner-Lotto and Associates. 1988. Training - the competitive edge: Introducing new technologies into the workplace. San Francisco: Jossey-Bass.

Rothwell, William J. 1994. Improving on-the-job training. San Francisco: Jossey-Bass.

Sonnenfield J.A., and C.A. Ingols. 1986. Working knowledge: Charting a new course for training. Organizational Dynamics, Autumn: 63-79. 
Taylor, F.W. 1911. The principles of scientific management. New York: Harper.

Waldrop, Mitchell M. 1992. Complexity: The emerging science at the edge of order and chaos. New York: Simon and Schuster.

\section{About the Author}

DAVID W.PARTaIN is the Director of Employee Development for the Metropolitan Atlanta Rapid Transit Authority, a past Fellow of the National Transit Institute, and a multiple recipient of the NTI Innovations in Training Award. 